\title{
PRACTICING WITH RESPECT: What does that mean for teachers working with infants?
}

\section{By Toni Christie}

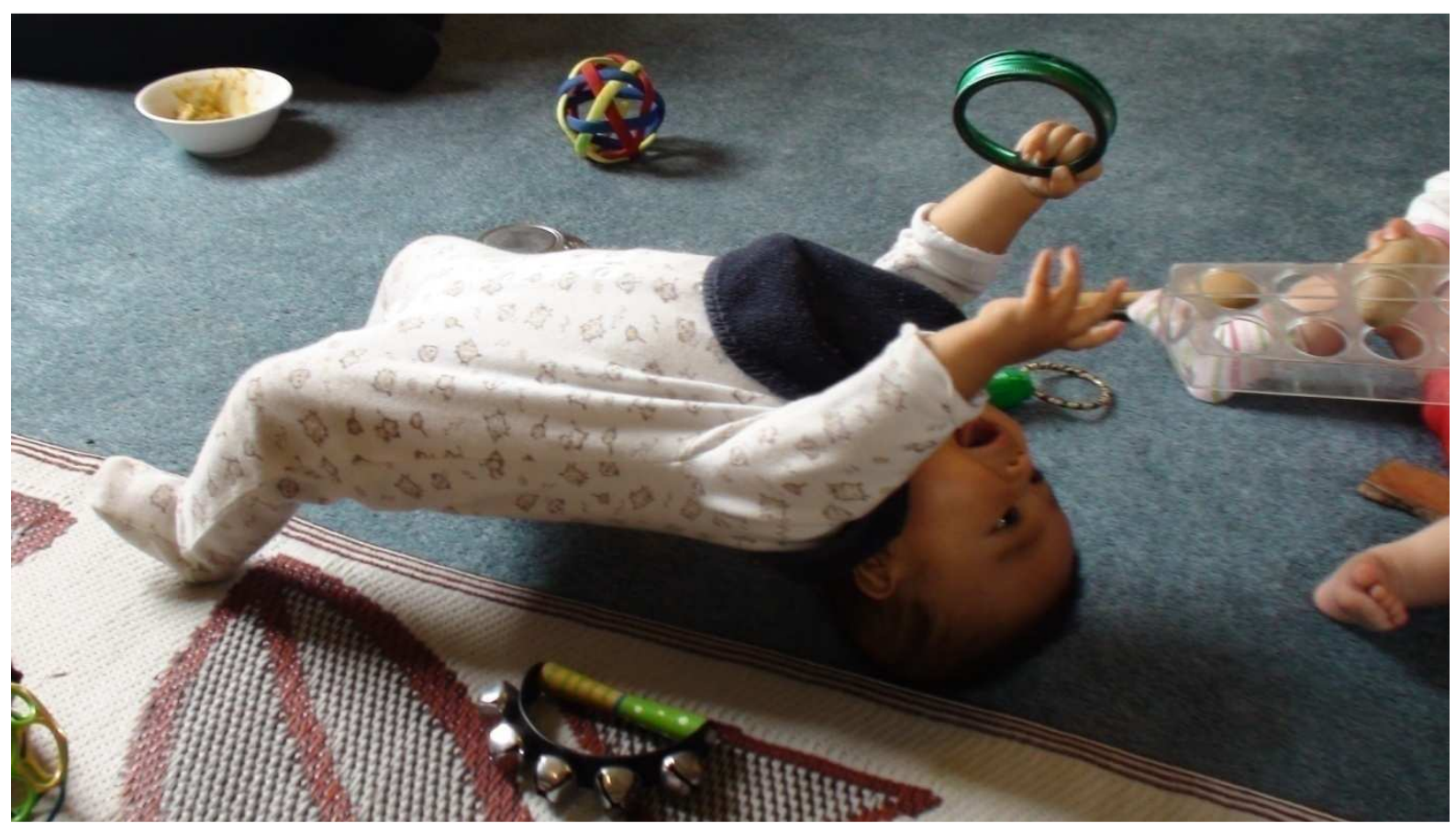

A four paper thesis submitted to the Victoria University of Wellington in partial fulfillment of the requirements for the degree of Master of Education.

Victoria University of Wellington Faculty of Education 2010. 


\section{ABSTRACT}

This qualitative case study examines the teaching practices, inspired by the Pikler approach and RIE philosophy, in one infant and toddler centre in a main city of New Zealand. Specifically the practices studied were primary caregiving, freedom of movement and respect for infants' confidence and competence. Recommendations for practitioners are made at the conclusion of this thesis. Data were collected through non-participant observations, semistructured interviews with teachers, a focus group interview with parents, and collation and analysis of relevant documentation. The framework for data interpretation and analysis was based on a thematic coding of observations and interview data.

The findings indicated that a culture of respect was embedded throughout all aspects of teachers' interactions with children, colleagues and parents within the centre. Respect, defined as treating with consideration, was the overarching feature underpinning the values and actions of teachers. Teachers engaged in ways that would suggest they accept each person as an individual with rights and freedoms. Teachers invited children to engage with them and no action would be initiated for or with a child without his or her agreement. This agreement was shown through cues and gestures, to which the teachers were all highly attuned. Teachers slowed their pace intentionally and offered children choices in their care and education. Peaceful observation from teachers enhanced their ability to interpret individual children's needs and wants and they would provide support for children rather than intervene unnecessarily.

Limitations to this research included the fact that I only studied one early childhood centre and completed observations over a limited period of two weeks. The centre studied had ratios better than the minimum ratios required by early childhood regulations, which means 
that other early childhood settings may not be able to replicate the findings unless they also have a ratio of teachers to children greater than that required by law.

My recommendation for further research is based on the lack of empirical evidence available to support the idea of unassisted motor development. Existing research derives from an orphanage setting which raises questions as to its relevance to the situation of infants growing up in family homes. Future research could take the form of a longitudinal study which would be ideal to fully understand the consequences of practicing free movement, particularly natural motor progression, with infants in early childhood settings. 


\section{ACKNOWLEDGEMENTS}

Writing a thesis is a huge undertaking, particularly while working in a full time position and raising a young family. I have received a great deal of support from everyone with whom I work and play.

My sincere thanks are due to Natasha Kibble who introduced our organisation to the Pikler approach and RIE philosophy, to the team of teacher researchers at our centre of innovation who piqued my interest and demonstrated the possibilities for improved practices to follow new knowledge. Huge thanks to the whole team at the case study centre where I undertook my research and most particularly to the two nursery teachers who so generously allowed me to observe their interactions with infants and toddlers. Your passion, commitment and skill in your work and play with the babies are an absolute inspiration and example to everyone in the field of early childhood education.

I was very fortunate to have two highly skilled and experienced research supervisors, Associate Professor Carmen Dalli and Dr. Mary Jane Shuker, who were so patient and kind throughout the process of this whole undertaking and I thank them for their wisdom and support. In addition to having two official thesis supervisors, I was fortunate to benefit from the wisdom and advice of Dr. Anne Meade. Anne acted as an unofficial supervisor and offered her time and support in reading my initial draft report and throughout the consent process which has been beneficial.

Norah Fryer and Janet Gonzalez-Mena were interested in my thesis and offered me valuable advice and input. Thankyou Norah, for always encouraging me to think for myself and for stimulating my thinking with interesting questions! Thank-you Janet, the history you 
provided on the Pikler approach and the RIE philosophy, as well as the differences between the two was invaluable and helped deliver a rich background on the origins of my subject.

To my friends and colleagues at our home office who put up with me spending too much time on my study and not enough time on my work. You picked up my slack like the true professionals you are and managed to keep a very complex organisation running smoothly in the absence of its Director on many occasions throughout this process. I am forever grateful that I get to work with such a thoughtful, committed, hard-working and fun team. It's over now so let's celebrate!

Most importantly I thank my beautiful family, Robin, Max and Tui. The three of you have always accepted and supported my ambitions and crazy ideas. I love you most dearly and you will always be the most important people in my world. 


\section{Contents}

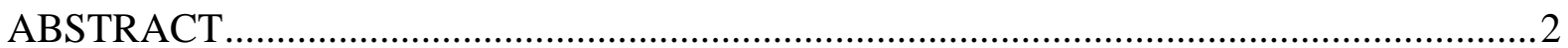

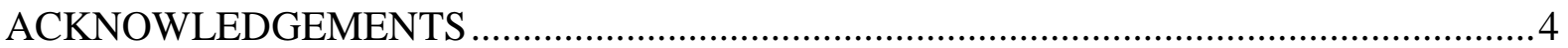

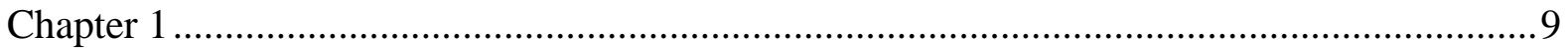

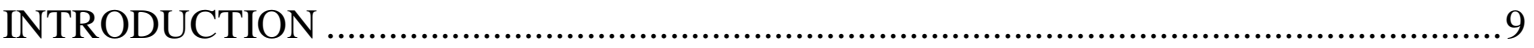

1.1 Respectful care practices with infants and toddlers......................................... 9

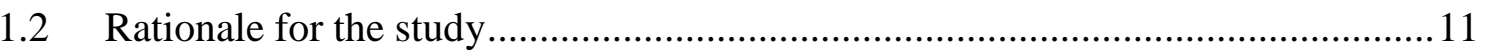

1.3 The aims, benefits and values of the research .................................................... 14

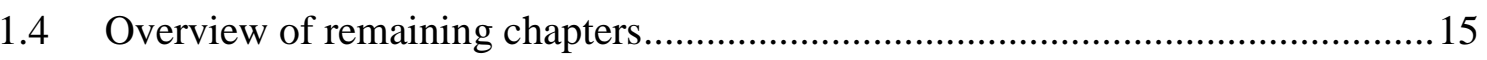

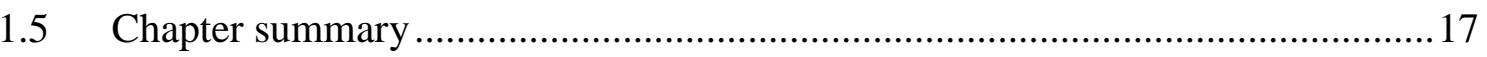

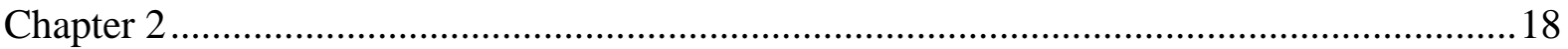

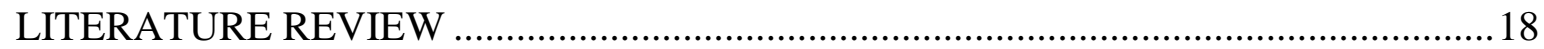

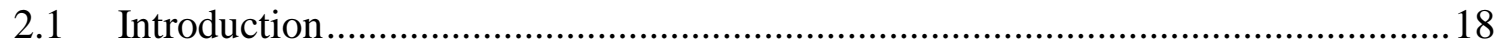

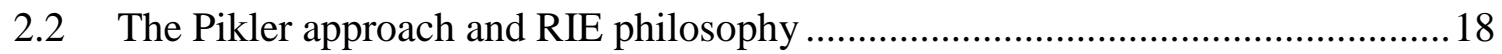

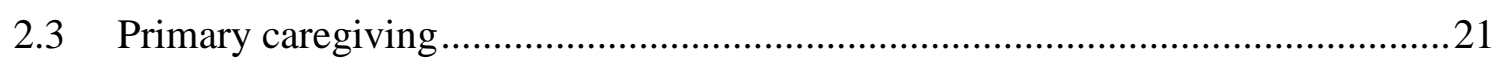

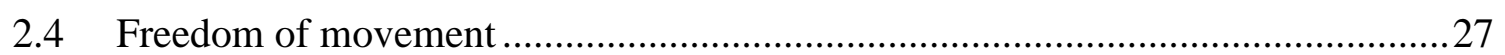

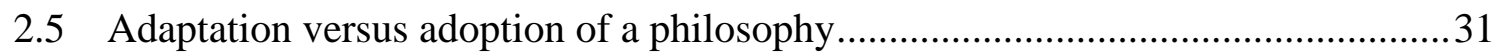

$2.6 \quad$ Respect for children's confidence and competence ...........................................33

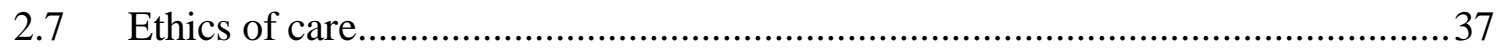

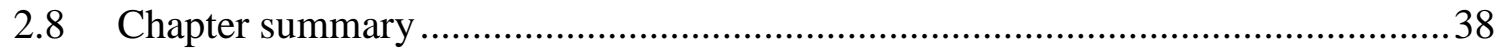

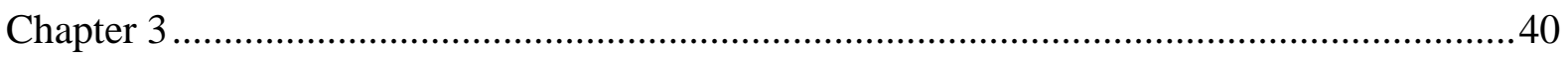

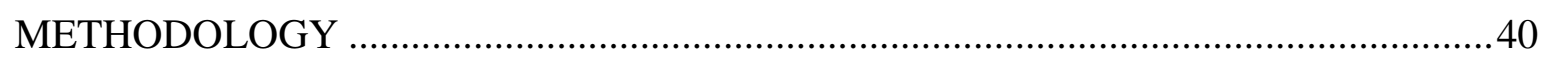

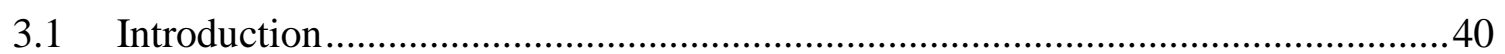

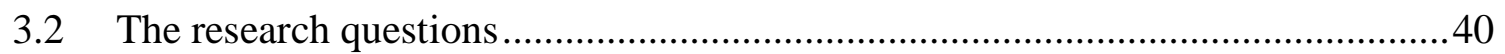

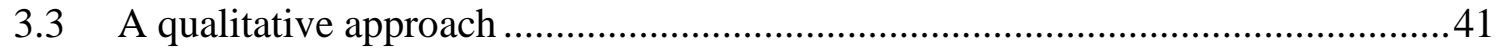

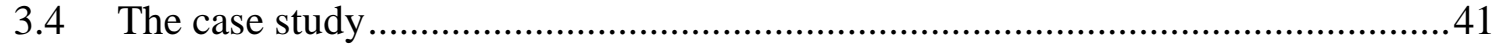

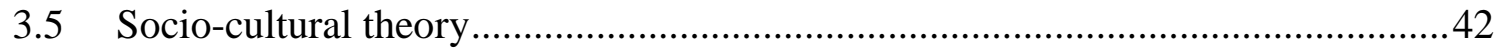

3.6 Introduction to the setting, teachers and children .............................................43

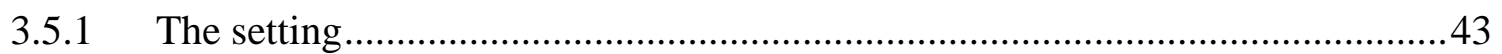

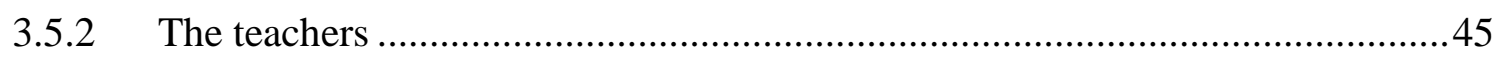

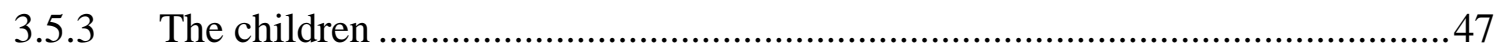

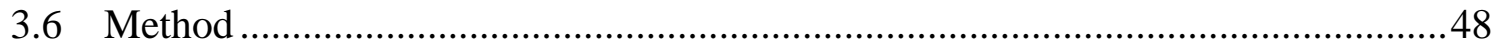

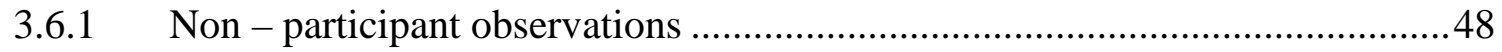

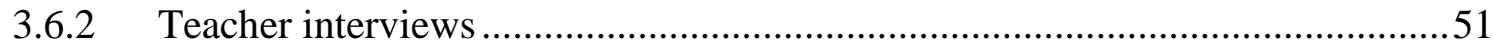

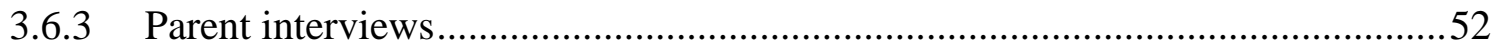

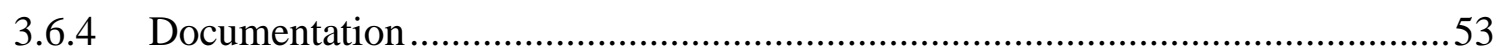

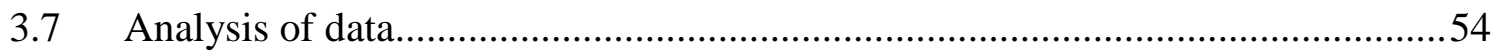




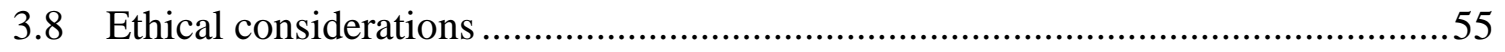

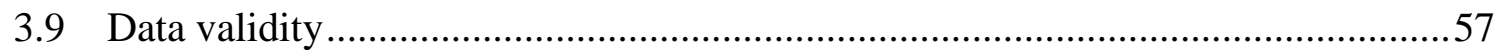

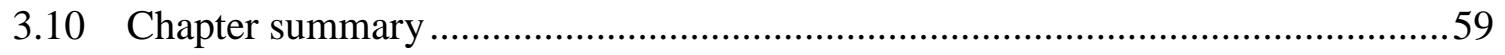

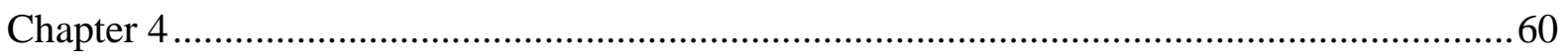

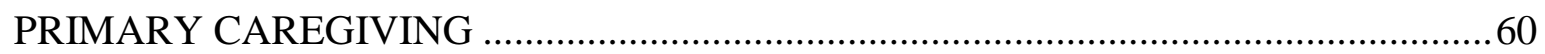

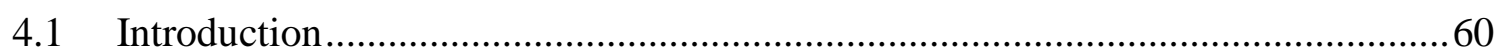

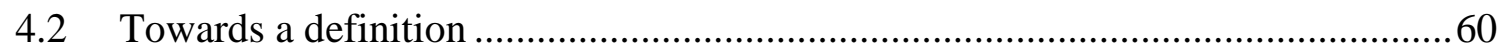

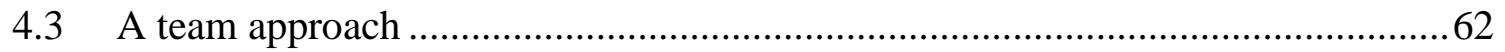

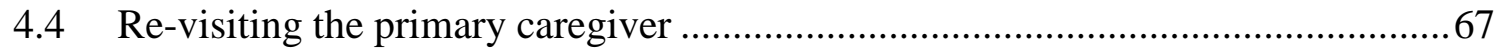

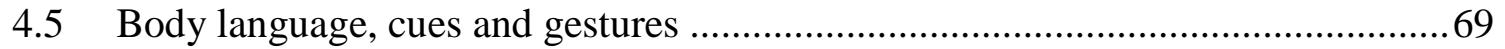

4.6 Language as invitation and explanation.......................................................... 71

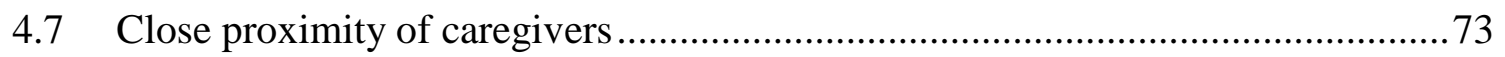

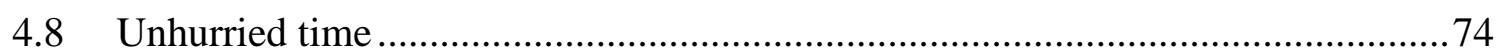

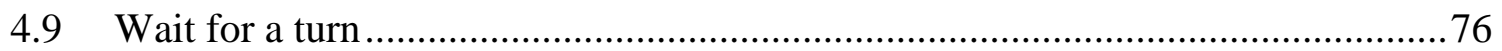

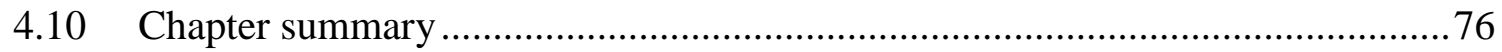

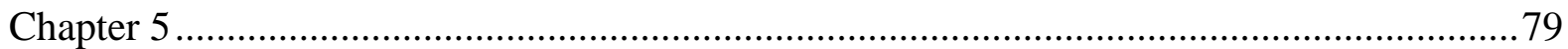

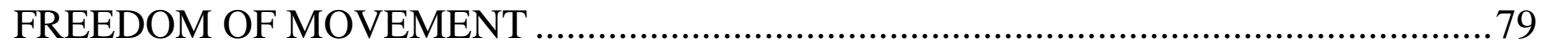

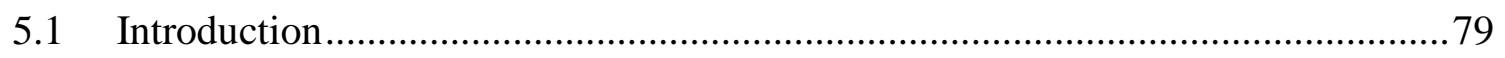

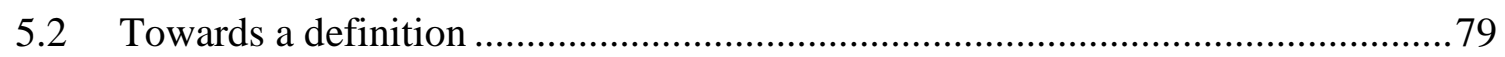

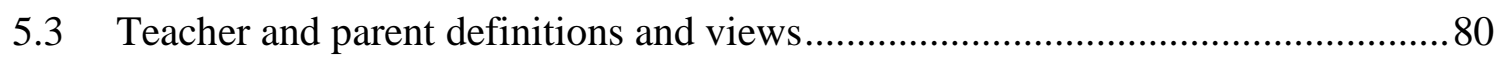

5.4 Teachers support and intervene only when necessary ........................................83

5.5 Following free movement principles at home strengthens movement in the centre

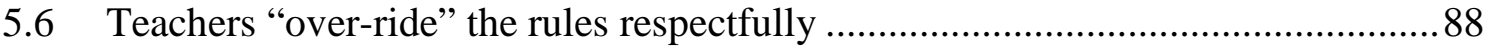

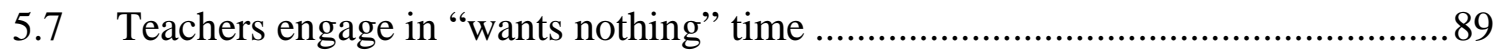

5.8 Adaptation versus adoption of a philosophy ....................................................92

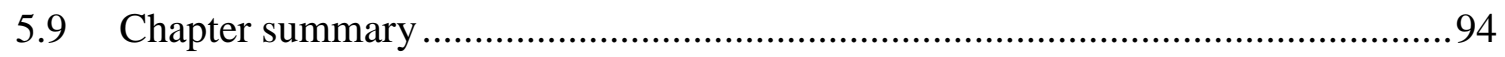

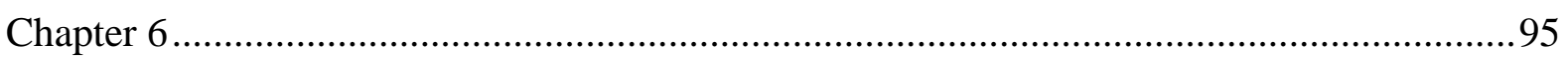

RESPECT FOR CHILDREN'S CONFIDENCE AND COMPETENCE ..........................95

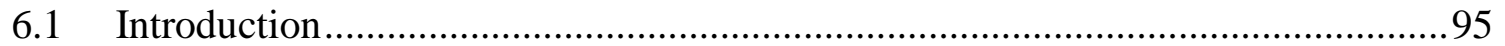

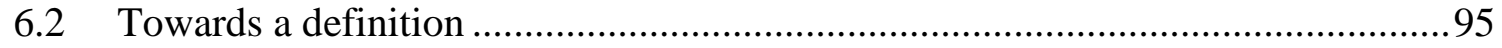

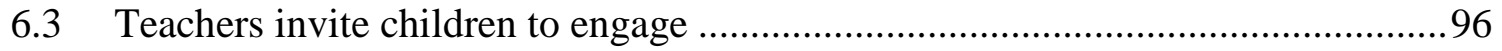

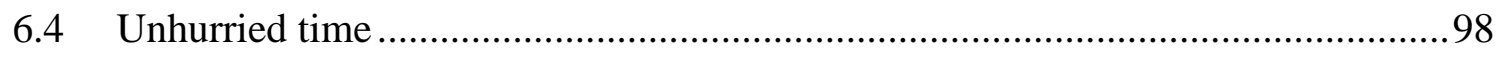

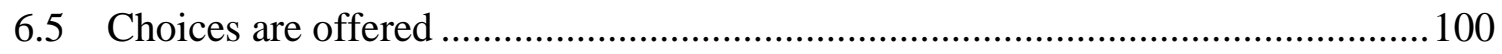

6.6 Teachers interpret a child's intentions by paying close attention ......................... 102

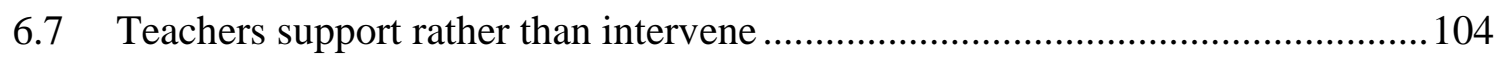

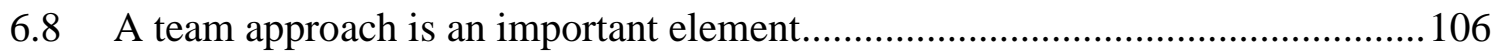




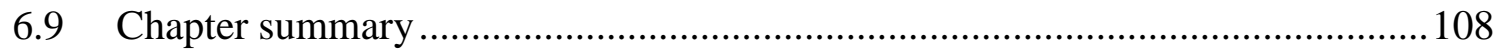

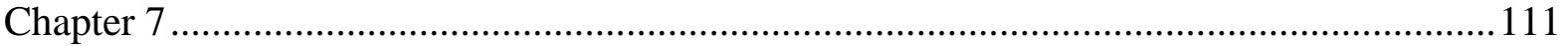

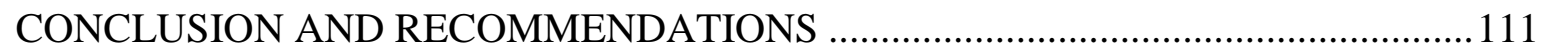

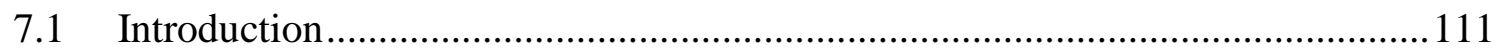

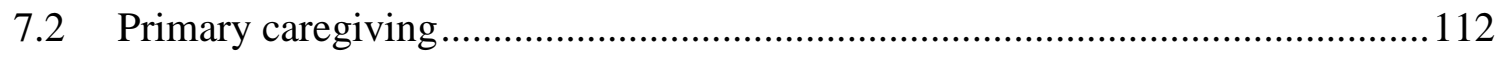

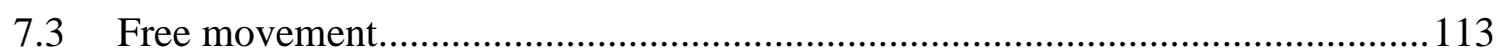

7.4 Respect for infants' confidence and competence.................................................114

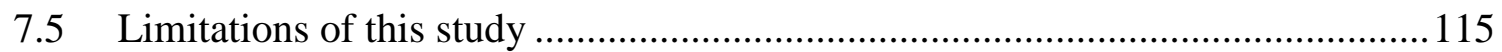

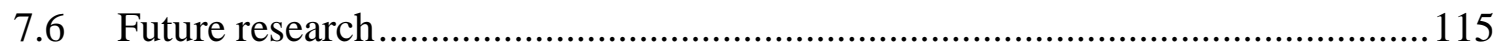

7.7 Implications and recommendations for policy makers .........................................116

7.8 Practical recommendations for teachers ............................................................116

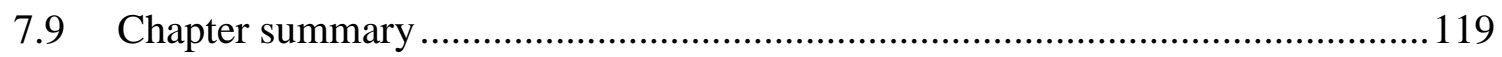

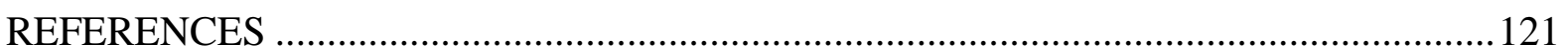

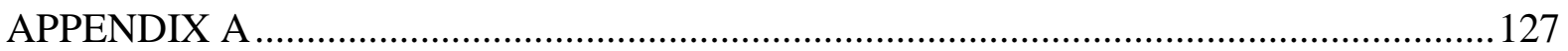

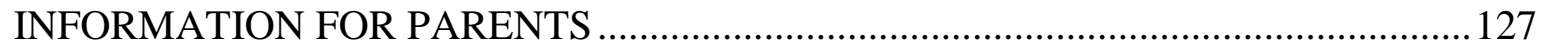

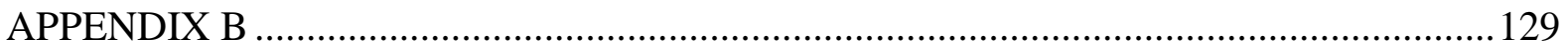

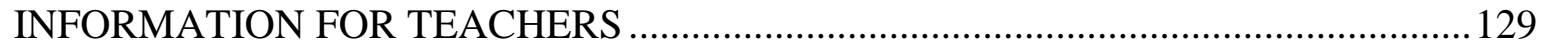

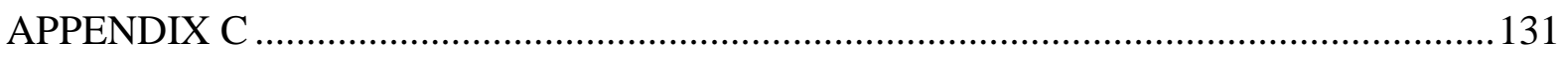

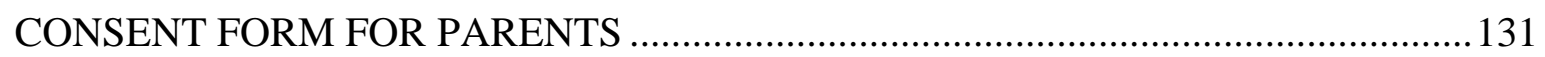

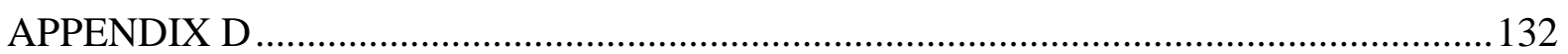

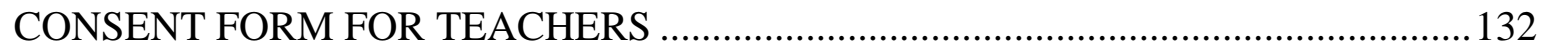

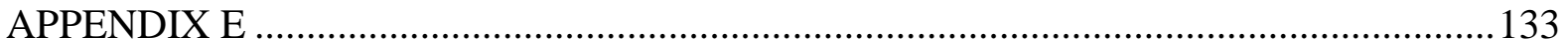

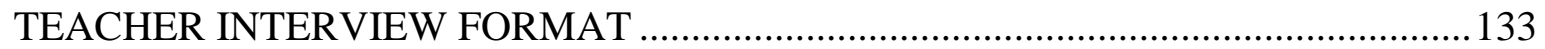

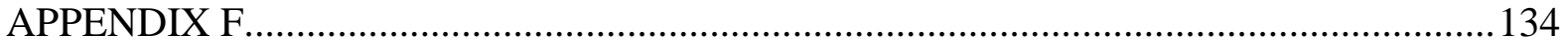

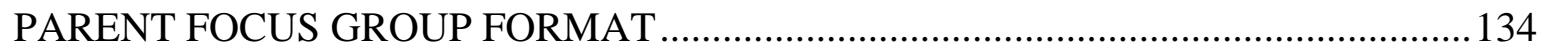




\section{Chapter 1}

\section{INTRODUCTION}

\subsection{Respectful care practices with infants and toddlers}

My research explores one early childhood centre's philosophy and practices, inspired by the Pikler approach and Resources for Infant Educarers (RIE) philosophy. The specific practices observed involved primary caregiving, freedom of movement and respect for infants' confidence and competence. My intention was to examine what such a programme looked like in practice and to illustrate what teachers and parents understood of the philosophy and practices. The overall aim of the study was to explore these practices for the benefit of other practitioners wanting to emulate a similar environment. My research also aims to uncover some of the culture within the case study setting which enabled these practices to be applied consistently by each member of the team.

In the following paragraphs I have defined the terms primary caregiving, freedom of movement, and respect for infants' confidence and competence in order to clarify for readers the meaning of these terms. Primary caregiving can be defined as a way of working in an early childhood setting in which each team member is focused on enabling and supporting close attachments between individual children and individual teachers (Elfer, Goldschmied, \& Selleck, 2003). Each teacher has responsibility for establishing and maintaining close reciprocal relationships with a small group of children and their families.

Freedom of movement can be described as never putting a baby into a position she cannot get into or out of all by herself (Gerber, 2002). This includes the elimination of all movement 
restricting devices such as swings, bouncinettes, and high-chairs from the environment. Freedom of movement also means unassisted motor development. For instance, infants are always placed on their backs until they can roll over on their own. They are not propped to sit or pulled up to stand via adult intervention.

Respect for infants' confidence and competence means considering them to be equal human beings, capable of problem solving and decision making. Viewing the child as capable means allowing them time and space and trusting them to develop and explore without unnecessary intervention.

Early childhood educators, researchers and policy makers are increasingly recognising the impact of very early experiences on later learning. The early childhood curriculum document, Te Whāriki, asserts: “The care of infants is specialised and is neither a scaleddown three or four year old programme nor a baby-sitting arrangement" (Ministry of Education, 1996, p. 22). As we understand more of the importance of brain development and the significance of emotional security for the brain development of infants and toddlers (Shonkoff \& Phillips, 2000), we are increasingly realising the need for our infants and toddlers to be cared for with deep respect and by people who understand the unique development and learning occurring for each child at this age. Infants and toddlers have no choice about where they are cared for, who cares for them and myriad other aspects of their daily life. As adults it is important to acknowledge this fact and act responsibly in the best interests of the youngest and most vulnerable members of society.

Over the last ten years, the number of children less than two years old enrolled in early childhood services has grown by around 50\% (Ministry of Education, 2007). Furthermore, 
there has been a $21.2 \%$ increase in the number of children under one year old enrolled in early childhood services from 2005 - 2009 (Ministry of Education, 2009). This growing trend for younger children to be in early childhood services, and for longer hours, highlights the need for appropriate research into the programmes of our early childhood centres catering for infants.

\subsection{Rationale for the study}

Te Whāriki (Ministry of Education, 1996) states that any infant programme must provide:

One to one responsive interactions (those in which caregivers follow the child's lead); an adult who is consistently responsible for, and available to, each infant; sociable, loving and physically responsive adults who can tune into an infant's needs; individualised programmes that can adjust to the infant's own rhythms; a predictable and calm environment that builds trust and anticipation; partnership between parents and other adults involved in caring for the infant (p. 22).

Primary caregiving, freedom of movement and respect for infants confidence and competence are some of the practices being used to fulfill the goals of Te Whäriki in the case study early childhood centre. Over the last five years teachers at the case study centre have developed and refined their philosophy which has been strongly influenced by the Pikler approach and RIE philosophy (see, for example, Gerber, 2002; Sensory Awareness Foundation, 1994; Gonzalez-Mena \& Widmeyer, 2007). The teaching team has been exploring ways to increase opportunities for infants and toddlers to be seen as the competent and capable young people they are and to be given the time and respect that enables trusting, authentic and co-operative relationships to develop. The Pikler approach and RIE philosophy are detailed in depth in the literature review section of this thesis (section 2.2).

Together with my husband, I have owned and operated early childhood centres for over sixteen years. Currently our organisation operates five early childhood centres in a main city 
of New Zealand. In addition we have founded an early childhood institute specialising in providing professional development for teachers, resources and publications for early childhood education and consultancy services for environment design and all aspects of early childhood education. One of our centres was involved in round four of the Ministry of Education's Centre of Innovation (COI) action research programme (see, for example, Meade, 2010). This selection further highlighted our organisation's interest in researching our philosophy and practices. Unfortunately the Centre of Innovation programme was terminated due to government budget decisions part-way through our study round. This meant our teacher-researchers were unable to complete their enquiries and have had minimal opportunities to publish their findings. This was disappointing for everyone involved in the research. The premature termination of the project contributed to my decision to base my masterate thesis on respectful caregiving for infants. The COI research studied primary caregiving in some depth but was terminated before the next steps of exploring free movement and sensitive observation were able to be taken. While my research examined similar practices as the COI research, it was undertaken in a different setting with me as the sole non-participant observer as opposed to a team of teacher action researchers.

Tentative findings from our Centre of Innovation research were that primary caregiving enabled a deep level of sensitive responsiveness between adults and children (Kibble, CairnsCowan, McBride, Corrigan \& Dalli, 2009). The teacher researchers discovered that the primary caregiver played a key role in establishing safe and secure relationships with the child and family. The team found the literature supported those findings (see, for example, Elfer, Goldschmied, \& Selleck, 2003; Lally, 1995; Rockel, 2002; Theilheimer, 2006). Our research team found that primary caregiving, some would say "paradoxically", involved a team approach and that its efficacy relied on a secondary caregiver, good systems, and 
collaboration with the child's family (Kibble et al, 2009). The findings indicated that the primary caregiver / child relationship was not an exclusive relationship and nor was it a replacement for parents. The idea that the relationship between one adult and a few children might be exclusive or a replacement was mooted by previous literature as a reason some centres were against the idea of primary caregiving (Rockel, 2002). The COI teacher researchers found that all teachers shared with all children a deep level of sensitive responsiveness and were able to read intricate signs, subtle and overt gestures and non-verbal cues. The infant's primary caregiver often had a deeper knowledge of such cues. The Centre of Innovation teacher researcher team uncovered a systematic approach to the way primary caregivers interacted which each child. This approach was used in the same way by all the adults in the environment. It involved the teacher "inviting", "suggesting" and then "engaging" in each interaction. They labeled this form of interaction "ISE" (invite, suggest, engage) (Kibble et al, 2009).

At this point in our research the COI programme funding was stopped and we were unable to research our practices any further. The next steps planned by the team were to investigate how teachers fostered free movement and engaged in sensitive observation. My research continued the focus on primary caregiving and went on to explore teacher practices connected to infants and toddlers having free movement. I also wanted to observe and unpack the ideas of respect for infants' confidence and competence and understand how this culture of respect was made possible within the teaching team. Finally, my research sought teacher and parent views as to the factors which might enable and/or constrain these practices. 


\subsection{The aims, benefits and values of the research}

Research has generally advocated the use of a primary caregiving system (Elfer, Goldschmied, \& Selleck, 2003; Theilheimer, 2006; Rockel, 2002; Lally, 1995; Kovach \& Da Ros, 1998). While these researchers have advocated the use of primary caregiving in group care settings, only Elfer and colleagues have gone on to describe a strategy for implementation. One of my aims was to develop practical recommendations which might assist practitioners to develop such a system in their own settings. Recommendations based on current research could increase the uptake of primary caregiving for infants in early childhood services.

Recent research into primary caregiving (Rockel, 2002) has highlighted the need for teachers to better understand the practices involved in primary caregiving. Rockel believes teachers' reluctance to adopt a primary caregiving model in their work environment is based on the false assumptions that primary caregiving is exclusive and difficult to manage. This assertion of Rockel's is certainly my experience in a practical sense as an early childhood teacher educator. One aim of my study was to add strength to the growing body of research in support of primary caregiving by examining the actual practices involved in an infant curriculum based on primary caregiving. The benefit of which, I am hoping, will be an increase in the practice on publication and dissemination of my findings. I am hoping my research might shed light on any inaccurate perceptions and also provide practitioners with a real example of how the practice of primary caregiving can support and benefit children, teachers and parents.

Further aims of this research were to examine the practices of free movement and discuss the value of adapting the RIE philosophy and Pikler approach and their relevance for early 
childhood settings in New Zealand. My final research aim was to unpack the term 'respect' as it pertains to infants' confidence and competence and develop recommendations for respectful practice (see Chapter 7).

\subsection{Overview of remaining chapters}

Chapter 2: Literature review. This chapter situates my research within current literature regarding the RIE philosophy and Pikler approach, primary caregiving, adaptation versus adoption of a philosophy, free movement, the ethics of care, and respect for infants' confidence and competence. It highlights where there are gaps in the available literature and suggests where my research might contribute to filling such gaps.

Chapter 3: Methodology. This chapter outlines the methodology utilised in this study and the approaches taken for data collection and analysis. I describe the ways in which qualitative data were collected through non-participant observations, a parent focus group interview, teacher interviews and various documentation sources. Ethical considerations and data validity are discussed and methods for analysis are described.

Chapter 4: Primary caregiving. This chapter highlights my findings regarding primary caregiving. The themes which emerged from the data were: primary caregiving involves a team approach; children would revisit their initial primary caregiver; children and teachers tuned in to each other's body language, cues and gestures; language was used by teachers as invitation and explanation; infants were soothed by the close proximity of their caregivers, teachers intentionally slowed their pace and interacted using unhurried time; and infants were able to wait for a turn. Each of these themes is discussed in detail in chapter 4. 
Chapter 5: Freedom of movement. This chapter highlights my findings regarding freedom of movement. The themes which emerged from the data were: that teachers support children rather than intervene; following the free movement principles at home strengthened movement in the centre; teachers 'over-rode' the principles of free movement when it was respectful to the child and family; and teachers engaged in "wants nothing" time which I labelled peaceful observation. Each of these themes is discussed in detail in chapter 5 .

Chapter 6: Respect for children's confidence and competence. This chapter highlights my findings regarding respect for children's confidence and competence. The themes which emerged from the data are discussed in detail and they included: that teachers invited children to engage; teachers engaged with children in unhurried time; choices were offered; teachers interpreted infants' needs and wants by paying close attention; teachers supported infants rather than intervening; and a team approach was evident to ensure a deep level of respect was embedded in the philosophy and practices at the centre.

\section{Chapter 7: Conclusions and recommendations.}

In this chapter I summarise the main findings from my research at the case study centre. I discuss the limitations of the study, the implications for practitioners and policy makers, and give recommendations for future research. I outline practical recommendations for teachers working in early childhood settings with infants. These recommendations are intended to provide a framework for practitioners wanting to emulate similar practices as those observed at the case study centre. The recommendations are based on the findings from my research. 


\subsection{Chapter summary}

Out of home care for infants and toddlers has increased dramatically in recent times. The RIE philosophy and Pikler approach have provided the inspiration for curriculum delivery at the case study centre. My intention is to explore how these models have been adapted to fit the context at the case study centre and describe how they are understood and implemented. 


\section{Chapter 2}

\section{LITERATURE REVIEW}

\subsection{Introduction}

In examining the literature I give a broad overview of the origins of the Pikler approach and RIE philosophy which have heavily influenced the philosophy and practices at the case study centre. Secondly, I examine the existing literature pertaining to primary caregiving and discuss the concept and associated practices in detail. I look critically at the available literature on freedom of movement and also on adaptation versus adoption of a philosophy or approach. Finally I examine the literature pertaining to respect for children's confidence and competence, exploring the concepts and associated practices in detail.

\subsection{The Pikler approach and RIE philosophy}

The Pikler Institute is a residential nursery founded by Dr Emmi Pikler in 1946 in Budapest, Hungary. It was originally named the National Methodological Institute for infant care and education and often referred to as "Lozcy", after the street on which it is located. It originated after World War Two when the Hungarian government asked Pikler to open a residential nursery (orphanage) for children under three whose families could not care for them. Before Pikler came along it seemed clear that institutionalising babies had drastic outcomes. Maternal deprivation was one term used to explain the ruined lives of babies who failed to thrive (J. Gonzalez-Mena, personal communication, August 2010). Pikler's challenge was to teach caregivers to work with children in ways that allowed them to develop normally and resulted in their growing up to be productive citizens who were more like a 
cross section of the population than damaged people (J. Gonzalez-Mena, personal communication, August 2010).

Pikler was a pioneer in the care and education of infants and toddlers in orphanages in her country. She advocated for infants to be given our highest respect focusing on the establishment of authentic trusting relationships between the adult and the infant. Her peaceful approach urges early childhood practitioners to consider infants and toddlers as competent, confident and unique individuals who are focused, self-initiating, involved, resourceful, secure, cooperative and curious (Gerber, 1984). She uses the descriptor "peaceful" because she believes we need to create a safe, quiet environment, to slow down, pay attention and allow infants to move and play in their own way. Pikler was a dedicated researcher and kept meticulous records over many years detailing the normal development of infants at Loczy. Unfortunately because this work was conducted in communist era Hungary, when communication with the west was extremely limited, only recently have Pikler's findings been translated into English (Sensory Awareness Foundation, 1994). When Emmi Pikler died in 1984 the institute she started and ran dedicatedly for some thirty-eight years was renamed the Emmi Pikler National Methodological Institute for Residential Nurseries and is often referred to as the Pikler Institute.

Magda Gerber met Dr. Emmi Pikler prior to her work with the orphanage, when she was a paediatrician working with families in the 1930's. Gerber was so intrigued and impressed by the respectful way Pikler spoke to Gerber's child, she became interested in Pikler's approach and subsequently worked alongside her at Loczy. Magda Gerber was able to pioneer Dr. Emmi Pikler's work in the United States, when she emigrated there from Hungary. The Resources for Infant Educarers, (RIE) Institute is located in California, and was founded in 
1978. RIE is a non-profit membership organisation concerned with improving the care and education of infants (Gerber, 2002).

Both Pikler and Gerber suggest we demonstrate our respect every time we interact with infants. Respect to these pioneers meant treating an infant as a unique human being with problem-solving and decision making power and ability, not as an object (Gerber, 2002).

Because the ideas and practices are similar, the Pikler approach and RIE philosophy are often grouped together as though they are one philosophy. For example, the RIE / Pikler philosophy is defined as a respectful interactive approach to infant and toddler care and development through responsive and reciprocal relationships (Kovach \& Da Ros, 1998; David \& Appell, 2001). Respect is the basis of Dr Emmi Pikler's approach and Magda Gerber's RIE philosophy but there are some differences between the two.

One difference is obviously in the approach versus philosophy. The word approach was chosen carefully by Anna Tardos, Pikler's daughter, who did not want Pikler's ideas rigidly defined as a methodology. Gerber was the one who used the term philosophy (J. GonzalezMena, personal communication, August, 2010). Another difference between the two was that Pikler was a dedicated researcher while Gerber used to say that research can prove anything one wants to prove and, for whatever reason, her philosophy was never researched (J. Gonzalez-Mena, personal communication, 12 August 2010).

The final and most fundamental difference between Pikler's approach and Gerber's RIE philosophy is that Pikler worked predominantly with institutionalised children (orphans) in Hungary, and Gerber worked with families in Los Angeles teaching a parenting philosophy. 
Pikler caregivers were trained to create a special kind of attachment so that separation was not devastating to either caregiver or baby when the children leave to be adopted or move on to somewhere else (J. Gonzalez-Mena, personal communication, 12 August 2010). Paradoxically, the RIE philosophy, borrowing heavily from the tenets of the Pikler approach, was taught as a parenting philosophy to promote parent-infant attachment. Indeed, a masters thesis completed recently (Triulzi, 2008) focussed on whether the Pikler and RIE methods (once again considered as one combined method) promoted infant-parent attachment. In her conclusion, Triulzi (2008) found that "Pikler and RIE are empowering tools that can support families in finding their own unique way to health" (p. 69). Essentially, Pikler's approach was dedicated to helping disadvantaged (orphaned) children to develop normally, and the RIE philosophy is dedicated to supporting parents in their role with infants.

\subsection{Primary caregiving}

In New Zealand, research regarding primary caregiving for infants has only recently emerged (see, for example, Dalli, 2000; Rockel, 2002; Kibble, Cairns-Cowan, McBride, Corrigan, \& Dalli, 2009, 2010; Dalli \& Kibble, 2010). The term primary care is used to explain the responsive relationship between an infant and the most significant adult in their life, usually their mother (Bernhardt, 2000). It can also be used to describe an approach where a whole centre is focused on enabling and supporting close reciprocal relationships between small groups of children and individual teachers or caregivers. Primary caregiving should not be confused as taking over the important primary care role of a parent, and for that reason some researchers investigating primary caregiving approaches have labeled it "The key person approach" (Elfer, Goldschmied \& Selleck, 2003, p. 18). Primary caregiving or the key person approach is a central tenet of the Pikler approach and the RIE philosophy and is a corner stone of the philosophy at the case study centre. There is an understanding that 
valuable learning is taking place for the infant in the crucial routine care times in which they are engaged with one sensitive and responsive adult, with whom they can develop a trusting relationship (Elfer, Goldschmied \& Selleck, 2003; Gonzalez-Mena 2007; Dalli, 2000; Rockel, 2002; Kibble, Cairns-Cowan, McBride, Corrigan, \& Dalli, 2009, 2010; Dalli \& Kibble, 2010).

Gonzalez-Mena (2007) uses the term caregiving as curriculum, discussing the importance of adults' being fully present during individual care times with infants. The term caregiving as curriculum refers to the idea that crucial learning is taking place during routine care times. Being fully present means paying full attention to the child during those care times and not being distracted by any other demands or happenings within the environment. The adult should not feel pressure to split his or her attention between the child being cared for and other responsibilities (Hammond, 2009). David and Appell (2001) suggest Pikler's approach includes an overall plan to help each child feel individually respected and secure in a close relationship with one special caregiver and several others. These routine times where a relationship is strengthened through one-to-one uninterrupted care times are sometimes referred to as wants something time (Gerber, 2002) or prime times.

Several researchers have identified the prime times or routine times such as feeding, changing and sleeping as when children and their primary caregiver are engaged together (see, for example, Greenman \& Stonehouse, 1997; Hutchins \& Sims, 1999; Theilheimer, 2006). These prime times offer opportunities for adult child interactions during intimate care moments. When these interactions are supported by team members who are able to help ensure the teacher and child have uninterrupted time together, opportunities are created for 
the development of trusting and secure relationships between adults and children. Gerber (2002) recommends paying full attention suggesting:

Whenever you care, do it absolutely with full attention. If you pay half attention all the time, that's never full attention. Babies are then always half hungry for attention. But if you pay full attention part of the time, then you go a long way. That's what I would recommend: To be fully with a child and then let him be (p. 7).

Assistant Professor Dr. Denise Da Ros and former lead teacher, Angela Wong (1996) identify three types of quality time; the first is providing a "secure base" which they argue is similar to what Gerber calls "wants nothing" time. This is when the teacher is present in the environment but asks nothing of the child, rather the teacher is simply present, observing, listening and not in any way directing the child. "She or he is responsive and receptive, but not in charge" (Da Ros \& Wong, 1996, p. 216). The second type of quality time, according to Da Ros and Wong (1996), is "wants something" time which takes place when the teacher has a goal to accomplish with the child such as routine times when the teacher and child are engaged in a one to one caregiving or cooperative task. The third quality time is "shared activity" when the adult and child are simply enjoying each other's company. It is useful to note that it is the teacher the authors are suggesting "wants" something or nothing of the child. What they might look like in practice and how teachers support each other to enable consistent caregiving around these times has not been addressed in sufficient detail in the literature.

Dalli and Kibble (2010) investigated three characteristics the team of action researchers at an infant and toddler centre found regarding their style of interactions with children. These were:

1. [The interaction] Starts with an invitation by the teacher

2. Is followed with a suggestion 
3. Ends with an engagement in an activity or "joint attention" sequence in which the teacher and the child co-operate in achieving a shared goal. (p. 31).

This style of interaction was consistently applied by all members of the team when approaching a "wants something" time. Further, they found there was minimal difference between the characteristics of interactions when the primary caregiver or another teacher was with the child. The difference was in the pace of the interaction based on the knowledge of the child:

In comparing the interactions of the same teacher with different children, the only difference that we could see was that the less familiar the caregiver was with the child, the slower the pace of the interaction and the more time the caregiver took to verbally, physically and emotionally engage in the intimate caregiving activity. Overall, the style of interaction however was the same with each child... In analysing the videos it was clear that when the teacher was the primary caregiver for a child, she appeared to have an extra special knowledge of that child. In other words, the teacher did not need to continually use a lot of words to communicate with that child; rather she just seemed to 'know' what the child wanted, needed, liked or disliked (Dalli et al, 2009, p. 41).

This deeper understanding or 'knowing' appears to be a strong argument for the practice of primary caregiving. After more than twenty-five years experience as an early childhood educator, centre director and now early childhood professor, Cheshire (2007) recommends establishing a primary caregiving system:

Consistency of care helps children develop trust, autonomy, and initiative. A strong relationship is formed with the families as daily communication is shared. Teamwork and cooperation are required of primary caregivers in a classroom. This improves staff relationships. Everyone wins when a primary caregiver system is implemented (p. 38).

Te Whäriki clearly states that an infant's ability to thrive and learn is reliant on the establishment of a reciprocal, intimate, responsive and trusting relationship "with at least one other person within each setting" (Ministry of Education, 1996, p.22). Recent neuroscientific research regarding the influence of early childhood experiences on the developing 
brain suggest the role of primary caregiver is crucial with infants and toddlers when they are cared for outside the home (see, for example, Shonkoff \& Phillips, 2000).

This focus on relationships means an important consideration in the care of babies is to ensure the child's healthy identity formation. Lally (1995) looks at five policies and practices which directly impact the formation of an infant's identity. The first of the five policies and practices he considers important in the positive formation of identity is the assignment of a primary caregiver. Lally asserts that this practice enables the child to form an intimate relationship with a known/trusted adult, ensuring there is a safe and secure base from which he or she can explore the world. The other four policies and practices Lally considered crucial to the identity formation of infants in child care settings were: i) continuity of care; ii) small group size; iii) responsive as opposed to intellectually stimulating curricula, and iv) cultural continuity and common language. Interestingly, these last four policies and practices also relate to primary caregiving and would be more difficult to achieve in the absence of a primary caregiving system.

There is support for primary caregiving in the literature (see, for example, Theilheimer, 2006; Rockel, 2002: Bary, Deans, Charlton, Hullett, Martin, Martin, Moana, Waugh, Jordan, \& Scrivens, 2009; Hammond, 2009; Elfer, Goldschmied \& Selleck, 2003) but this does not accurately reflect the practices in early childhood settings (Rockel, 2002). In her master's thesis, Rockel found that primary caregiving is not widely practiced because of the view that it is exclusive and therefore difficult to make work in a setting where the primary caregiver will not always be available to the child. Elfer and colleagues (2003) list many reasons practitioners might be against a primary caregiving or key person approach including:

1. It brings staff too close to a parental role and they risk becoming overinvolved. 
2. If children get too close to any one member of staff, it is painful for them if that member of staff is not available.

3. It can be threatening for parents who may be jealous of a special relationship between their child and another adult.

4. The key person approach is complex to organise and staff need to work as a team, not as individuals.

5. It undermines the opportunities for children to participate in all nursery community relationships (Elfer, Goldschmied \& Selleck, 2003, pp. 8 \& 9).

Most of these reasons insinuate that primary caregiving is an individual approach as opposed to a team approach. As already noted, more recent research has found that primary caregiving is indeed a team effort and needs to be fully supported by a secondary caregiving system (Bary et al, 2009) and is in no way a form of replacement for the parent (Kibble et al, 2009).

An article by writer and adult educator, Bernhardt (2000) expresses a similar view and argues that a thorough understanding of primary caregiving is important. In this opinion piece, Bernhardt suggests, rather than being exclusive, the primary caregiver has principal responsibility. Teamwork is essential for the system to run smoothly and effectively requiring good communication, understanding, commitment and flexibility. Bernhardt also believes that primary caregiving benefits the child, the teacher and the parent. She suggests this practice enables the child a secure base from which to further explore his world. She believes separations are eased and strong peer relationships with those in the same primary caregiving group are forged. Interestingly, Bernhardt submits teachers often show more reward and sense of value when they have a primary caregiver group and primary caregiving provides parents with a primary contact which can ease separations due to the bond of trust formed between parent and caregiver.

The literature reviewed supports the implementation of a primary caregiving system. Strong arguments against the use of primary caregiving are based on perceptions as opposed to 
empirical evidence (Elfer, Goldschmied, \& Selleck, 2003; Rockel, 2002). Of all the recent research into primary caregiving or the key person approach, the only study to suggest a system for implementation was Elfer, Goldschmied and Selleck, (2003). I believe there is a need for more practical guidelines to support teachers to implement a flexible, team-centered approach to primary caregiving. Having evidence of the benefits explained in a practical sense and also clarifying that primary care is not about exclusivity or replacement will hopefully garner further support for the practice.

\section{$2.4 \quad$ Freedom of movement}

Free movement and independent exploration is another essential element of the Pikler approach, RIE philosophy and the philosophy at the case study centre. Pikler sums up her thinking behind this practice:

While learning during motor development to turn on the belly, to roll, creep, sit, stand and walk, he is not only learning those movements, but also how to learn. He learns to do something on his own, to be interested, to try out, and to experiment. He learns to overcome difficulties. He comes to know the joy and satisfaction which is derived from his success, the result of his patience and persistence (Pikler, 1969, p. 8).

Pikler's research (1963, 1969, cited in Sensory Awareness Foundation, 1994) involved the systematic observation of infants and young children in attendance at the National Methodological Institute for infant care and education on Loczy Street in Budapest. Specifically, nurses responsible for their care and education recorded each child's development and activity with the goal of completing a scientific study of the natural development of infants and small children. Pikler found that children who can move naturally through the developmental milestones (from supine to prone; crawling to sitting; standing to walking to climbing) are not only more able physically but also more able intellectually, socially and emotionally. She taught that freedom of movement means that 
babies are never put into positions they cannot get into or out of by themselves. They are on their backs until they can turn over, and they are not propped into a sitting position or restrained in any kind of device (an obvious exception would be in a car seat while travelling by car for safety reasons). Pikler was clear that the adults' role in infants' motor development is not to interfere with it (Gonzalez-Mena, 2007). What Pikler found through systematic observation was that freedom of movement promotes the focus and motive needed for self-education and gives the infant a lasting view of herself as a competent learner (Sensory Awareness Foundation, 1994; David \& Appell, 2001). These findings were supported by Gerber who argued that freedom of movement can affect infants' dispositions and character (Gerber, 1979). Gerber opines that children may develop a high tolerance or need for stimulation if they are constantly stimulated and entertained. She thinks entertainment may be fun but that the more infants get, the more they want. Once they are used to being entertained by somebody, she thinks, they lose the ability to entertain themselves.

Another devotee of Pikler's motor development research, Janet Gonzalez-Mena (2009) discusses the links between developing motor skills and later learning. She states:

Through their fascination with their bodies and strong motivation to develop movement, they prove to be highly competent, independent learners. Their persistence to increase movement skills sets a theme for later learning (p. 139).

As stated previously, free movement means always placing a child in a position she can get herself into or out of without adult intervention, and making sure that each child's body is completely supported at all times. This means that when you lay small babies on the floor it is important to always lay them slowly on their back letting them know what you are doing. It also means that when the children are playing it is important for the adult to be nearby to observe and support them (Cairns-Cowan \& McBride, 2009). The adult's role is to be 
closely attuned to and to facilitate an environment that is stimulating and exciting, but also peaceful and respectful. The adult is there primarily to observe attentively and not to interfere. Gerber (2002) defines this as wants nothing time, when the adult wants nothing of the child. The adult is there just to observe with sensitivity.

Money (2006), in her book about infants' natural motor development, inspired by the RIE philosophy, makes the link between moving freely and exploring and the child's social and emotional gains. She says:

An infant who is free to move his body toward an object he wants is selfrewarded by a feeling of mastery and develops a can-do attitude toward life that spills over into social, emotional and cognitive realms (p. 6).

Others investigating free movement have observed joy, self-rewards and social and emotional gains for infants of being allowed to move freely and progress through the typical physical motor development stages without adult intervention (see, for example, Brownlee, 2009; Gonzalez-Mena, 2009; Cairns-Cowan \& McBride, 2009). However, like Money, these are opinion pieces inspired by RIE and Pikler but not based on empirical evidence.

Freedom of movement, or not putting a child into any position he cannot get into or out of by himself, is twofold: Firstly there is the premise that infants should always be laid on their back and not propped to sit or pulled to stand so they can learn to roll, sit, crawl, and walk unaided; and secondly the idea that it can be harmful for infants to be placed in movement restricting devices such as high chairs, walker trainers and jolly jumpers. While there is a lack of empirical evidence to support the first part of the principle, there is over-whelming support in the available literature for the later principle regarding movement restricting devices. 
Hannaford (2005), a scientist, educator and the author of a book based on brain development research, writes: "The body plays an integral part in all our intellectual processes" (p. 15). Furthermore, she asserts: "Movement, a natural process of life, is now understood to be essential to learning; creative thought, high level formal reasoning, and our ability to understand and act altruistically towards all those that share our world" (p. 235). This evidence would suggest that children who are not restrained from moving will have greater opportunities for the important intellectual processes outlined above.

As stated previously, infants' learning and development is hampered when they are in car seats or restrictive devices such as baby carriers, swings, jolly jumpers, walker trainers and the myriad other 'containers' available for adult convenience (Gerber, 2002; David \& Appell, 2001; Hannaford, 2005; Porter, 2003). The term "container", to describe the mobility restriction placed upon infants by devices such as swings, walkers, high chairs, was coined by Porter (2003). Porter carried out research on movement restricting devices between 1991 and 1996. She asserts:

These devices can actually HARM an infant's natural muscular-skeletal development and should NEVER be utilised. In point of fact, they should NEVER have been invented in the first place (p.4).

Hannaford (2005) supports this view and is adamant that excessive use of any movement restricting devices is unwise: "[such devices] can inhibit active muscular movements either of the neck or core muscles" (p. 111).

Because the majority of research available to support the idea of children progressing naturally through the physical motor development stages without adult intervention originated from an orphanage in Hungary, there is important discussion to be had around the environmental differences between an orphanage in Hungary and family homes and child- 
care centres in New Zealand. While the teachers in the case study centre have embraced the free movement philosophy originating from Hungary, they had to adapt the understanding and practice of free movement in the centre to fit within a context where children are loved and cared for in family homes while not in attendance at the centre. At the Pikler Institute in Budapest where the children are consistently exposed to the principles of free movement, and the nurses are specifically trained in the approach, one might expect to see entirely different behaviour, consequences and benefits to an early childhood centre where the care is shared between centre and home where the cultural norm may be to 'entertain' the baby.

Many authors have celebrated, adapted, adopted, and otherwise implemented Pikler's teachings with regard to free movement (see, for example, Brownlee, 2009; Gonzalez-Mena, 2009; Cairns-Cowan \& McBride, 2009; Hammond, 2009). While there is considerable support for the idea that movement restricting devices can be harmful to an infants' natural motor development, there is a distinct lack of empirical evidence to support Pikler's ideas regarding the danger of adults intervening in the natural motor progression of infants brought up in a family home. Pikler's research was carried out in an orphanage where, by the very nature of the institution, it was essential that infants learned to entertain themselves. The philosophy of free movement as it pertains to adults' non intervention in infants' natural motor progression, while attracting many devoted followers, has never been researched outside of an orphanage setting. A systematic search of the literature failed to provide further evidence of the benefits or otherwise of this aspect of free movement.

\subsection{Adaptation versus adoption of a philosophy}

When a philosophy is adopted it is embraced, believed and practiced in its purest original form. This can have unintended or unexpected consequences when the philosophy is transferred to an entirely new context. We know that socio-cultural context is inextricably 
linked to learning and development (Rogoff, 2003). Therefore, we should not expect that the same philosophy, practiced in two different contexts might yield the same outcome.

This leads us to adaptation of a philosophy which is when the essence of a philosophy is believed and followers adapt the practices to suit the individual cultural context into which it is being transferred. Saracho and Spodek (2003), writing about innovation in early childhood education, state:

It is important that early childhood educators consider and reflect on current trends rather than hurriedly and carelessly adopt a trend, although a concept or trend should not be denied merely because it seems new. It is important to assess each idea, programme and innovation to determine its worth and applicability to the children's culture and community (p. 182).

An Australian literature review looking at innovative ideas for child and family services and particularly 'diffusion of innovation', highlighted the complex interplay of the innovation, the individual, the organisation and the wider environment on the spread of innovative policies, programmes and practice (Slaveron, Arney \& Scott, 2006). They consider the adoption versus adaptation debate and suggest:

The three methods of defining the success of diffusion, identify the complex trade-offs between adopting versus adapting an innovation when transplanting it to a new context. For example, faithful replication of a programme may be more likely to lead to desired outcomes, but the programme may not fit well with local settings and therefore may spread to a lesser degree and be less likely to be sustained. It cannot be assumed, however, that a programme (whether transplanted in pure form or adapted) will lead to the same outcomes as at its original site. Therefore it is important to rigorously evaluate and carefully monitor any innovation introduced in a new setting (p. 42).

Gerber adopted Pikler's approach and suggests: "I have felt sometimes like the bridge between Dr. Pikler and American society" (Gerber, 1998, p. 189). Teachers at the case study centre have adapted the Pikler approach and RIE philosophy to ensure they are a good fit with the cultural context of the centre and families who attend. 


\subsection{Respect for children's confidence and competence}

Respect for children's confidence and competence is the final element of the Pikler approach and RIE philosophy I examined in-depth. One element of respect according to Te One (2008) is to consider the rights of children. “Children's rights do not receive widespread public or political support in New Zealand" (Smith, 2007, p. 1). Article twelve of the United Nations Convention on the Rights of the Child states: "The child has the right to express his or her opinion freely and to have that opinion taken into account in any matter or procedure affecting the child" (United Nations Committee on the Rights of the Child, 2003). However, adults do not always see infants and toddlers as capable of having an opinion and often matters or procedures affecting the child are simply decided by adults responsible for the child (Te One, 2008).

According to Brownlee (2008), some of the general practices taken for granted with infants and toddlers are actually very disrespectful when we examine them more deeply. Picking children up without telling them, washing a face in a hurry, dressing a child without talking through what you are doing are just a few examples of minimal respect. Brownlee argues that just because an infant or toddler has less ability to verbally communicate their desires does not mean they are any less confident or competent than any other human being (Brownlee, 2008).

Gonzalez-Mena (2009) is in agreement with Brownlee and considers one aspect of respect to be predictability, which is, helping babies anticipate what will happen next. Babies should know what to expect each step of the way when they are being dressed, changed, washed, groomed or fed (Gerber, 1984). Predictability leads to a sense of security for babies. If we think about it as adults we know what we are doing, why we are doing it, where we are going 
and what we are doing next (generally). According to Gerber (2002), Pikler (1969), Gonzalez-Mena (2009), and Brownlee (2008) spelling this out for children is a simple matter of respect.

Respect is shown when adults treat children in ways similar to how they would like to be treated by others (Cheshire, 2007).

This is the Golden rule of quality care. If a person comes up behind adults unexpectedly and touches them, the first reaction is one of surprise. People may jump or flinch. Adults expect to be informed when someone is about to touch them. Therefore, teachers and other adults show respect when they approach an infant or toddler by moving in front, so the child sees someone is coming. Then respectful adults speak and tell the child what is going to happen (p. 36).

Because human beings tend to treat others as they have been treated (Bowlby, 1988), teachers need to model empathy. If we were always instructed about what will happen for, with and to us, rather than consulted with and respected as an individual with rights and freedoms, then we would feel powerless and insignificant. When a child is treated with empathy he or she will learn empathy towards others.

Reporting on her doctoral thesis, Te One (2010) states that if we knew more about children's rights, we would be better advocates for the principles of high quality early childhood practices. She comments:

The biggest barriers to understanding children's rights are adult misconceptions that children lack the capacity to make sensible decisions; that children's rights undermine adult authority; and, that complying with children's rights requires too much effort (p. 8).

These misconceptions can lead adults to neglect the relationship factor in education. James L Hymes Jr, wrote prolifically from the 1930 's to the 1980 's on the need for adults to understand and regard children's socio-emotional needs. His belief was that the foundation 
for true education is relationship based. Hymes (1975, cited in Anderson, 2009, p. 14) wrote: "What matters most when you're three, four, six or eight - I'm afraid it's what matters most while 12, 79 and so on - it's PEOPLE." This idea of relationship-based learning is at the heart of respect for children's confidence and competence as well as primary caregiving with infants.

If we are to truly understand the relationship-based potential for education of infants then we need to develop greater empathy. One way we can empathise with infants is to slow down and recognise that infants may be better off not having to be rushed (Brownlee, 2008). Time is another aspect of respect for infants' confidence and competence, particularly the use of unhurried time. That is being fully attentive and slow enough to pick up on the individual rhythms and cues of the child. In her article: "Time", Raewyne Bary (2009) asserts: “Relationship building takes time. It can't be hurried and it cannot be programmed into a daily roster system" (p. 19). She suggests: "Maybe we should follow their sense of time.... To be in the moment: to be in the space of time and let go of the ticking clock. Let the infants and toddlers lead us. Let's follow their rhythm, instead of that of the ticking clock" (p. 18). Bary also recommends four key elements for the development of trusting relationships between children, teachers and families:

- Being available

- Being tuned in

- Being responsive

- Being consistent All of the above requirements have one thing in common, and that is the need for time (p. 18).

Unhurried time may prove central to showing respect for infants. Responding with sensitivity and developing nurturing relationships both involve the use of unhurried time. These two aspects are the first two of twelve ways Stacie Goffin (1990) argues we can show 
our respect when interacting with children: Showing respect for childhood, she believes, involves the following:

1. Responding with sensitivity to children's individuality

2. Developing nurturing relationships with children

3. Using adult authority with wisdom to facilitate children's growth into caring adults

4. Considering how day-to-day practices influence children

5. Recognising discipline as a learning experience for children and viewing mistakes as potential learning opportunities

6. Acknowledging children's competencies

7. Organising a curriculum that provides children with interesting things to think about

8. Supporting and strengthening parents in their childrearing responsibilities

9. Acknowledging the expertise needed to be a professional in early childhood education

10. Speaking out on behalf of early childhood education as a profession

11. Speaking out on behalf of children's needs to parents, school administrators, business and community representatives, and policy makers (pp. 37-40).

I agree with each of Goffin's guidelines and consider two points particularly noteworthy in relation to respect for children's confidence and competence. “Acknowledging children's competencies" suggests that we must consider the child as capable. We must view them as able and resist the urge to do too much for the child and, instead, allow ourselves the time to see what they can accomplish on their own. Gerber's assertion: "Do less; observe more; enjoy most" (quote displayed on the wall at the case study centre) is in agreement with Goffin. The second of Goffin's respectful 'ways' that really resonated with me in relation to this research was: "Responding with sensitivity to children's individuality." This means considering a person's decisions, choices, preferences and styles of responding and interacting to be valid even when they are different to your own. 


\subsection{Ethics of care}

The notions of empathy and respect are at the heart of the "ethic of care" discourse prevalent in the feminist moral theory literature (Goldstein, 1998; Dahlberg, \& Moss, 2005; Noddings, 1984; Tronto, 1993). The general premise of the ethic of care debate is that "caring is not something you are, but rather something you engage in, something you do" (Goldstein, 1998, p. 247). The word 'care', as it pertains to teaching, is often linked to feelings, personality traits, or a person's temperament. However, Goldstein argues, this simplistic view of care obscures the "complexity and intellectual challenge of work with young children" (p. 245).

Noddings (1984) is in agreement with Goldstein and states: "Caring involves stepping out of one's own personal frame of reference and into the other's" ( p. 24). Noddings (1984) calls this motivational shift of putting aside your own choices, preferences, ideas, and really receiving another person as "motivational displacement" (p. 24). This shift "compels the one-caring to give primacy, even if momentarily, to the goals and needs of the cared-for" (Goldstein, 1998, p. 246). This motivational displacement coupled with attentive, receptive engrossment will lead the one caring to support the one cared for in a manner most suited to the cared for. For example, a teacher may believe that a child has no need or use for a security toy, but in reading the gestures and cues of the infant (attentive, receptive engrossment) may offer the infant their security toy against their own beliefs (motivational displacement).

Noddings (1984) proposes that each caring encounter will be unique, situated and variable: "the actions of [the] one-caring will be varied rather than rule-bound, predictable in the global sense but unpredictable in detail" (p. 24). For instance, a teacher who believes that children should progress naturally through the stages of motor development will predictably 
lay a child gently on his back to explore. Perhaps unpredictably, she might then prop this child to sit (motivational displacement) if he becomes upset lying on his back (attentive, receptive engrossment). Responsibility, communication, attentiveness, competence, responsiveness, empathy, intuition, compassion, love, and commitment are all attributes described by the various researchers contributing to our understanding of an "ethic of care."

\subsection{Chapter summary}

In examining the literature I gave a broad overview of the origins and components of the Pikler approach and RIE philosophy and the differences between them. Essentially, Pikler worked with families as a paediatrician first and later with orphans in an institution. Her ideas were developed based on the research she completed with these orphans and the nurses trained to care for them. The RIE philosophy adopted Pikler's approach and espouses all the same ideas but is aimed at working with families and early childhood services.

The literature associates many benefits with primary caregiving but also suggests the practice is not yet widespread in early childhood services. Few authors make suggestions of practical guidelines for early childhood education practitioners wanting to implement such a system in their setting. This is where I believe there is a gap in the literature and a contribution to be made for the early childhood sector.

Freedom of movement is a term understood as meaning never putting a child into a position she cannot get into or out of all by herself. There are two aspects to this premise: one is not interfering in any way with the natural motor progression of the infant (for example, from lying on his back, to rolling, then sitting, then crawling, and eventually pulling himself up and standing); the other premise is not putting children in any type of container, such as a high chair, walker-trainer, swing or jolly-jumper. In the literature freedom of movement is 
associated with benefits to children's physical, emotional, and cognitive functioning. However, a lack of empirical evidence to support the first premise when applied to children developing normally in family homes was identified in this chapter. This led me to examine the literature on adaptation versus adoption of a philosophy which was also discussed in this chapter.

Respect for children's confidence and competence is advocated in the literature. Actions demonstrating such respect include predictability, empathy, developing nurturing relationships, considering the child as a capable and equal human being, being fully present and engaged with each child and observing and responding sensitively. Respect for children's confidence and competence also involves intentional caring or an ethic of care where the teacher is intentionally able to displace her own motivation in order to truly understand the needs and wishes of the child and then act in the best interests of the child and not just on his or her perceived best interests of the child. 


\section{Chapter 3}

\section{METHODOLOGY}

\subsection{Introduction}

I undertook a qualitative case study that investigated the practices of primary caregiving, freedom of movement and respect for children's confidence and competence. A thematic coding of observational and interview data was used to interpret and analyse the data. Observation data was gathered by non-participant pen and paper observations and video recording. Documentation records such as ERO reports, prospectus information, children's individual discovery projects, wall displays, newsletters and information for parents were useful in triangulating data generated by observations and teacher interviews as well as a parent focus group interview.

\subsection{The research questions}

For this research there were two key questions:

1) What do practices that are inspired by the RIE philosophy and Pikler approach look like in an infant and toddler setting which uses

(a) primary care-giving;

(b) free movement;

(c) respect for infants' confidence and competence.

2) What are the understandings of teachers and parents as to the efficacy of these practices and the factors which might enable and / or constrain these practices? 


\subsection{A qualitative approach}

Adopting a qualitative approach enabled me to observe authentic interactions in their natural setting. Denzin and Lincoln (2005) explain:

... This means that qualitative researchers study things in their natural settings, attempting to make sense of, or interpret, phenomena in terms of the meanings people bring to them. (p.3)

To help describe the phenomena being researched Denzin and Lincoln (2005) recommend researchers use a variety of sources for data analysis such as personal experiences, interviews, artifacts, observations and texts. A range of data were used to analyse the practices at the case study centre. They included: full and contextual non-participant observations of the environment and the community of learners; semi-structured interviews with teachers and a focus group interview with parents; and analysis of documentation sources such as learning stories, wall displays, Education Review Office (ERO) report, routines, newsletters, parent information and education handouts.

\subsection{The case study}

The strategy of enquiry (Denzin \& Lincoln, 2005) for this project was an ethnographic case study which was carried out over a two-week period.

A case study is an empirical inquiry that

- Investigates a contemporary phenomenon within its real-life context, especially when

- The boundaries between phenomenon and context are not clearly evident (Yin, 2003, p. 13)

A case study was the most appropriate mode of enquiry for this research as it sought to unpack complex social phenomena (Yin, 2003). In this case the phenomena being the adaptation of a philosophy derived from work with infants in orphanages in Hungary to a New Zealand context. 
Merriam (1998) suggests researchers should employ a case study design when they wish to gain "an in-depth understanding of the situation and meaning for those involved" (p. 19). The focus for case study research is to provide rich description of a bounded case. The case could be a person, a setting or a concept. In the case of my study it was the setting at the case study centre.

\subsection{Socio-cultural theory}

A socio-cultural theoretical framework (Rogoff, 2003) suggests that "people develop as participants in cultural communities. Their development can be understood only in light of the cultural practices and circumstances of their communities" (p. 4). Socio-cultural theorists maintain that higher order brain functions are developed through an individual's membership of and engagement with a community (Rogoff, 2003; Tharp \& Gallimore, 1988). This framework sits well with an ethnographic case study design as ethnography is characterised by understanding and describing the beliefs, values and attitudes that structure the behaviour of a group (Merriam, 1998), and case study design is characterised by the intense, holistic description of a group. Socio-cultural theory, ethnography and case study highlight the importance of context and detail.

The New Zealand early childhood curriculum framework document Te Whäriki has influenced the popularity of socio-cultural theory. Some argue that it can also be used as a framework for analysis in qualitative case study research (Terreni, 2009). This socio-cultural

understanding that higher order functions such as thinking and learning develop out of social interaction (Tharp \& Gallimore, 1988) is consistent with the underpinnings of Te Whâriki which states: 
This curriculum emphasises the critical role of socially and culturally mediated learning and of the reciprocal and responsive relationships for children with people, places and things (p. 9).

\subsection{Introduction to the setting, teachers and children}

\subsubsection{The setting}

The environment at the case study centre is a renovated villa on a main road between a large suburb and the central city where many of the parents of children who attend the centre work. At the time the research was carried out, the centre catered for 22 infants and toddlers and was open from Monday to Friday from 7.30am until 6pm. This centre has a homely environment with a kitchen, dining room, sleep room, nappy change / bathroom, laundry, staff room, and three separate play spaces (one for infants, one for toddlers, and an outdoor play space). The service caters for both full-time and part-time attendance.

The case study centre is divided by age into two distinct groups. The Nursery group has up to seven children under fifteen months with two teachers and the toddler group has up to fifteen children from fifteen months to two and a half years of age with four teachers. The centre manager divides her time between the infant and toddler rooms relieving for teacher breaks and helping out as required. These ratios are more favourable than those required by the minimum standards for current early childhood regulations in New Zealand, which are 1:5 for all children under two years of age.

A range of natural, open-ended objects for exploration are available to the children. There is a distinct absence of plastic manufactured 'baby' toys; this reflects the philosophy of the teachers who agree with Gerber and Johnson (1998) that: "the best [toy] choices are a variety 
of sturdy, simple objects that allow the infant to explore their properties through her touching and mouthing... her intellect develops as she stores these experiences in her memory" (p. 88).

There is a large basket outside the nursery room where teachers and other adults entering the environment are instructed to place their shoes. All adults are invited to remove their footwear before entering the infants play space as a mark of respect for the infants who are using the floor surface to move, explore, and learn. There are numerous beautiful wall displays espousing the centre's philosophy. Some of these displays include the following:

\section{S L O W \\ D O W N}

Every baby is the divine child

Every child is a miracle

Every child is born capable

Every child is a free and equal human being

Every child is born to act out the love story

Every child wants to dance in the heart.

Just notice... (With a picture of a big key)

Young children need time

Tender

Intimate

Moments

Everyday

\section{FREEDOM TO MOVE AND PLAY}

\section{Principles:}

The relationship is all - it is a matter of life to the baby so nothing jeopardises the relationship.

The baby is capable.

The baby is designed perfectly so it needs support but neither help nor interference.

The baby is a free and equal human being.

The relationship is always partnership because free and equal human beings have partnership.

The care moment is the most important moment in the baby's life. The care moment is when the relationship is grown.

\section{Practices:}

Full attention.

With and not to. 
Respect in seeing, in listening, in touch, in speech, in partnering.

Enjoyment, pleasure and satisfaction in food.

Freedom to choose

The centre's most recent ERO report (2008) made the following comments regarding the environment and overall atmosphere at the case study centre:

The indoor and outdoor environments promote curiosity, investigation and exploration. Strategically placed viewing windows in a range of designs and colours extend the child's view of the centre and outside world. The nursery play space provides a safe and interesting area for infants to move in freely and at their own pace. A range of different surfaces and levels enables easy access to various parts of the room, including a raised area that provides challenges for children at early stages of mobility.

The overall atmosphere is friendly, welcoming and calm. Individual care needs are woven throughout the programme in a peaceful and unhurried way. Children are well supported by attentive adults in making their own decisions and developing their independence. They play amicably alongside each other and confidently approach adults for support. High teacher to child ratios provide good levels of individual attention (Education Review Report, 2008).

\subsubsection{The teachers}

There are nine staff at the centre; one manager, five full time teachers, two part time teachers and a cook. The centre manager and six of the other staff are fully qualified and registered early childhood educators. The only non-early childhood qualified adults employed in the service are one of the nursery teachers (who is a qualified accountant) and the centre cook (who has qualifications in food service). In the nursery there are two full time teachers and the manager also spends a considerable amount of time in the nursery relieving during teacher breaks and "non-contact" (child-free) times.

The teachers strongly believe in a child-centred approach, cherishing and respecting children's individual interests and routines. In the case study centre there is a strong view that by providing an environment that supports free movement, the teachers are allowing 
children to develop at their own pace, and this in turn empowers them to develop selfconfidence, self-esteem, determination, persistence and a sense of learning how to learn.

The philosophy developed by the teachers is based on respect and support, guiding children to be confident and competent learners. The following is the centre philosophy created by the teachers employed at the case-study centre at the time the research was conducted:

In order to provide the best environment for children to learn, we respect and recognise the importance of peer learning, self reflection, professional development and sharing knowledge within our community.

We believe in the importance of partnerships, developing honest and respectful relationships with children and their whanau.

At the heart of our approach are responsive and respectful relationships, which are empowering and reciprocal. We celebrate each child's journey, documenting their interest and accomplishments, strengthening connections between home and centre and ultimately promoting appropriate opportunities/experiences to support this learning and discovery.

We value the diversity of our teaching team appreciating each individual's knowledge, experience and teaching skills. The cooperative support and dedication of our team enables us to provide a peaceful harmonious environment for all.

We embrace and celebrate the significance of preverbal, new and existing languages and cultures; placing emphasis on tikanga and te reo Maori, which is woven throughout each day.

We enjoy our unique, safe, but challenging environment and take time to create aesthetically pleasing and visually interesting spaces where children can become confident and competent learners. We believe that children learn through exploration of space, colour, tactile and sensory experiences with a focus on natural materials.

We incorporate aspects of the R.I.E philosophy into our programme which focuses on the importance of respect and the opportunity for children to progress at their own natural pace.

In order to ensure that children develop an awareness of good environmental practice we model and promote the "three r's" - reduce, reuse and recycle (case study centre philosophy @ December 2009).

The following were statements made by ERO (2008) regarding the teachers at the case-study centre. 
Teachers focus on the importance of respect and the opportunity for children to progress at their own natural pace. A primary care-giving system operates at the centre in accordance with this philosophy.

Teachers work as a team and all embrace the centre's philosophy. They respect the children as confident and competent learners and value their contributions to the programme. They follow the lead of the children and take a flexible approach to programme provision (Education Review Report, 2008).

The following grid details the names of the three teachers I observed as part of this research (pseudonyms I have based on the names of native New Zealand birds). Also detailed is their training background, length of service and number of years qualified.

\begin{tabular}{|l|l|l|l|}
\hline \multicolumn{1}{|c|}{ PSEUDONYM } & \multicolumn{1}{|c|}{ TRAINING } & LENGTH OF & NUMBER OF \\
& BACKGROUND & SERVICE & YEARS \\
& & & QUALIFIED \\
\hline Tui & B. A. / B. Teaching & Three years & Seven months \\
\hline Kea & Qualified accountant & Eleven years & N/A \\
\hline Huia & B.Ed. ECE & Six years & Six years \\
\hline
\end{tabular}

\subsubsection{The children}

There were six children directly involved in the research, each of whom was attending in the nursery. Several of the toddler parents gave permission for their children to be involved. This meant that when the children came and went from the nursery to say a "hello" to their former primary caregivers I was able to record such interactions also. The children involved attended the centre for a variety of hours and days ranging from full time to just one or two 
days per week. The youngest child observed was just five months old and the oldest child at the centre was two years and three months of age. Most children were of European descent. One child was Japanese/Indian, one child was Dutch, and one French. When at home, each of these three children was spoken with in their native languages and was only exposed to English when they were in attendance in the centre and outside of their home. All children observed in the study were from two parent families, and all but one child were the first (and currently only) child in their family.

The following grid details the primary caregiving groups in the nursery (using pseudonyms) at the time the research was undertaken.

\begin{tabular}{|l|l|}
\hline \multicolumn{1}{|c|}{ CHILD } & \multicolumn{1}{|c|}{ PRIMARY CAREGIVER } \\
\hline Rosie & Kea \\
\hline Charlotte & Kea \\
\hline Elsie & Kea \\
\hline Madeline & Tui \\
\hline Ben & Tui \\
\hline Max & Tui \\
\hline
\end{tabular}

\subsection{Method}

\subsubsection{Non - participant observations}

All observations, interviews, and gathering of documentation data took place within the centre over the two-week period. During that time, I assumed the role of non-participant observer (Denzin \& Lincoln, 2005; Mutch, 2005; Merriam, 1998; Stake, 1995). I spent my 
time in the Nursery observing relevant interactions and dividing my time between observing teachers and children to ensure I recorded a variety of interactions. From these observations I developed full and descriptive field notes for analysis in order to answer the research questions. Observation emphasis was placed on the research questions pertaining to primary caregiving, free movement and respect for infants' competence and confidence.

A combination of video camera and digital camera was used as well as written observations and descriptive field notes to record interactions regarding primary caregiving, free movement, and respect for infant's confidence and competence. Only observations of specific interactions which connect with the chosen research questions were recorded.

My criteria guiding what I would (and would not) observe and record is outlined below.

Primary caregiving is defined in the literature as a special relationship with one other person in the environment on whom the infant can rely to meet his or her individual needs (Elfer, Goldschmied, \& Selleck, 2003; Gonzalez-Mena \& Widmeyer Eyer, 2009). Thus I focussed on one-on-one interactions between a child and teacher (not only between a child and their primary caregiver but also between children and other adults in the environment). I used video recording to document the detail of prime times or caregiving routines such as changing, meal-times, and preparing children for rest. I also recorded the information discussed and exchanged between caregivers (between teachers and also between teachers and parents).

Freedom of movement is defined in the literature as only placing children in positions they can get into or out of on their own and not restricting their movement by using any form of container (Sensory Awareness Foundation, 1994; Gerber, 1998, 2002; Hammond, 2009). 
Thus I recorded children's movement in and around the nursery room. I also recorded teacher and parent discussions and comments regarding the physical development of individual children. Finally, I recorded teachers' actions and language directed to children regarding their physical development and infants' body language, cues and gestures.

Respect for children's confidence and competence was more difficult to define and therefore required me to think quite carefully about what I considered to be respectful practice. The following is a list of characteristics which guided me in knowing when to do event records:

- Any time a child was offered a choice in his or her care and development.

- When teachers waited for a response before engaging with the child.

- When teachers were careful to explain to a child regarding the process in which they were engaged.

- When teachers would respond to the language, cues and gestures of the child.

- When a teacher would sit back and allow a child to solve his or her own problems rather than rushing in to solve them on his or her behalf.

In general my guide for beginning an observation of a respect "event" was: Is this how I think the child would wish to be treated? This guiding question relates to the ethic of care literature which suggests that caring is a complex intellectual endeavour as opposed to a personality trait or temperament. A caring encounter or "event" is one in which the one caring is able to displace his or her own motivation in order to act on the actual interests of the child (Noddings 1984; Goldstein, 1998).

While I was familiar with the environment, I have not been actually engaged in teaching within the environment on any regular basis for several years. I was able to observe without 
being involved in any way with the activities taking place. There were benefits to my having some familiarity with the environment including my ability to give in-depth description of the environment. Stake (1995) suggests "it is important to provide details of the physical context. What readers understand about the case should be considerably enhanced by knowledge of the setting" (p. 138). Observing as a non-participant was an advantage as I was not in a position to manipulate any events being observed (Yin, 2003).

\subsubsection{Teacher interviews}

For the purposes of this research I interviewed three teachers in total. I interviewed the two full time teachers working with infants in the nursery (one of whom is qualified and registered) and the centre manager (also qualified and registered). The teacher who is not qualified specifically in early childhood education is a qualified accountant with eleven years of service as a nursery teacher at the case study centre.

Semi-structured interviews (Merriam, 1998; Mutch, 2005) were conducted face-to-face individually with each of the three teachers involved. These interviews took place during the two-week period of data collection. Silverman (1997, p. 141) suggests that "The interview is a pipeline for transporting knowledge." In this way the interviews were semi structured and active in that they sought to extend both the interviewer and interviewees' knowledge and understanding. The advantage of employing such interview methods enabled me to pursue new directions of questioning as they arose due to various answers given and discussion arising.

Interviews recorded perceptions and developing understandings of primary caregiving, freedom of movement, respectful practices and respect for children's confidence and 
competence. Interviews also recorded participants' perceptions of the impact of these practices on infant and toddler development and learning. Interviews were recorded and transcribed by me from Dictaphone or video camera and given back to participants to check for accuracy.

\subsubsection{Parent interviews}

A focus group interview with parents was also part of my research. According to Denscombe (2007), the advantage of conducting focus group interviews rather than individual interviews is that:

Listening to one person at a time effectively restricts the number of voices that can be heard and the range of views that can be included within a research project. Group interviews, however, provide a practical solution to this. By interviewing more than one person at a time the researcher is able to dramatically increase the number and range of participants involved in the research (p. 177).

Other advantages of focus group interviews are that the style of interview can be very natural and relaxed, thereby creating an atmosphere more like a discussion than anything as formal as an interview. This was the case for my research as I set up a video camera in the corner of the room where the focus group took place. This recorded the whole discussion and eliminated the need for me to use pen and paper or take any notes, which definitely helped to create a less formal atmosphere. Focus group interviews are also an efficient way to get many perspectives and opinions in a short space of time (Wilkinson, 2004).

Each of the forty parents whose twenty-two children were enrolled at the time of my study was invited to join our focus group evening. Only four parents (all mothers) and the centre manager came to the focus group interview which was held one evening at the centre. Wine and food was provided as an incentive to come and be part of the process. The focus group 
interview lasted for two hours and was videotaped at the time and later transcribed by me. A copy of the questions discussed at the focus group is included in Appendix F. Typed copies of the written transcription were circulated to the parents and the centre manager who attended the focus group interview. I asked the participants to confirm the transcription for accuracy which is known as member checking (Merriam, 1998; Stake, 1995). My transcription was accepted as a true and correct record and no changes were requested. The grid below details the participants who were in attendance at the parent focus group interview.

\begin{tabular}{|l|l|l|l|l|l|}
\hline PARENT & \multicolumn{1}{|c|}{ CHILD } & GROUP & PLACE IN & LENGTH OF & \multicolumn{1}{|c|}{ OTHER } \\
\hline Alisa & $(\mathbf{p s e u d o n y m )}$ & & FAMILY & ENROLMENT & SIBLINGS \\
& Jon & Toddler & $2^{\text {nd }}$ Child & Six months & Older brother \\
\hline Janine & Liv & Nursery & $2^{\text {nd }}$ Child & Five months & Older brother \\
\hline Vicky & Charlotte & Nursery & $1^{\text {st }}$ Child & Three months & N/A \\
\hline Jenny & Tony & Toddler & $1^{\text {st }}$ Child & Four months & N/A \\
\hline Huia & Centre & N/A & N/A & N/A & N/A \\
\hline & manager & & & & \\
\hline
\end{tabular}

\subsubsection{Documentation}

Yin (2003) suggests "the most important use of documents is to corroborate and augment evidence from other sources" (p. 87). Documents used in this study included learning stories, 
teaching stories, the centre's most recent ERO report, wall displays, the centre philosophy, routines, newsletters, and parent information and education handouts. These many sources of documentation were analysed alongside the other data I collected, providing a further source of triangulation.

\subsection{Analysis of data}

Data analysis was conducted as an activity simultaneously with data collection (Merriam, 1998; Stake, 1995), interpretation and narrative report writing. I searched for themes and coded the data according to these following what Merriam called the constant comparative method (Merriam, 1998; Stake, 1995). Patterns and connections were established as findings. Direct observations of specific phenomena and useful quotes were also highlighted and used as illustration in writing up the qualitative story. After analysing the data I looked for any patterns that emerged and compared my research results with patterns in other studies reported in the literature, and predicted in theories.

Observations were coded into each of the three specific areas outlined in the research question, as were interviews with the three teachers and the focus group of parents. Video footage provided a level of detail necessary to enhance pen and paper observations of the same phenomenon. Documents recorded included learning stories, routines, ERO report, the centre philosophy, newsletters, parent information and education handouts, wall displays, and research consent forms.

I was able to gather data only related to the areas of focus as I had considered carefully the phenomenon I wished to observe prior to recording. The observations, along with interview data and documentation, over the two week period, provided an entirely manageable set of 
data. Therefore, all video and pen and paper observation data gathered were coded and analysed. I developed a coding system so I could capture particular patterns of behaviour and therefore describe that behaviour in general terms. This coding system involved coding the data initially into one of three areas: primary caregiving; freedom of movement; and respect for children's confidence and competence. Once coded into these three areas I further refined my coding into individual themes which emerged within the three initial areas. Some of these themes were evident in more than one of the initial areas and those are discussed in some detail in the findings section of this thesis (Chapters $4-6$ ).

\subsection{Ethical considerations}

As the owner of the case study centre I was aware of the ethical issues involved in my research, in particular the need to avoid the possibility of coercion. Cullen, Hedges, and Bone (2008) caution that "voluntary participation of staff may be constrained by a power relationship" (p.2). However, in this case as I had been approached by the teachers at the case study centre about the possibility of my doing research within their centre, rather than the other way around, I felt confident that no one was uncomfortable about my presence in their centre for the duration of the study. I was also confident that the teachers wanted to be involved in the research and I was careful to ensure each teacher understood what was involved in the research.

In order to avoid coercion I asked Dr. Anne Meade to handle the consent process with the teachers at the case study centre. Dr. Meade agreed to support my research. As an advisor to our Early Childhood Institute, Dr. Meade is familiar with our approaches, our centres and our team at the case study centre. She is also an adjunct research associate at my University. Dr. Meade came to my initial meeting with the teachers and was the person who distributed the 
participant consent forms, answered participant questions to do with consent (and withdrawal), and gathered in the completed consent forms. At this initial meeting I left the room while she explained the process and answered any questions so that any concerns would remain confidential and could not affect any employment relationship. Consent forms were clear that teachers had the right to withdraw from the study at any time up until the data were being analysed. All teachers at the centre agreed to the particulars of my research and signed consent forms to that effect. Appendix D contains a copy of the teacher consent form.

Obviously as observer and researcher in the environment, I had a different role to my usual role as owner/principal. I discussed with the teachers the different role and was satisfied that they were comfortable with my presence as observer and researcher. I discussed with the teachers the steps I needed to take to ensure they were comfortable being observed. I reassured the team that as researcher and observer I was not there as a practitioner, nor was I there to criticise any of their practices. I met with the group prior to the start of the research to discuss any issues for the teaching team. I was also available to the team throughout the on-site stage of the research to answer any queries they had about my study.

The age of the children involved in my research prohibits the ability to gain informed consent from them. However, through sensitive observation one is able to gauge a child's assent. An example of gaining children's assent was when I moved with one of the caregivers through to the nappy change room and was videoing the interactions when the child became quite agitated. My reflection on the situation was that the child was not happy to be observed during such an intimate care routine and I quickly turned off the camera and backed out of the room to respect his wishes. 
The name of the case study centre was not identified and pseudonyms were used for children's, teachers' and parents' names. During the course of the research all the written data, video data and photographs were only accessible to me and protected by passwords. In accordance with information and consent forms all data will be destroyed after five years.

\subsection{Data validity}

Stake (1995) recommends a diary or $\log$ in which a record of everything to do with the research is kept like calendar, telephone numbers, observation notes and so forth. I found a little notebook very useful in this regard. Such an audit trail (Merriam, 1998) ensures adequate documentation of the entire process from methodology to analysis and why and how decisions were made throughout the research process. By clearly documenting research decisions, design, data gathering and analysis techniques I have further strengthened the trustworthiness of my research.

It is essential that the reader considers qualitative research to be trustworthy and credible (Denzin \& Lincoln, 2005; Mutch, 2005; Stake, 1995; Merriam, 1998, 2003). Toma (2006) recommends that qualitative researchers reject the accepted quantitative standards and suggests: "a more individualistic approach to rigor in qualitative research" (p. 406). Мy rigorous approach covered the concepts of trustworthiness including credibility and transferability as suggested by Toma (2006). This is explained below.

A very common approach to trustworthiness in case study research is to use multiple data sources. My research utilised this concept of triangulation (Toma, 2006; Stake, 1995; Merriam, 1998, 2003). Various data collection methods included interviews, non-participant observations, video footage, and documentation records. Another common tactic for 
establishing trustworthiness in qualitative research is having key team members review the draft case study report (Merriam, 1998; Stake, 1995). I kept participants informed throughout the research process, including checking transcripts of interviews to ensure the meaning is as they intended, as well as sharing observations and descriptions, and asking for feedback on findings as they emerged and initial draft reports.

In order to assist with the credibility of my research I made several observations of specific practices in the centre. Merriam (1998) suggests repeated observations of the same phenomenon will increase credibility when it is not possible to observe over a long period. I have made my biases clear at the outset in declaring my interest, ownership, and theoretical orientation to enhance transparency and strengthen the credibility of my research (Creswell, 2003).

Transferability is the last of my methods to ensure reliability and validity. In case study research there is always the problem of whether we can generalise our findings to other situations (Stake, 1995). However, because the centre involved is operating under the same regulations as all early childhood settings in New Zealand, it is possible that other centres following this philosophy could be interested in replicating the research findings. The only limitations to this assumption are:

- While the official ratio for infants and toddlers according to the early childhood regulations is $1: 5$, at no time during my observations were there any more than $1: 4$ and most times the ratio was more like $1: 2$ or $1: 3$ and often $1: 1$.

- Again, according to regulations the requirement is for one person present at the centre to hold a specific Early Childhood qualification at the bench mark level of Diploma of teaching ECE at all times. At the case study centre all but one teacher held the higher 
qualification of B.Ed. ECE or the double degree of B.A./ B.Teach. Therefore, the staff are clearly well above the minimum standards of qualifications required by regulation.

- The philosophy at the case study centre has been practiced and refined for the past seven years and therefore has become deeply embedded in the teachers' practice. The teachers have also each attended several specific courses and conferences aimed at deepening their understanding of respectful practices for infants and toddlers.

Other centres following a similar philosophy long enough for respect to have become deeply embedded in their practices could possibly replicate the findings if they had excellent ratios, and qualified staff who have opportunities for professional development specific to the philosophies of respectful practice for infants and toddlers.

\subsection{Chapter summary}

This chapter has outlined the methodological approach and related methods utilised in this study and the approaches taken for data collection and analysis. It has described the ways in which qualitative data were collected through non-participant observations, parent focus group interview, teacher interviews and various documentation sources. Ethical considerations and data validity were discussed and methods for analysis considered. 


\section{Chapter 4}

\section{PRIMARY CAREGIVING}

\subsection{Introduction}

In this chapter I examine teacher and parent participant understandings of the term primary caregiving. The findings from my research related to primary caregiving include: a team approach; children re-visit their primary caregiver when they move to the next group and later; body language, cues and gestures are used by both children and adults; language is used by teachers as an invitation and explanation; children are soothed by the close proximity of their caregivers; teachers are unhurried in their interactions with children and operate according to the individual rhythms of the children as opposed to the clock; and children are comfortable to wait for their turn. These findings are each explained in detail below.

\subsection{Towards a definition}

Primary caregiving is a key element of the RIE philosophy and Pikler approach and is a corner stone of the philosophy at the case study centre. Adopting a primary caregiving system in an early childhood setting essentially means that one teacher is primarily caring for a small group of children. For the children this means someone they can 'bond' with and build a close, trusting relationship. It also means someone who will be there for them and respond to their needs and care for them. For the parents and whanau it means someone they will get to know well and with whom they will feel comfortable leaving their child. The primary caregiver is someone with whom both parents and child can build a close and trusting relationship. 
Teachers interviewed made the following statements when asked about their understanding of primary caregiving:

This is describing our practice here where we have a small group of children each and we are responsible for all the nappy changing, feeding and sleeping for the child. We are the first point of contact for the child and the family and we build up a relationship of trust and respect (Kea: teacher interview).

Primary caregiving is based around the principle of children having one secure and trusting relationship with one adult [at the centre] other than their parents. In terms of our practice, each teacher has a group of children with whom they build a loving and secure relationship with the child and their whanau. Parents have a person they know they can talk to and approach with any concerns (Tui: teacher interview).

[This means] having one teacher primarily caring for a small group of children. For the children this means someone they can 'bond' with and build a close, trusting relationship. It also means someone who will be there for them and respond to their needs and care for them (Huia: teacher interview).

For the parents and whanau it means someone they will get to know well and feel happy / comfortable about leaving their precious child with. The primary caregiver is someone with whom they can build a close, trusting relationship (Huia: teacher interview).

Teachers all understood primary caregiving to mean they would form a strong bond with the infants in their care group as well as the parents of those infants. Parents were asked the same question regarding their understanding of primary caregiving and made the following comments in the focus group interview:

That your child has one person - and for my children it's like having their other mother when their mother is not there. That one person they know if they hurt themselves or if they're sleepy or tired or hungry that they've got a connection with that person that emotionally is going to look after their needs (Janine: parent focus group interview).

The connection is the important thing - if the caregiver is away then someone else is still going to look after their needs (Alisa: parent focus group interview).

Parents and teachers both had a good understanding of primary caregiving and defined it as a practice of having one teacher primarily responsible for the well- 
being and emotional security of each child. Both parents and teachers considered the primary caregivers role to include the building of a reciprocal relationship and strong communication with the parents of each child.

\subsection{A team approach}

The most recent research in New Zealand (Dalli \& Kibble, 2010) considered primary caregiving within a given centre to have been enacted as a team approach and found that all teachers in the environment had a good understanding and relationship with each child in the environment. My findings support this research. Communication between teachers was respectful, clear and unhurried. Teachers shared information about children's needs and development. For example:

Kea to Tui "while I give Ben his bottle maybe Charlotte needs a change?"

Tui to Kea "I changed her after her sleep so she is probably all good - Max might need a sleep soon and then maybe we should take the others outside for a while?"

Kea: "She (indicating Charlotte) will like that - she has been really interested in exploring the sand recently." (Observation data from pen and paper)

The two teachers read and discuss the notes made regarding changes, bottles, feeds and sleeps.

Tui to Kea "Rosie had her bottle early?"

Kea: "Her mum said she woke early and had breakfast early too. She let me know she wanted that. Liv hasn't had hers but she's been busy exploring the pegs and mirrors again." (laughs)

Tui: "do you think Rosie will want a sleep soon?"

Kea: "yeah, maybe I'll see if she wants a fresh nappy first."

They communicate quietly and collegially. (observation data from pen and paper)

This collegial team approach was evident throughout the centre, not exclusively between the infant teachers. A good example was the exchange below between the cook and one of the infant teachers:

Kea is feeding Rosie on the mat. The cook comes by and checks on requirements for the afternoon. 
"How many will we have? (Kea answers just three this afternoon)... and will I need to do something softer for Max?"

Kea makes suggestions and recommendations for which children she thinks might want what and in what portion sizes. "Rosie loves yoghurt at the moment so she will have plenty of that and she didn't have much lunch so a good serving for her. Max is enjoying banana recently. Liv will have whatever we give her! She has a great appetite" (laughs with cook). (observation data transcribed from video)

Analysis of the observations showed that all teachers and support staff had a good knowledge of each individual child but the primary caregiver was usually the most knowledgeable and was therefore consulted or directly responsible for most decisions concerning the child or engagement in routine care times. On several occasions I observed teachers soothing a child anticipating the return of their caregiver to give them a meal or take them for a change or sleep when they became available. I observed the primary caregiver taking responsibility for one-on-one care routine times whenever possible to ensure consistency and continuity for each child.

Huia (centre manager relieving in the room for a break time) asks Kea "is Max ready for a sleep?" Kea replies that Tui will be back soon and she will put him to bed. (observation data from pen and paper)

When Tui returns from her lunch break Kea has been soothing Max gently rocking him standing up and looking out the window together. Tui invites Max by putting out her hands. He tips forward toward Tui. She heats his bottle while she holds him. She feeds him his bottle on the nursery floor. Afterwards she takes him for his sleep. (observation data transcribed from video)

I observed teachers gathering necessary resources for each other. For example one teacher would heat a bottle for another teacher or warm a facecloth so the teacher engaged in caregiving could have un-interrupted time with the child fully concentrating on him or her. These observations were supported by the COI action researchers who made similar observations:

Part of what makes the primary caregiving system successful is that the team members are there to support one another. They see when someone needs to spend an extra moment with a child, or help out when it is tricky 
for the primary caregiver to do so. Primary caregiving should not replace a team approach (Dalli et al, 2009, p. 41).

The teachers were really careful to ensure they had all the correct details if they were coming back into the room after a break or just beginning a shift. They clarified this for me in the interviews saying: "It is only respectful to have a full picture of what is happening before launching in without the facts." (Huia: teacher interview)

Tui returns from lunch and asks "where are we at Mumma?" (a term of endearment she uses to refer to Kea at times). Kea fills her in on sleeps, changes, and who has eaten and drunk what. (observation data from pen and paper)

The COI research team found:

Because one person can't do everything and we don't want this relationship to be exclusive, it is important that every child has another caregiver they are also happy with... this secondary caregiver is someone with whom the primary caregiver can comfortably leave the child when they go to lunch or with whom the child can feel safe if the primary caregiver is away (Kibble et al, 2010, pp. 6\&7).

My findings were similar regarding primary caregiving existing within a team approach.

Parents at the focus group interview for my research agreed stating:

Primary caregiving can never replace a team approach. There is no way that each of those children in the nursery doesn't have a strong and secure bond and relationship with both of the teachers in there. And it is just the nature of full day care that with shifts and everything parents will need to communicate information to a teacher other than the primary caregiver sometimes and children will be without their primary caregiver maybe at the beginning or end of the day, when they take breaks, or non contact and over their lunch break (Janine: parent focus group interview).

So it's not an exclusive relationship - definitely a team approach (Alisa: parent focus group interview).

I think it is all the staff. Everyone is different but they are all the same kind of people. Like I know that Tony would be happy with anyone - that you all have a relationship with each of the children. Its primary caregiving but it's not restricted. It's quite open. That is hugely reassuring. I drop him off, we have a chat and he's off and loving it. That has always been the case for me (Jenny: parent focus group interview). 
One parent had an opinion I had not considered about primary caregiving, teamwork and the benefits of group care:

If I get a nanny in my home - then I have to just trust one person - all your eggs in one basket. I have to trust that they are a good person. That's what I like here: the team can support each other so no caregiver can become overwhelmed or stressed and they are very nice people so you can trust them individually but [them] just having that support means more (Janine: parent focus group interview).

The idea of having a nanny in a home setting may appeal to some parents so the nanny can form strong bonds with both the child and parent. Similarly, parents reported feeling their own attachment to their child's primary caregiver in the centre context:

I think too that the primary caregiver is like my primary caregiver. Like managing me and giving me feedback. Like if you are running out the door and you need to leave it's being able to say to that one person he's had a sleep, he's had half a piece of toast and no milk. So that they know his needs and where to pick up (Janine: parent focus group interview).

This observation is similar to what the COI teacher-researchers involved in recent primary caregiving research found:

We are not the child's primary caregiver, we are the primary caregiver for the family, and together - in partnership with the family - we do what is best for the child (Kibble et al, 2010, p. 7).

Supporting documentation from the Education Review Office (ERO, 2008) reiterated the successful use of a team approach in the case study centre:

Teachers have a collaborative, proactive approach to providing high quality care and education for infants and toddlers. They work as a team, communicating frequently throughout the day about individual children and the organisation of the centre. They share the responsibility for routines and the programme (p. 5).

Teachers were clear in their interview about primary care being a whole team commitment: 
Because they have the attachment with me but will build that up over time with the other teachers in the room (Kea: teacher interview).

If one is away the other becomes the primary caregiver to all and the regular reliever is still known but has to do what fits in with the children's wants. For example if they are not happy to be fed/changed etc by the reliever then the other caregiver does this (Kea: teacher interview).

Analysis of the data lead me to conclude that having a primary caregiving system in the case study centre required a full commitment from each member of the team. Everyone had to be clear about the value of primary caregiving and supportive of each other to ensure children were able to have uninterrupted care times with their primary caregiver. There was also general acceptance of the fact that children would be consulted by way of teachers being sensitive to their cues and gestures regarding their desire or otherwise to be cared for by anyone other than their primary caregiver.

Another aspect of a team approach was the exchanges between parents and caregivers. They would exchange information with the clear understanding that they were working in partnership to deliver the best care for each child. For example:

Max arrives with his Dad and they are greeted by Kea. Dad exchanges information saying "Max wasn't very interested in breakfast this morning so he might be hungry but he slept really well for the first night this week." Max tips his body forward to move himself from Dad to Kea. Kea receives Max, greets him warmly with a smile and congratulates dad on a full night's sleep. (Observation data transcribed from video).

Mum comes in and Liv waves her hands, smiles and moves towards her they cuddle and kiss for a minute or two and Mum chats with Kea about Liv's day. When Tui comes in she is happy to chat a while as well and they discuss Liv's bowel movements, teething, walking and eating. (Observation data from pen and paper).

Elise's mum arrives and Tui fills her in on how her day has been. She has brought a recipe for Tui which is for home made rusks. They discuss Elise's day and lack of sleep and Mum checks the paper work to see when she had her last bottle and details of her changes and sleeps. (Observation data from pen and paper) 
Kea: "I want to show you the right cream" Parent: "Is that not the right one?" "It is alright for every day but there is a better one for when there is a bit of a rash." The parent clearly values Kea's knowledge and listens carefully to her advice. (Observation data transcribed from video)

The examples above are as one might expect from the review of the literature. There is much support in the literature for the notion that teachers and families are working in partnership for the best interests of children in early childhood settings (Kovach \& Da Ros-Voseles, 2008; Elfer, Goldschmied \& Selleck, 2003).

Building strong relationships and alliances between families and caregivers increases the possibility of providing quality care for babies. Families can provide valuable insights and information to help caregivers understand their baby. Often, families have important information about babies' habits that help caregivers interpret their needs. In addition, caregivers can support families and develop mutually trusting professional relationships with them (Kovach \& Da Ros-Voseles, 2008, p. 163).

In the case study centre parents and teachers exchanged information at arrival and departure times. The nature of the interactions was friendly and informal. Mostly they would discuss the immediate needs of the child but often their discussion would move to a more personal exchange of information which would in turn aid the building of strong and trusting relationships between parent and caregiver.

\subsection{Re-visiting the primary caregiver}

I observed children re-visiting their primary caregiver from time to time during the course of each day. This would typically be at the child's request or during times when the infant and toddler groups were outside together and able to easily access any teacher they chose. One such instance was while all the children were outside together, a group of toddlers came back to the primary caregiver they had in the nursery previously:

Kea sings songs with Charlotte on her knee and a few of the busy toddlers leave what they are doing and make their way over to join them. Two of the three toddlers who join Kea and Charlotte were in Kea's primary caregiver 
group when they first started in the nursery. (Observation data from pen and paper)

One of the toddlers (Jon) has come in to see Kea and he climbs onto her lap for a big cuddle. Rosie who is sitting next to Kea gives a little protest but it doesn't last long as Kea has enough cuddles for both of them. She says both of their names as she cuddles them both. Rosie moves away to play with something else briefly but she protests again and Kea asks her "are you tired?" She moves in for another cuddle and Kea says "I know you are tired but you are going home soon." Rosie has a cuddle for a little while and then moves off to play with something else. Jon remains cuddling into Kea's body throughout the interaction. (Observation data transcribed from video)

This is important to illustrate how secure attachment (Kovach \& Da Ros-Voseles, 2008; Lally, 1995) can create strong bonds between teacher and child. These bonds can be so strong that the child will seek out their initial caregiver even when they have moved on to another group within the centre or even years later when they have moved on to primary school. The below example illustrated this exact phenomenon. A school aged child returned to her primary caregiver in the nursery when she came with a parent to pick up a younger sibling from the toddler room:

Kelly comes in (she is the sibling of one of the toddlers and is 6 years old). She was once one of Kea's primary care group in the nursery and she asks if she can come and be with Kea and the babies while her Mum gets her brother. Kelly seemed very comfortable being in the nursery and chatting with Kea. The two infants remaining in the nursery watch Kelly skip and jump around the room chatting, chanting and counting as she jumps around the boxes. She stops to say bye to both the babies and Kea when her mum comes to ask her to leave. (Observation data from pen and paper)

In the example below one parent explains some of her feelings about primary caregiving and about how her children have had particularly strong bonds with their first primary caregivers at the centre:

The primary caregiving thing I know for sure it makes them more confident because they are more secure. Both my children have had primary caregivers. They share a really special bond and relationship with their first primary caregiver. Even more special unfortunately than with their 
grandparents but that is just the nature of knowing someone really well and seeing them every day. I know that even now if I couldn't be there it is flexible enough at [the case study centre] so that a teacher would go and get his first caregiver with whom he shares a special bond and she could be with him until I could get there. Knowing that is really reassuring (Janine: parent focus group interview data).

These findings indicate that children share a reciprocal relationship with their initial primary caregiver. In the case of the school aged child it is apparent that she felt comfortable some years later. Also apparent in these findings was the bond shared between parent and caregiver and the trust placed in the caregiver by the parent.

\subsection{Body language, cues and gestures}

Through sensitive observation teachers are able to accurately read infants' body language, cues and gestures. On many occasions I observed open hands held out with palms facing upwards by way of invitation from teachers in the environment. Acceptance of this invitation was usually indicated by the infant tipping his or her body forward towards the inviting teacher. There were several examples of this exact sequence of events including:

When Tui returns from her lunch she invites Max by putting out her hands. $\mathrm{He}$ is being held by Kea at the window and he tips forward toward Tui demonstrating his acceptance of her invitation. (Observation data transcribed from video)

Tui holds her hands out to Ben with her palms facing upwards and Ben accepts the invitation by smiling and leaning towards Tui knowing this means it is time for a cuddle if he would like one. (Observation data from pen and paper)

Tui returns from putting Ben to bed and holds her hands out to another child "shall we go and change your nappy now?" He tips forward into Tui's waiting hands to suggest this would be good for him. (Observation data from pen and paper)

I also observed similar examples of the invitation and acceptance sequence of cues working in the reverse order. Most often this involved children gesturing with open arms a request or invitation for the caregiver to pick them up or cuddle them: 
He holds his hands out to Tui [as if to indicate that he needs her]. She picks him up and suggests they go and change his nappy. (Observation data from pen and paper)

She puts her hands out in invitation/request for Tui to lift her from the change table. (Observation data transcribed from video)

Charlotte arrives with her Mum and she smiles and holds her hands out to Kea as she sees her coming back to the nursery from changing Max. She tips right forward out of her Mums arms and into Kea's. (Observation data from pen and paper)

Other examples of cues and gestures involved teachers reading the facial expressions and movements of children attempting to indicate their needs and wants. For example:

Kea feeds Charlotte a few spoonfuls and then Charlotte moves away with her body and screws up her face. Kea says "shall I put your lunch away?" She puts the lunch away without any other cue from Charlotte. (Observation data from pen and paper)

After a while Max turns his head away from the bottle. Tui retries and then says "Have you had enough?" "OK then, let's go nunn-nies." He cuddles into her shoulder. (Observation data from pen and paper)

Charlotte eats her lunch sitting on Kea's lap. Kea feeds her when she indicates by opening her mouth. (Observation data from pen and paper)

"Would you like a bottle Ben?"

Ben makes "huhuhu" sounds and squeezes his hands together. Kea gets up slowly and goes to the fridge and microwave to get his bottle ready.

During the observations, it appeared that teachers were finely tuned to the body language of each individual child and peacefully observed each one to try and read his or her needs and wants.

"You must be hungry because you didn't have much lunch" (to another child) The third infant Rosie, pointed to the mat and Kea said "Oh so I know you want to have some more lunch because you are letting me know you want the mat out". Kea gave her a bowl with finger food in and she seemed satisfied to sit on the mat and eat the food. (Observation data from pen and paper) 
It is essential that caregivers are able to read the cues and gestures of pre-verbal infants as these are their primary form of communication. Kovach and Da Ros-Voseles (2008) sum up the importance succinctly:

For babies to thrive and be content, caregivers must accurately read their cues. When babies have the opportunity to express their needs and preferences, their well-being is recognised and maintained (p. 45).

\subsection{Language as invitation and explanation}

During the observations teachers were careful to explain what they were doing and why. As previously stated, this is a matter of common courtesy for an infant who is otherwise unaware of what might be happening next. Below are some examples of these verbal explanations by teachers.

When Tui comes back to the nursery Kea has been cuddling Max and Tui heats his bottle. She gently removes his jersey. This is a slow process and she talks to him about how she is moving his body "one arm through, now the other arm, and over your head." (Observation data transcribed from video)

She talks to him while she is preparing the bottle:

"Ben, I am just going to put it in the microwave to make it nice and warm and that will take just half a minute. Then you will have your bottle..."

Kea uses a really soft and gentle voice to communicate this information. (Observation data transcribed from video)

Teachers used language to initiate engagement with children or as invitation. Further examples of this sequence of events are listed below.

"Rosie, do you want some vegies and fruit?" Rosie moves towards Kea. Kea says you will need to come and sit on the mat. Rosie obliges by moving to the mat ready for kai. (Observation data from pen and paper)

Kea says to Max "shall I get your bottle ready? - I think I will heat up the water" Max follows her direction with his head and slightly shuffles his body from his position on his tummy so he is facing Kea. Max gives a little grizzle and Kea asks if he would like a cuddle. He sits on Kea's knee and enjoys shaking one of the shakers while they wait for the water to warm up. (Observation data transcribed from video)

"Ben, shall we go and have a sleep?" Ben tilts towards Tui and raises his arms for her to pick him up. Tui picks Ben up and takes him into the sleep room. She spins all the sleep room stars and he watches the stars as she lays him down to put his sleeping bag 
on him. As she does so she asks him when she would like him to bend his arm to fit it in the sleeping sack. She explains about the buttons, zips, "socks off too?" "We're ready. Ready for bed... shall we put some music on?" Tui turns the stereo on and spins the stars again. She asks him if he is ready for bed and he nods his assent and then lays him down in his cot. (Observation data transcribed from video)

"Can I get you a bottle Charlotte?" Charlotte shuffles with Kea over to the fridge. "Yep, a bottle" Kea decides this is Charlottes indication that she is ready for a bottle. (Observation data from pen and paper)

These interactions are important to illustrate the idea that children are the initiators of activity concerning their own well-being. The teacher may be the one who asks or initiates the interaction but it is through the cues and gestures of the child that their assent is gauged. Only when the child indicates his or her assent, will the activity take place. Teachers used language to initiate activity with the child and they also used language in the examples below to explain for a child what they might be feeling or what they might need:

Rosie gestures and cries to Kea who says "shall I get your milk?" Rosie cries harder and moves towards Charlotte who is sitting up and holding her own bottle to drink. Kea says "yes your milk is just here" "I know you are feeling hungry and that seeing Charlotte has her milk is making you a little bit sad and frustrated." while she prepares a cup of milk. (Observation data transcribed from video)

"Oh are you tired?" Charlotte is rubbing her eyes - she shuffles closer to Tui and she says "maybe you would like a bottle first? A bottle and then bed?" (Observation data from pen and paper)

Tui to Max: "I can see you are getting a little bit frustrated there... You've moved yourself into the corner and maybe you're feeling a little bit lonely and squashed in there. Can I help you move back towards the toys here and the other children?" (Observation data from pen and paper)

ERO (2008) commented on the high quality of interactions used when working with the infants and toddlers. Their examples included:

- Using a calm, respectful and gentle manner;

- Interpreting non-verbal communication effectively;

- Promoting oral language development through modelling vocabulary, including names for people places and things;

- Asking well-placed, open-ended questions to extend children's thinking and problem solving and allowing children time to respond;

- Promoting positive approaches to managing behaviour; and

- Encouraging independence and self-help skills (p. 5). 
The findings from my research indicate that teachers were able to use language to initiate interactions, and also to explain actions and emotions. This is an essential skill for teachers working with infants as the infants are unable to communicate verbally through language and rely on the interpretation of sensitive caregivers to label their emotions and verbalise their desires.

\subsection{Close proximity of caregivers}

Refuelling (Petrie \& Owen, 2005) is a common term used in connection with attachment and it refers to the repeated returns that a child makes to an attachment figure for emotional reassurance and comfort while they are exploring their environment. Below are examples of this phenomenon observed in the case study setting.

Charlotte moves closer to Kea and launches herself forward from her hips quite forcefully towards Kea who says "cuddle time?" Charlotte stays for about a minute and cuddles into Kea's body, then tips away and shuffles towards the mirrors. (Observation data from pen and paper)

Charlotte is crying when Kea returns from her break. Kea says "that was a big sleep bubba" as she picks Charlotte up for a cuddle. Charlotte is instantly soothed and Kea talks to her about going to have a nappy change. She comes back from her change and sits with Kea to read a book. (Observation data from pen and paper)

These examples suggest that close proximity of their primary caregiver is enough to soothe a distressed infant. Sometimes this is referred to in the literature as providing a secure base (Petrie \& Owen, 2005, p. 144). Providing a secure base is similar to the idea of refuelling in that refuelling is initiated by the child as they touch base with the caregiver like a touch stone giving them the courage to continue independently exploring. Providing a secure base refers to the role of the caregiver in offering closeness and reassurance to the infant while they independently explore. Teachers are comfortable to be nearby but are also comfortable not 
intervening and thereby allowing children to solve their own problems as much as possible.

In the following example Kea demonstrates the ability to observe and not rush in to 'save' the child.

Kea to Rosie "wow - (a little anxious) did you put the whole thing in your mouth?" She watches as Rosie regurgitates the food that was too much to swallow. Kea is confident Rosie can solve her own problem and remains calm and reassuring as well as alert instead of trying to help Kea regurgitate the food in any way. (Observation data from pen and paper)

When Max struggles to swallow, or slightly chokes on the banana, Tui checks his face and strokes his face. She says was that a bit much? And Max regurgitates and swallows the mouthful properly. Tui just watches, alert but reassuring and continues to feed him when he is ready. (Observation from pen and paper)

\subsection{Unhurried time}

Kovach and Da Ros-Voseles (2008) suggest babies need quality time which is time when:

[The adult is] emotionally available during caregiving times... [And the quality time is] based on the emotional richness of an experience, not the length of time (p. 85).

The following example provides a rich illustration of the unhurried process teachers and children work through together. Teachers are often just waiting for a response avoiding rushing the child into moving faster than they desire.

Tui asks Liv if she would like her nappy changed and I video the process. The change table is surrounded on three sides by dowel incase the children prefer to be changed standing up. Liv is happy to lie down and before she does she selects her nappy out of her locker and Tui gives Liv some cream to hold onto. Tui explains every part of the process to Liv as she is changing her. Telling Liv when, how and why she is going to move her body. At one point she asks Liv if she can please move her leg down and Liv immediately obliges. Tui moves slowly and wipes Liv's bottom with two warm cloths telling her when she is going to use them and explaining once more just so we get all the poos off your bottom. When Tui asks "can I please have the cream now?" she holds out her hand and Liv places the cream into her hand. Tui moves slowly and explains everything as she is doing it. Before long she has put a clean nappy on and re-fastened her body suit and she says "shall we wipe the table together?" Liv rolls over and stands herself up. She puts her hands out for Tui to lift her from the change table. Tui sprays the table and pulls two paper towels. She says "one for me and one for you" and they wipe 
the table together talking about making it nice and clean for the next body and nice and dry for the next body. They each put their paper towels into the rubbish bin (Tui has to bend down with Liv in her arms so she can reach the bin herself to dispose of her paper towel). (Observation data transcribed from video)

On several occasions I witnessed teachers allowing children's needs and rhythms to dictate their break times. Though the clock suggested a break time the teacher would only leave once the children were settled. The teacher needed to be satisfied it was an appropriate and convenient time for the children before they would take a break.

"Rosie has been a bit sad today - she has teeth coming through and I think it's making her a bit grumpy" Tui tells Huia when she comes in to relieve Tui for a break. Tui doesn't immediately go on her break. She remains with one child on her knee and continues to help the children with their kai time while it is busy for everyone. After some time when the environment has calmed, she asks the child she is sitting with if he would like to sit with Huia. He leans forward towards Huia to show his approval and Huia takes him onto her lap. Tui has a quick tidy up of the nursery floor space before she goes on her break. (Observation data transcribed from video)

Dalli and colleagues (2009) found similar attitudes and actions to following the children's lead instead of the clock for break times:

"If you've started something with a child, you don't just stop it because it is lunchtime you let them finish and allow for that" (p. 42).

I had noticed the teachers move slowly in the environment making things seem less hurried and more peaceful in general so I asked Tui in her interview about this observation and the following was her answer:

The teachers do move slowly and fluidly. We try not to make any sudden movements so as not to startle the children. Fluid movements create the respectful and peaceful environment and we model that to the toddlers so they learn appropriate ways of moving and being around the babies (Tui: teacher interview).

This decision to move fluidly and slowly is an aspect of the respect teachers' show to infants in the case study centre. The comment above indicates the teachers' actions are purposeful by decision. Their slow and fluid movements imply their recognition of the space as one 
belonging to the infants and therefore demanding their respect as bigger and potentially more disruptive beings within that environment.

\subsection{Wait for a turn}

Because there are more infants than teachers in the environment it is essential that infants learn to wait for a turn. I observed that through teachers' explanations children were able to wait their turn in the knowledge that their needs would be attended to as soon as the caregiver was able. Below is an example of one such interaction:

Kea is feeding one child. Another child shuffles over and tries to physically get between Kea and the child she is feeding by pulling up on Kea and sliding her hand down Kea's front - she explains "I am just helping Duncan with his water - then I will get you some milk." The child sits back down and picks up a nearby silver ball. (Observation transcribed from video)

It seemed the child was satisfied by Kea's explanation that she would be next and was comfortable to wait for her turn. Teachers also help each other while children are waiting for their intimate caregiving times by soothing the child who is waiting.

"I know. I know you are getting tired. I can tell. It will be your turn next. OK?" Tui is saying this to Max while she is giving Charlotte her bottle. Kea begins to sing which calms Max while he waits for Tui to give Charlotte her bottle and put her to bed. (Observation data from pen and paper)

\subsection{Chapter summary}

I have discussed my findings regarding primary caregiving in relation to the themes emerging from the data and supported by the documentation. These themes included: primary caregiving is a team approach; children often re-visit their initial primary caregiver; teachers and children communicate with body language, cues and gestures; teachers use language as invitation and explanation; infants' are soothed by the close proximity of their caregivers; 
teachers deliberately slow their pace so they are engaging with the children in unhurried time; and infants are able to wait for a turn.

Primary caregiving is not exclusive, not a replacement for parents and, some might say, "paradoxically," involves a team approach. All members of the team have to be committed to developing and maintaining the primary caregiving system and it involves a deep level of communication, understanding and teamwork between teachers in the environment.

Infants' attachment needs are understood and supported by the close proximity of caregivers in the environment. Infants' periodically re-visit their caregiver for emotional reassurance and comfort in between periods of independent exploration. This re-visiting of the initial primary caregiver was apparent in the case study centre after children had moved on to an older group and a new primary caregiver. Even after children had gone to school they would re-visit their initial caregiver on return to the centre with a younger sibling.

It is essential that teachers interpret and act on the cues and gestures of infants' as this nonverbal communication is their main form of communication. Observing, understanding and responding to these cues and gestures demonstrates to infants' that they are valued, important, and capable of making decisions involving their care and education. The use of language for teachers interpreting these cues and gestures is an important aspect of primary caregiving in the case study centre. Teachers used language to explain their actions to infants, to invite interaction with infants and to label emotions or explain how they might interpret an infant's feelings. 
Perhaps because of this constant use of language as explanation, infants were able to wait for their turn when circumstances were communicated to the child. Teachers would take time to communicate carefully with each infant and their use of unhurried time created slow and peaceful interactions between infants and teachers engaged in caregiving routines such as feeding, nappy changing and preparing for rest times. Break times were not rigidly observed by the clock but rather by the rhythms and needs of the children. Teachers in the environment moved slowly and fluidly so as to reduce their impact on what they considered to be an environment specifically set up for the needs, pace and nature of infants' development. 


\section{Chapter 5}

\section{FREEDOM OF MOVEMENT}

\subsection{Introduction}

In this chapter I will discuss my findings in relation to freedom of movement. I outline the themes which emerged through analysis of observational data, parent and teacher interviews and supporting documentation. These themes included: Teachers would support children and intervene only when necessary; children whose parents followed the free movement principles at home showed a greater range of movement in the centre; teachers would override the principles of free movement when they felt it was respectful to the child to do so; teachers engaged in wants nothing time; and the teachers have adapted rather than adopted the free movement philosophy. Each of these ideas is explored in this chapter.

\subsection{Towards a definition}

The term free movement needs definition. The concise Oxford Dictionary defines 'free' as 'not under the control or not in the power of another,' 'unrestrained,' 'not or no longer confined.' However, infants especially are often confined and restrained. Free movement means allowing children time and space to move and develop at a natural pace and can be summed up with Magda Gerber's caveat, "Never put a baby into a position she cannot get into or out of all by herself." (cited in Hammond, 2009, p. 81). The Pikler initiated practice of free movement means only putting children in positions they can get into or out of by themselves, and making sure their bodies are completely supported at all times. Pikler's seminal research conducted over many years at the National Methodological Institute for Infant Care and Education in Budapest, Hungary, shows that typically developing infants do 
not need to be taught how to crawl, sit, stand, or walk (Pikler, 1971). Pikler, and those who have adopted her philosophy, believe that infants must experience all movement for themselves, in their own space and in their own time. Propping an infant to sit, for example, is not allowing him free movement, nor is restricting the child's movement by placing him in a highchair, jolly jumper, walker trainer or similar movement restricting device. The adults' role in all this is simply to observe and not to interfere (Hammond, 2009; Sensory Awareness Foundation, 1994; Gerber, 1998, 2002).

\subsection{Teacher and parent definitions and views}

All teachers involved in my research reported a high level of support for free movement in their interviews.

I think freedom of movement means allowing infants and toddlers' time and space to explore their body without intimidation or expectations placed upon them. Freedom of movement means exactly that, FREEDOM (this word was emphasised) to move and play out all the natural and innate biological need within us all (Tui: teacher interview).

It is essential that we allow children the time and space to learn to move in their own time and at their own pace (Huia: teacher interview).

When mums start at our centre and I tell them about free movement they sometimes feel bad that they haven't been doing this at home. So I reassure them that neither did I do this with my children and it is not wrong but that now we know what is best for the child - best for their backs, balance, they fall over less... we must do what we know is best practice for the children. I am definitely going to do it with my grand-children. It does make sense for the respect of the children (Kea: teacher interview).

In each interview I asked teachers what they considered to be the environmental factors essential for promoting free movement for infants. The following were their opinions of the necessary environmental factors:

The physical and aesthetic environment is very important for the promotion of free movement. Having equipment that is challenging and developmentally appropriate is vital for children's movement and confidence to grow. A clear, uncluttered floor space is needed for infants 
[who are] learning to be continuously aware of their surroundings to roll and crawl. Steps, ramps, handrails, and the dynamics of the environment encourage and support infants and toddlers to explore and discover the world around them from different perspectives or 'developmental stages'. The environment allows children to understand how and what their bodies can do, or can't. Equipment and resources within the environment should also be well thought out. We minimise mobiles that hang above babies, restricting their motivation to move (Tui: teacher interview).

Children need space to move - not too many things out at once.

No highchairs, jolly jumpers etc.

A safe, child-friendly space and comfortable yet challenging, interesting, open ended resources to explore.

Peaceful, non-hurried time to practice and support their own development.

Encouragement from teachers in the environment (Huia: teacher interview).

Space is important and less toys on the floor means more space.

It should be a peaceful place.

Enough room for lying babies to not be disturbed by walkers and crawlers.

Teachers move quietly and slowly to relax the space even further.

There are no containers of any kind like jolly jumpers, swings, bouncers, highchair, tripillows for propping children to sit etc.

Also we have only a few mobiles so there isn't over stimulation visually in the environment on the ceiling and the walls (Kea: teacher interview).

To summarise, teachers believed the environmental factors necessary for the promotion of free movement were: the absence of any movement restricting devices such as high-chairs, swings and jolly jumpers; clear and uncluttered floor space; a peaceful, non-hurried and supportive environment; challenging and open ended equipment, furnishings and resources to explore; and the deliberate restriction of visually over-stimulating aesthetics and resources such as mobiles.

In an opinion piece, Kibble (2009) agrees with the point made by each teacher regarding visual over-stimulation stating:

For some reason we have led ourselves to believe children, particularly infants, need colourful stuff positioned and dangled everywhere to keep them actively stimulated. Stimulating? Yes. Satisfying? Questionable. Information overload? Most definitely! Where is the space for resting and re-gathering their thoughts? (p. 22) 
Gonzalez-Mena and Widmeyer Eyer (2007) think the same way. They suggest that when babies are not distracted by hanging objects and toys they can concentrate for long periods on the movements of their hands and fingers. They call this hand regard and it is important as they consider the hands to be the infant's first toy and a connection to understanding the way his or her body works.

In the focus group interview, parents were asked about their understanding of the term freedom of movement:

I think it's about just letting the children learn for themselves and letting them make mistakes and learn from them (Jenny: parent focus group interview).

And everything in their own time (Janine: parent focus group interview).

Not forcing them to do anything they're not ready for developmentally (Vicky: parent focus group interview).

Not restraining or restricting them because it's convenient for you (Janine: parent focus group interview).

They clearly had a good understanding of the term but differed in their approach to applying this consistently at home:

Like this morning when I left and my partner was ironing and watching football. I had to leave and thought mmm baby, iron, football, man multi tasking.... High chair! (Vicky: parent focus group interview)

I followed them [the principles of free movement] to the letter with my first child - and then just practically having babies fifteen months apart I had to bend the rules with Liv. Each baby is different and Liv particularly just screamed 24 / 7 if I lay her on her back. So in the end I had to prop her up because she wasn't happy lying. She was very happy sitting up so I just got over it (Janine: parent focus group interview).

We still do the high chair even though he doesn't use it here. I find that he will eat in the high chair a bit more than when we do the dining outside or at the table style (Alisa: parent focus group interview). 
These comments from parents highlight the essential difference between where the theory of free movement originated (an orphanage in Budapest) to where it is being adapted (in the case study centre). Infants attending early childhood care and education services are going home each day to a different environment. Parents generally seem less likely to adopt a strict approach to the philosophy and practices of free movement and this, in turn, has, or is likely to have, an effect on each child's desires to be on their back as opposed to propped to sit. For example a child propped to sit at home may find it difficult to be lying on his or her back at the centre. A child constantly cuddled and held will find it difficult to entertain his or herself on the floor (Hammond, 2009; Gerber, 1998, 2002).

\subsection{Teachers support and intervene only when necessary}

On several occasions I observed teachers moving toys a little closer to alleviate an infant's frustration. The following excerpt transcribed from video recording provides an example of this:

Soon Max begins to cry. "You seem a bit frustrated; shall I put some more toys closer to you?" Tui moves some magnetic toys closer and Max stretches but cannot reach. Tui moves them closer and Max reaches out and grasps the magnets and places the ring in between them (observation data transcribed from video recording).

Teachers seem to interpret the child's body language or cries to mean they are bored or

frustrated. Rather than picking the child up they are attempting to enable the child to solve his or her own frustrations through movement and action.

Elise has just woken and is delivered by one of the toddler teachers to Kea's waiting arms. She is humming to a child who is lying on his back in a bed and going off to sleep. Kea keeps humming, Elise is happy to look around. Kea takes her out of her sleeping bag. She places her very gently and slowly onto her back on the floor. Elise raises her feet up and pulls off one of her socks. Kea places objects close by but not quite within reach unless the child moved in order to grasp one of the objects. Elise rolls onto her side and grasps a wooden ring and mouths it. She rolls from one side to the other. She 
releases one object and picks up another (observation data transcribed from video).

Instead of holding the child or cuddling her on her knee in the example above, Kea laid the child gently on her back so she could be free to move and explore. This is an important aspect of the philosophy being practiced at the case-study centre. Teachers consciously encourage independent exploration for infants and are available should the infant indicate they need physical affection or closeness. It is important to differentiate that this physical affection and closeness is not initiated by the teacher and they will not cuddle a child who they think is comfortable to otherwise be exploring independently.

\subsection{Following free movement principles at home strengthens}

\section{movement in the centre}

The interview process highlighted a difference in practice between home and centre. While all parents and teachers shared an understanding of the term free movement, teachers at the centre would follow the guidelines more strictly than parents would at home. This practice at home would also differ greatly between families and so I was able to observe what impact that might have on the infants' at the centre. The following is an observation of a child who is exposed to the principles of free movement consistently between home and centre.

When I arrive Tui is in the nursery with four babies. She is feeding one and the other three are on the floor. One baby of 6 months is on his back and practicing arching his back up resting all his weight on his head and heels and chattering while he is playing with a large ring. He is reaching, rolling, stretching and grasping. He rolls onto his stomach, keeps talking and studies the ring in his hands more closely. (Observation data from pen and paper)

I know from discussion with teachers that this child has had free movement principles practiced at home and is clearly comfortable with his own body and movement. His movements all morning have been displaying strength and flexibility. 
Liv's mum came in to pick her up and had a long chat with the teachers and encouraged Liv to show the teachers how she is taking some steps. She walks into her Mum's full embrace and is very happy with herself with a big grin and long cuddle with her Mum. Mum and Tui enjoy swapping stories about Liv's motor development. Mum takes time to talk with Liv in the same way that the teachers do - inviting her with her hands and talking to her about what is happening. Offering her choices about whether she comes with her to get her bag from the locker. (Observation data from pen and paper)

Ben is sitting up and Tui says "He doesn't actually sit up by himself but he gets sat up at home and he will often become frustrated with lying down so we sit him up." (Observation transcribed from pen and paper)

Since I had observed previously that Ben became frustrated or disengages sometimes when he is on his back I was not surprised by these comments and actions of the teachers. The teachers (Tui and Kea) are careful to tell me that they think this is more respectful of Ben's wants. It is of interest to note that while the action of sitting a child up is not in accordance with the philosophy of free movement, if infants' have been sat up at home they may become frustrated. Therefore respect for the child came through as the number one principle above all else.

From this incident I wondered if Ben prefers sitting up to lying down on his back how can the teachers be sure that other children would not also prefer that? When I asked the teachers this they pointed out that he only prefers this as it has been his experience at home. I also wondered if an infant is propped to sit, would he prefer this position? If he is never propped to sit, how could we be sure of his preference? Furthermore, if there is a pattern of children preferring to be sat up once they have experienced this, and there is (Hannaford, 2009; Gerber, 2002), then how do we know we are acting in the child's best interests by always placing them on their backs? Pikler and Gerber would suggest we are acting in the infant's best interests by always laying him on his back to ensure he experiences typical sequential physical motor development (rolling, then sitting, then crawling, then walking). According to Hannaford (2005), children who are propped to sit might possibly skip the important stage of 
crawling and therefore miss the cross-lateral movement that is so important in overall brain development (Hannaford, 2005). Gerber (1989) says sitting a baby up before he can get in or out of the position on his own teaches a baby to be helpless. I am inclined to agree with Magda Gerber when she suggests "No one will ever ask on a job interview, "At what age did you learn to walk?"'(Hannaford, 2009, p. 88). Similarly, no one will ever ask on a job interview, "Were you propped to sit when you were an infant?"

No matter how devoted a teacher is to the principles and practices of free movement, there is no escaping the fact that infants' may become frustrated while experiencing free movement. It is the adult who has to decide how strictly they will follow the principles and practices of free movement and whether they might need to bend the rules out of respect for the wishes of the infant.

Teachers discuss the physical development of the infants and discuss how sometimes Max seems to be frustrated on his tummy. "He can roll onto his tummy but seems to need help sometimes to roll back onto his back where he is sometimes more comfortable." (Observation data from pen and paper)

One teacher commented in her interview that often parents are not practicing free movement at home but she felt strongly that they should:

I believe that we need to educate more new parents about encouraging their children to spend more time 'on the floor' on their backs exploring their hands, feet, arms and legs (they don't need any other things to begin with like toys, mobiles, exercise gyms to stimulate them). Getting down there with their babies if they are a bit unhappy and talking to them will encourage more 'free movement' instead of propping them up or using other restrictive devices to "keep them happy" (Huia: teacher interview).

This opinion is aligned with that of Magda Gerber (1998) who does not believe children get 'bored' when they are in an appropriate environment. Rather, she thinks this is our own projection. Gerber suggests if adults constantly stimulate and entertain infants that they may develop a high tolerance or need for external stimulation. She thinks they should instead be exploring, from the beginning, their own hands and feet. Again, I think this may illustrate the 
fundamental difference between the case study centre and the orphanage where the theory originated. In an orphanage situation children will be receiving less external stimulation than they will be if they are receiving shared care between the case study centre and a family home.

Sharing the care between home and centre is clearly different to the circumstances where the free movement ideas originated and is a much more common circumstance in New Zealand and many other parts of the world. Falkner (2009) wrote an article based on her experience of bringing her child up with free movement and admitted by doing this she was "going to do things a bit differently from the majority of parents in New Zealand" (p. 13). This quote from Falkner illustrates the point that practicing freedom of movement is outside the norm of family culture in New Zealand.

Socio-cultural theory (Rogoff, 2003) suggests we learn what we live with and in New Zealand in general infants are immersed in a culture where to cherish and show love for an infant we acculturate them with cuddles, love and attention. While elements of the RIE philosophy and Pikler approach believe love and attention are important they are reserved for routine care times and one-to-one interactions which means they are balanced with the need for children to be exploring independently and learning to entertain themselves (which they need to in an orphanage). Cuddles, love and attention translates into our general culture as what Gerber might have referred to as interfering or smothering.

Analysis of data from my research was unable to confirm or negate the free movement principles and practices. This was a surprising finding and certainly lays a challenge for further research into free movement within an early childhood setting or family home. 
Instead of confirming the need for infants to progress unaided through the natural motor development stages, my research questioned and explored the idea of adaptation versus adoption of a philosophy. The teachers at the case study centre had clearly adapted the principles of free movement as they would "over-ride" the rules when they felt it was the most respectful action for the child.

\subsection{Teachers "over-ride" the rules respectfully}

Respect for children is paramount in the case study centre. According to the focus group interview and observation data, free movement practices differed between individual families. There were families who had only recently heard of the philosophy and were taking on board some of its values and ideas. Other families felt unable, for whatever reason, to continue with the practices at home. Some families were strictly following the guideline of never putting their child into any position they cannot get into or out of on their own. For each teacher, respect for the individual child and their differing home circumstances defined the terms of practicing free movement at the case study centre as highlighted in the following observations.

Teachers discuss the physical development of the infants and discuss how sometimes Max seems to be frustrated on his tummy. "He can roll onto his tummy but seems to need help sometimes to roll back onto his back where he is sometimes more comfortable." (Observation data from pen and paper)

Ben is sitting up Tui tells me "He doesn't actually sit up by himself but he gets sat up at home and he will often become frustrated with lying down so we sit him up." (Observation data from pen and paper)

Even though the teachers report a very high level of support for the principles and practices of free movement they consider the child's wants as paramount and they over-rode the rules regarding free movement if a child became too upset or frustrated. 
My mentor and teacher, Norah Fryer, a practitioner with some forty years of experience, including time learning and studying with Magda Gerber, recently said:

Over the past forty years, having been involved in the study and practice of early childhood education and care I have observed many 'methods' whose passionate followers truly believe it is 'the way.' What I now understand is that it is not the 'method' but the daily respectful interactions that teachers demonstrate through their knowledge, skill and attitude that becomes both the foundation and the framework for their pedagogical values... [Teachers display] intentional nurturing and teaching and it is the 'person' within the teacher and the 'respect' within the method which can enhance or diminish the quality (N. Fryer, personal communication, July, 2010).

Fryer's words highlighted for me the idea of 'respect' being an over-all driver of the philosophy at the case study centre. The teachers are passionate advocates of the RIE philosophy and Pikler approach but in translating these methods to their centre environment they have adapted the principles and practices out of respect for the families and infants for whom they care.

\subsection{Teachers engage in "wants nothing" time}

Wants nothing time was identified in the literature (Gerber, 1984) as time when the teacher "wants nothing" of the child. This means the teacher is not engaging in a care routine time, neither is he or she initiating or engaging in any kind of activity with the child. The following were examples of "wants nothing" time from the observations made in my study:

Kea carries Max in and lays him gently on his back in the nursery. She gives him a soft toy which he discards and he is content to babble and play with his own hands and feet while she puts away his bottles. When Kea returns she sits near Max but doesn't speak or interfere. She is just watching Max. (Observation data from pen and paper)

Liv and Max are in the nursery and Charlotte is asleep. Tui sits between the two children who are awake and Kea goes to have a break. Max is happy on his tummy kicking his feet and waving his arms and babbling - he is moving himself ever so slightly backwards. Liv is drawing on a piece of paper and eating a piece of bread at the same time. This play is uninterrupted for some time (more than five minutes) and the environment is very quiet. Tui is simply observing the children. (Observation data from pen and paper) 
Gerber describes this situation when the caregiver is simply watching but not engaging as “wants nothing" time (1984). More recently, Da Ros and Wong (1996) call it "providing a secure base" (p. 216). They consider that the art of being fully present with young children provides an opportunity to actively observe the children and reflect on their progress, language, and interests without needing to intervene in the infant's current explorations. Gonzalez-Mena and Widmeyer Eyer (2007) suggest that being fully available and responsive but not intervening is a skill most adults need to learn. From my observation, however, I am going to label this phenomena peaceful observation. It is peaceful as it is quiet and no-one is making any demands of another person. This is a time when the teacher simply observes the child.

It can be a challenge for teachers who are used to being busy all the time to simply sit and observe children peacefully. Gerber (2002) states:

In our society, we're trained to do, do, do. And if you don't, you pretend to do, do, do. You must act as if you are very busy, because being busy is virtuous. Not doing anything is considered laziness.... Nobody talks about being observant. The more we do, the busier we are, the less we really pay attention (Gerber, 2002, p. 63).

The practice of paying attention demonstrates an additional way of showing that we really care. We set up the environment to ensure we are engaging in sensitive observations. This is when we can just sit and be with a child taking in more of their learning and development and their uniqueness. We can stop long enough to clear our mind of what we think they might need or want and see what the child is communicating about what he or she actually needs or wants. This peaceful observation time may be something that takes some getting used to, particularly if teachers have been working in large, busy settings where the perception is that activity equals good work and, as Gerber challenged, inactivity equals laziness. 
Leon-Weil and Hewitt (2008) are two early childhood educators challenging themselves to use trust as a teaching skill. They considered the importance of simply observing the children in their environment and decided:

We often make snap judgements about what a child is thinking or feeling, and they may be completely inaccurate. If we sit back and continue to observe, we get the opportunity to watch as events unfold, and children are able to follow through with their own ideas (p. 26).

As adults, maybe we have become culturally conditioned, as Gerber (2002) suggests, believing that being busy means we are being productive and virtuous. If we are not constantly talking at infants does it mean we are perceived as indifferent? In agreement, Brownlee (2009) asserts: "We are not indifferent when we just notice, it is just that we are respectful enough not to offer support until the child needs it" (p.4). When teachers observe peacefully they are being productive, they are not indifferent, on the contrary, they are highly attuned to the individual capabilities, needs and desires of the child they are observing.

The perception that just being with a child and observing him or her sensitively can translate to the uninformed observer as missing valuable opportunities to extend children's literacy. This was a recommendation made by a recent education review officer who, upon visiting and observing an infant environment, could not understand that just 'being' with the children, watching and listening was, in-fact, a valuable part of the care and attention they need in order to learn, grow and develop at their own pace, peacefully. Because the reviewer's mandate from Government was to look specifically at language and literacy, she was tuned in to all the opportunities to extend each child's language and vocabulary by introducing them to as many new words and sounds as possible. For infants, we need to critique ideas that apply to formal school education and think in terms of care. In early childhood education, care is education and education is care. When a child is cared for he or she learns how to care. When a child is cared for by a sensitive, observant adult then that child learns that he or 
she is valued and unique. The adult fosters the development of self-esteem. Positive selfesteem is an important basis for all manner of literacy and other important outcomes of education. First, the child must know they are an important person who is valued enough to be allowed the time and space to explore and learn.

\subsection{Adaptation versus adoption of a philosophy}

A surprising finding was the way teachers did not practice the principles of free movement strictly. Parents did not either, even when they knew the principles. I believe this is a result of transferring a philosophy from an orphanage, where nurses are trained in the principles and children are present twenty-four hours a day, seven days a week, to a child-care centre setting, where teachers believe strongly in the principles but children are essentially in a shared care situation and are returning to family homes each evening and weekend. Children who have parents in this culture, by the very nature of being part of a family, will generally be picked up and cuddled, they might be propped up, pulled up, and bounced around and this may not always fit with the principles and practices of free movement.

These were a couple of comments from parents when asked about the limitations of practising freedom of movement at home.

I followed them [the principles of free movement] to the letter with my first child - and then just practically having babies fifteen months apart I had to bend the rules with Liv. Each baby is different and Liv particularly just screamed 24 / 7 if I lay her on her back. So in the end I had to prop her up because she wasn't happy lying. She was very happy sitting up so I just got over it (Janine: parent focus group interview).

Probably just the timing thing for trying to replicate it at home. There are constraints to these philosophies when practiced at home - particularly the always going slowly thing. Because at home there are always other things that need doing like we've got to get to the supermarket or pick up another child from school or get out the door so we can't always take as much time 
as the child might like - but that's kind of reality as well. (Alisa: parent focus group interview).

Three out of four of the parents present at the focus group interview reported their use of high chairs at home. This practice of restraining a child for the purpose of adult convenience was discussed as something that is "practical in a busy household." Some found managing mealtimes without a high chair too difficult or had already started using one before they were exposed to the centre's philosophy. We also learned that some of the children were propped to sit at home. Not many parents described their reasons; but for at least one the rationale was that the child became unsettled lying on her back. The parent, who had an older child she had raised strictly following the principles of free movement, was not practicing these as strictly with her second child. Her rationale for propping her younger daughter to sit was that she felt her child was becoming anxious (perhaps not feeling safe?) on her back as there was a fifteen month old toddler (the older sibling) present in the environment.

It is important to note that only four parents attended the focus group interview so it is therefore impossible to generalise my findings to the entire parent population of the centre or any wider. I can, however, suggest that further enquiry into the relevance and possible benefits of practising free movement in early childhood settings in New Zealand would be beneficial. It is important to evaluate and monitor innovations when they have been transplanted into another context as these may not fit well within local context and/or may not have the same outcomes as at the original site (Slaveron, Arney \& Scott, 2006; Saracho \& Spodek, 2003). 


\subsection{Chapter summary}

I have discussed my findings regarding freedom of movement in relation to the themes emerging from the data and supported by the documentation. These themes included: Teachers provide support and intervene only when necessary; Following freedom of movement principles and practices at home strengthens movement competence in the centre; teachers 'over-ride' the tenets of the philosophy when it is called for out of respect for the child's wishes; teachers engage in 'wants nothing' time which I have labelled peaceful observation.

I also found that the teachers at the case study centre have adapted rather than adopted the RIE philosophy and Pikler approach. The principles and practices of free movement have been adapted to suit children who are attending the centre part of the time and are part of a family culture in a home setting part of the time. This is different to the circumstances where the philosophy originated as children were orphans and spent their time only in one environment. 


\section{Chapter 6}

\section{RESPECT FOR CHILDREN'S CONFIDENCE AND COMPETENCE}

\subsection{Introduction}

In this chapter I will examine my findings in relation to respect for children's confidence and competence. I will outline the themes which emerged through analysis of observational data, parent and teacher interviews and supporting documentation. These themes included: teachers invite children to engage; teachers and children use body language, cues and gestures to communicate their respect for each other; time in the case study centre is unhurried when teachers are interacting with children; children are offered choices; teachers interpret a child's intentions by paying close attention; teachers support children rather than intervene; and a team approach is an important element. Each of these themes are discussed in detail in this chapter.

\subsection{Towards a definition}

Respect is "a fundamental human value that forms the basis of character and personality" (Miller \& Pedro, 2006, p. 293). Respect is deeply embedded in the philosophy and practices at the centre. Teachers engage in ways that would suggest they accept each person as an individual with rights and freedoms. They are prepared to receive each person without them being who the teacher might want them to be. This is evident when teachers interact with children. It is also evident when they interact with each other and with families who come into the environment. 


\subsection{Teachers invite children to engage}

Interactions with children at the case study centre would most often begin with some form of invitation by the teacher. Usually this would take the form of a verbal invitation accompanied by outstretched open hands with palms facing up. After this initial verbal and physical invitation, the caregiver would wait for a response. The response time from the child varied. The one constant in this sequence of events was that nothing happened until the child agreed:

Interaction between Kea and Charlotte: "Would you like a nappy change?" she says the words and offers opened arms and hands.

When Charlotte doesn't react Kea says "I'll wait until you are ready."

"You let me know when you are ready" Charlotte thought for about 30 seconds and then bum shuffled waving her hands over to Kea who scooped her into her waiting open hands and arms and took her for a nappy change. (Observation data transcribed from video)

In this exchange the child is offered the choice and therefore holds the power over when her nappy is changed. This was very typical of the interactions at the centre. A teacher would initiate with a verbal invitation, always accompanied by open hands held out as a gesture of invitation. Then the teacher would wait for the child's assent which would usually be a physical sign such as tipping forwards into the open arms or putting their hands up to be picked up or moving closer to be picked up.

When we discussed this at the parent focus group we found there were clear differences between interactions at the centre and at home:

The changing part is really difficult for us at home. Would you like to be changed? The answer is always NO (said with emphasis). (Vicky: parent focus group interview).

Two parents agreed on this point (Vicky and Jenny).

(INTERVIEWER) In my observations in the nursery so far I have noticed that both the teachers always say. "Would you like a nappy change?" Then they hold out their arms and wait for the child to decide. If they lean toward 
or move toward the teacher then the teacher interprets this cue as meaning they would like to have their nappy changed. When the child doesn't respond to an invitation or responds by turning away the teachers will respect that and ask again later. But I can see in my observations the responses that indicate yes, please, a nappy change now will be good thanks... (Interviewer comments at parent focus group interview)

(INTERVIEWER) I relay my understanding to the parents and manager present at the focus group interview of how the nappy changing happens in the centre environment in a very slow, peaceful and reciprocal way... so when these babies are on the table, the teachers will ask them could you please put your arm down so I can help move your arm through the hole... (Interviewer comments: parent focus group interview)

Well it doesn't happen like that at home! She screams and hates having her nappy changed (Vicky: focus group interview).

Another parent agrees. I think it's because so often we are rushing at home and that's way different to what you just described (Janine: focus group interview).

Parents discuss the child's desire not to be lying down when they are being changed. We compare the centre environment where children can choose to pull up on the surrounds around the change table (general discussion: parent focus group interview).

Well that's probably why it ends up being such a bad experience for all of us at home is cause we still insist on him lying down cause it's the only way I can get the nappy on securely (Jenny: parent focus group interview).

It was apparent that intimate care times at home were more rushed than those happening with children in the centre. Being rushed can be unsettling and undermining to the self esteem of the infant (Kovach \& Da Ros-Voseles, 2008). It was also evident that children had less control over the situation, for example whether they had a choice about lying down or standing up to be changed. One of the wall displays at the case study centre says: "The care moment is the most important moment in a baby's life" - Dr. Emmi Pikler. Other displays on the walls say: "When the experience is a pleasant one they will be willing to participate again... and again... and again!" "Freedom to move, responsive reciprocal relationships, making their own choices, working together, partnership and cooperation during care." 
The ideas espoused in these wall displays are evident in the teachers' practices at the case study centre. Hammond (2009) suggests:

When an adult speaks quietly about what is happening and waits for a response, the child does not need to be on alert that a change could be coming at any moment unannounced (p. 17).

An invitation and explanation is a simple matter of respect. Imagine being asked, being heard, and holding the power in matters affecting your physical well-being. For most adults this is accepted as a basic human right. Now imagine someone physically lifting or interfering with you in anyway to which you have not consented. In the second instance, when you were not invited or consulted, the experience is one of powerlessness. You might feel more like an object rather than a human with individual thoughts, opinions, freedoms and rights.

\subsection{Unhurried time}

In order to give infants unhurried time, teachers have to make a commitment to slow down and be emotionally present (Kovach \& Da Ros-Voseles, 2008) with infants. The following is an example, transcribed from video, of how teachers were unhurried in their interactions with infants at the case study centre:

When Tui comes back to the nursery Kea has been cuddling Max and Tui heats his bottle. She gently removes his jersey. This is a slow process and she talks to him about how she is moving his body. Tui takes Max and the bottle through to the sleep room. Tui cuddles Max as she feeds him his bottle. Ben is not yet asleep and he calls out when Max makes some sounds prior to his bottle coming. Max stops to have a look at the moving stars and Tui waits patiently until he wants his bottle again. She tries again but Max moves his head indicating he has had enough... "OK shall we put you to bed then?" She puts Max into his bed and strokes his head. She hums along with the music that is playing and Max makes little snuffling sleepy noises while she hums. He plays with her hand which is not stroking his head. Ben lets out some sounds and Max makes a small complaint. Not enough for Tui to take him out of bed. Max yawns and Tui rubs his chest gently. Max experiments with sounds and Ben joins in a little bit. Now Tui is rubbing his chest gently with one hand and his head with the other. Max' eyes close and 
Tui stays with him a while longer continuing to rub his chest. When she is sure he's asleep she gently removes her hand from his chest and fluidly secures the side of his cot and removes herself from his cot. She sits listening to Ben for a while I think she is deciding whether she should allow him to see her as till this point though he has heard her he hasn't seen her. He holds his hands out to Tui to indicate that he needs her. She picks him up and suggests they go and change his nappy. (Observation data transcribed from video)

The observation above is evidence of the teacher's commitment to slowing down and providing valuable, uninterrupted, quality time and attention to the infant. When she does this she demonstrates her ability to empathise with the infant and understand from his perspective what the experience of going to sleep at the centre must feel like. A supporting piece of documentation demonstrating that this is a conscious decision on the part of the teacher is a wall display in the infant room. The display says the word TIME twice:

$$
\begin{aligned}
& \text { T- Tender } \\
& \text { I - Intimate } \\
& \text { M - Moments } \\
& \text { E - Every day } \\
& \text { T - Try } \\
& \text { I - Imagining } \\
& \text { M - Meaningful } \\
& \text { E - Experiences from a child's perspective. }
\end{aligned}
$$

One parent at the focus group interview described a workshop (run by the teachers at the case study centre) where she and her husband, along with other partners present, had to feed each other:
We were role playing and one was the child and the other the adult and we had to role play the scenario where they are rushing the child. Her partner was feeding her yoghurt and talking on his cell phone at the same time and wasn't allowing her the time to swallow. She said by the end of it she was covered in yoghurt and really angry but the exercise taught her a great lesson about following the child's lead for when they are ready and how long they might need to swallow etc. Also, she was annoyed about him talking on the cell phone instead of paying attention to her (Janine: parent focus group interview).

Another aspect of unhurried time is the conscious decision that teachers have made to move slowly and fluidly in the infant room. They move as though they do not want to disturb 
anything. On several occasions I observed teachers moving slowly and softly, with small, quiet, and fluid movements. When asked about this in the teacher interviews they would explain their intention is to reinforce the idea that this is a children's space and teachers do not want to do anything that will disturb that slow, peaceful space and pace.

This practice of taking adequate time deepens teachers' awareness and knowledge of each child, sensing by their behaviour, body language and expressions. In the case above, the cues suggested Max might be a bit tired. Talking to him about tiredness and suggesting a sleep allowed the child to be the decision maker in the process.

My research indicated that when teachers give their time they show value for the person with whom they are engaged. When we rush an interaction we run the risk of leaving the person with whom we are interacting feeling unsatisfied and undervalued by the experience. Each child will have his or her own rhythm and pace. Respectful practice involves stepping out of our own rhythm and pace and adjusting to that of the infant. For adults generally this is going to mean slowing down a great deal in order to observe and interpret needs, invite children to engage, wait for their response and then engage in the interaction at the child's pace.

\subsection{Choices are offered}

On several occasions I observed teachers offering children choices and one of the most common was to offer children a choice in the colour of the bib they wanted to wear for a mealtime. This was something that happened prior to every meal time and was part of a sequenced routine for children. Wearing a bib indicated that they would have their meal next. I noticed that the action of choosing a bib aided children's ability to wait for a turn. 
The bib choosing exercise was a cue to the child that once they have a bib it follows that they will be having their meal next. The following example is indicative of this regularly occurring choice that was offered:

Tui offers Max his choice of bib for lunch. There is red or purple. He chooses purple and he is fed slowly - each spoonful waiting for his open mouth to indicate his readiness. (Observation data from pen and paper)

At mealtimes there were always choices for food prepared by the cook so teachers could cater to children's individual tastes. Also choices about when children were hungry and wanted to eat were decided by the child. Teachers would offer food and if it was not accepted they would put it away to offer later.

Teachers at the case study centre felt that offering children choices was an essential element of their philosophy and practices. Below are examples of the centre manager's opinion on the subject of choices:

It is important to offer children choices. You know especially infants - they don't get a lot of choice about anything really. So offering them a choice in anything that involves them gives the power over to them. They can see and feel how powerful they are in decisions which directly affect their well - being (Huia: teacher interview).

Talking to them about what is going to happen next and giving them the opportunity to respond and be a willing participant. Giving children choices (particularly infants who are often overlooked in this area) they will soon get the idea that their opinion is valued (Huia: teacher interview).

In agreement, Leon-Weil and Hewitt (2008) found "when we involved children in the decisions that affected their lives, they reached a different level of critical thinking and expression" (p. 25).

A parent who has adopted the philosophy of the centre at home agreed about the importance of offering choices. Janine made the following observation at the parent focus group interview: 
It was in offering choices that I realized one shirt was actually uncomfortable to get over my son's head. When I offered the choice he wouldn't choose that one and that was why (Janine: parent focus group interview).

Offering choices and inviting children to engage are both important parts of the programme provided at the case study centre. In both of these aspects the teachers consider it essential that they wait for a response. Suskind (1985, cited in Petrie \& Owen, 2005, p. 144) calls this time between teacher invitation and child response tarry time. This is another important aspect of offering choices which links to unhurried time. When a choice is offered, teachers need to allow time for a response (and this may take longer than expected in adult time) and then react according to the wishes of the child. I agree with Brumbaugh (2008) who sums up why it is important to offer children choices succinctly:

Giving children choices shows them that educators care. When educators trust children to make choices concerning their daily events and activities, they not only create a sense of autonomy, but also an environment of respect (p. 175).

\subsection{Teachers interpret a child's intentions by paying close attention}

My findings indicate that through subtle signs and gestures and in the presence of sensitive, attuned observers, even the youngest child can express his or her opinion and therefore have his or her human rights upheld (United Nations Committee on the Rights of the Child, 2003).

In the below examples the room was set up to follow children's emerging interests:

Charlotte's profile book is out in-front of her and she opens it to the first page. She has a little play with the sound the plastic sheets make but then she loses interest and goes back to posting pegs into the plastic container that has been set up this morning by the teacher who is following her interest and competence in posting. (Observation data from pen and paper)

The music skips and Charlotte comments with sound and by pointing towards the CD player. A teacher picks up what she is asking and chats to her about how the $\mathrm{CD}$ player is unreliable and the $\mathrm{CD}$ is a bit scratched while she starts 
the music again. Charlotte shows her appreciation by having a little boogie. (Observation data from pen and paper)

It is through observation that teachers learn what the child wants, needs, likes, dislikes and also what they are capable of and what their emerging capabilities are. This peaceful observation enables teachers to go further than feeling empathy. They go beyond "what would I want if I were her?" to actually consider "what does she want?" An example was when Kea put away a child's pacifier because she had thought she did not need it:

The child didn't complain but looked anxious so Kea gave it back and said "Do you feel you need that?" Liv put it down beside her and continued to explore without it.

In the example above, Kea felt Liv had no need or use for the pacifier but by paying close attention to the emotions of the child who did not complain but simply looked anxious, was able to interpret the desires of the child. The ethics of care discourse (Goldstein, 1998; Noddings, 1984) would suggest such attentive, receptive engrossment led Kea to give Liv the pacifier against her own better judgment (motivational displacement) because the ethics of care involve respecting another person enough to understand what they might actually want as opposed to what you think they might want.

This same ideology explains why I observed teachers over-riding the rules of free movement on occasion at the case study centre. Even though teachers believed strongly in the idea of natural motor progression and un-aided motor development, they would pick up a child who became upset lying on his back or help him roll back onto his back if he was upset on his tummy. By paying close attention or engaging in attentive, receptive engrossment (Goldstein, 1998) the teacher displaces her own motivation (Noddings, 1984) and acts as the child wants as opposed to the teacher's own perception of what the child wants. 
This ability to really see from the perspective of another requires close attention on the part of the teacher. On one of the walls in the infant environment there is a large picture of a key and inside the key are the words "Just notice." I found that teachers in the environment were very good at noticing what was happening for each child. Brownlee (2009) suggests: "full attention is focused and it neither judges nor labels. It just notices. Every little thing... Full attention allows you to be in the present moment, exactly as all infants are, all of the time" (p. 4). Our adult lives are crowded with time schedules and plans. We are always thinking ahead or planning ahead but an infant demonstrates how to be fully present in each moment. Magda Gerber says it clearly:

Pay full attention. Whenever you care, do it absolutely with full attention. If you pay half attention all the time, that's never full attention. Babies are then always half hungry for attention. But if you pay full attention part of the time, then you go a long way, that's what I would recommend: to be fully with a child and then let him be (Gerber, 2002, cited in Yeah baby! 2009, p. 19).

\subsection{Teachers support rather than intervene}

The teachers at the case study centre all felt very strongly that support rather than intervention was a mark of respect for the child. They felt that adults generally try to do too much for children and this can have a damaging affect on the child's perception of themselves as confident and competent learners. The following were some of the comments from the teacher interviews:

Our infants are exposed to an environment that respects them for who they are, their wairua is nurtured, honoured and celebrated. Our programme encourages our babies to feel secure and safe to make independent choices in all areas of their learning and development. I believe this teaches them a positive and healthy self image and ultimately and optimistically a healthy world view! (Tui: teacher interview)

I think respecting children's confidence and competence provides them with the mana that comes with working through feelings and emotions. When infants are allowed time and support to work through feelings like 
frustration they learn to self-regulate, collect themselves and focus. They also learn to trust and feel emotionally secure if they need that extra hand from someone else. Knowing when to lend that hand is really important. Children are capable of so much more than people often give them credit for. (Tui: teacher interview)

Giving children the freedom, and encouraging them to become confident explorers. Being there to support, but not interfere as they figure things out, for example how to use their own bodies to get to where they want to go in their own time. (Huia: teacher interview)

Parents also valued the idea of support rather than intervention for the healthy development of self-esteem. When I asked what is it to respect children's competence the parents at the focus group had the following definitions:

It's not stepping in too early to allow them to learn and master things on their own. He's doing what he thinks he can do and I shouldn't be the one to decide what that is. It's respecting that he will figure out himself - and he might fall off and he might get hurt but it's allowing that as a learning thing (Alisa: parent focus group interview).

It's like not wrapping them in cotton wool (Janine: parent focus group interview).

Trying to let him work it out for himself. When they work it out themselves they get a huge sense of satisfaction out of it (Jenny: parent focus group interview).

In the comments above it was apparent that parents felt children learn from their mistakes and have a greater sense of mastery and autonomy when they are able to try things on their own.

One parent told a story about a playgroup:

At this play group I watched my son negotiate the steps without any help and get a bike which he then careened off and grazed his head. He was a bit sore so he cried for me to comfort him and I went to give him a cuddle. What I loved was that he calmed so quickly and was determined to get back on the bike and continue mastering it. There was another mother watching who wouldn't allow her child to come out because she'd just seen what had happened. I was sad for her and her child because she was being overly anxious and her child would be denied a great learning experience (Alisa: parent focus group interview).

Giving him space to do it (Jenny: parent focus group interview). 
In the morning we like to make muffins and loaf and things like that and my two children really like to help. I tell them that the knife is really sharp and you can tell they know what that means and I explain that the element is really hot and they learn and understand. Having them bake with me is obviously messier and more time consuming but they are learning so much and gain a sense of confidence and competence about being part of the creation. But it's not dangerous - it's just really dirty! (Janine: parent focus group interview).

Yes, I think you can do something for a child so much but there is nothing like the satisfaction and learning that is cemented when someone does something for themselves or accomplishes something by themselves (Vicky: parent focus group interview).

These were all important points the parents brought up. They talked about offering their child support. In the case of the child with the bike at the playgroup it was in the form of a cuddle when he fell off. In the case of the children who help with baking the support was in the form of telling them that the knife is sharp and the element is hot. The parents did not intervene, however, stopping them from riding the bike or baking the muffins, and thereby allowed the child the sense of achievement and competence that comes with accomplishing a task autonomously.

Brownlee (2009) talks about "a baby's sacred quest for competence" and discusses why trusting children and waiting and watching is far more beneficial to the child than rushing in to save or rescue them. When a child learns to master anything on their own there is a sense of power and competence that no amount of doing it for them or rushing to save them could possibly hope to emulate.

\subsection{A team approach is an important element}

Respect is evident between teachers and with parents as well as between teacher and child.

Teachers display respectful relationships with each other and have developed some sound 
strategies for ensuring they have a shared understanding of what it is to be respectful of each other. The team contract created by the current teaching team at the case study centre is a good example:

- We will maintain our support for one another, valuing each other's individuality, friendships and bring out the best in each other.

- We will always remember the importance of our parents and whanau community and respect and value their contribution, knowledge and beliefs.

- We will take pride in our environment and show our respect for the children's learning by tidying and resetting relevant learning opportunities for the children during the day.

- We will aim to keep our display boards up to date, beautiful and meaningful for our children, parents and families.

- Before talking with another teacher, we will first consider the situation and relevance, and be respectful of teachers and children involved in special moments.

- When returning to the room we will keep dialogue open and remember to ask teachers in the room "where are we at?" or "what can I do?" When leaving an area we will exchange any important information with teachers remaining in the room.

- We will all contribute to 'housekeeping' type jobs, putting equipment and resources back in the correct places, keeping the washing up to date and clearing the kitchen.

- We will show our respect for nature and animals by looking after the needs of our smallest residents, Pinny and Gig, and allowing the children to be a part of their care.

- We will recycle/reuse/reduce and think about ways in which we can be kind to the environment wherever we can. (case study centre team contract, December, 2009)

This idea of a team contract is something all the teachers developed together by brainstorming everything that they felt was important to each of them. Everything in the contract had to be agreed to by all the parties and this has given the teachers shared understanding of respectful behaviour, a common reference point when boundaries are 
pushed and most importantly, because it was worked out together, each of the team has some ownership of the ideas the contract contains.

The teachers at the case study centre have a vision about how their centre should feel and what experiences will be like for infants and toddlers who come to their centre. The most important part of realising this vision is that every one of the teaching team shares the vision. Part of the philosophy with children is that teachers trust them to be confident and competent learners but the first level of trust necessary within the environment is among the adults as demonstrated by the team contract.

One element of a respectful team approach was the way teachers would always ask their colleagues what was happening when they returned from breaks or just arrived for the day. For example, see page 64. This practice of asking "where are we at?" was a common interaction used when teachers returned from breaks to ensure they had the correct information before interacting. This is respectful of everyone else in the environment and shows the teachers commitment to respecting what is happening right now for each child and adult.

\subsection{Chapter summary}

I have discussed my findings regarding respect for children's confidence and competence in relation to the themes emerging from the data and supported by the documentation. These themes included: teachers invite children to engage and wait for their response; teachers are unhurried in their approach to time; children are offered choices; teachers interpret by paying close attention; teachers support rather than intervene; and respect was evident between team members and with parents as well as between teachers and children. 
When teachers invite children to engage and wait for their agreement prior to engaging, infants are afforded control over their situation. The differences between home and centre regarding children's assent prior to engagement highlighted that children are more willing participants in routine care times when they have been consulted, invited, and offered choices.

Teachers at the case study centre have made a commitment to slowing down and being emotionally present with each child. This provides the infant with valuable, uninterrupted, quality time and attention. It also provides the teacher with a deepened awareness and knowledge of each child. Another aspect of unhurried time included the way teachers would move slowly and fluidly within the environment so as not to disturb the peaceful, age appropriate space and pace. The final aspect of unhurried time observed was that teachers took their breaks according to the needs and rhythms of the children as opposed to by the clock

Teachers were available to the children but resisted any unnecessary intervention which they felt contributed to each child's view of him or herself as a confident and competent learner. Teachers would pay close attention to each child and offered their support when it was requested. They valued each child's sense of autonomy and accomplishment which would lead them to offer support in such ways that they weren't actually doing anything for a child which they thought the child was capable of achieving on his or her own.

The respectful approach between teachers and infants was replicated in other relationships throughout the environment. Teachers showed respect for each other through their interactions and teaching practices and respect was also evident between teachers and 
parents. Interactions at all levels were respectful and this culture of respect influenced the actions and reactions of people in the environment. 


\section{Chapter 7}

\section{CONCLUSION AND RECOMMENDATIONS}

\subsection{Introduction}

For this research there were two key questions:

1) What do practices that are inspired by the RIE philosophy and Pikler approach look like in an infant and toddler setting which uses

(a) primary care-giving;

(b) free movement;

(c) respect for infants' confidence and competence.

2) What are the understandings of teachers and parents as to the efficacy of these practices and the factors which might enable and / or constrain these practices?

I undertook a qualitative case study that investigated the practices of primary caregiving, freedom of movement and respect for children's confidence and competence. A thematic coding of observational and interview data was used to interpret and analyse the data. Observation data was gathered by non-participant pen and paper observations and video recording. Documentation records such as ERO reports, prospectus information, children's individual discovery projects, wall displays, newsletters and information for parents were useful in triangulating data generated by observations and teacher interviews as well as a parent focus group interview.

In this chapter I summarise my conclusions and recommendations in relation to the questions above. I also highlight the limitations of my study, the suggestions I have for further research and explain the implications for practitioners and policy makers. I outline practical 
recommendations for teachers working in early childhood settings with infants. These recommendations are intended to provide a framework for practitioners wanting to adopt similar practices to those observed at the case study centre. The recommendations are based on the findings from my research.

\subsection{Primary caregiving}

Parents and teachers involved in my research had a good understanding of primary caregiving principles and expressed their unanimous support for the practice at the case study centre. A team approach to primary caregiving meant the practice did not translate into an exclusive relationship between one teacher and one child, nor was it reliant on the primary caregiver having to always be available to the child. On the contrary, all teachers shared reciprocal relationships with all children with a deeper level of understanding being evident with teachers and the children in their primary care group.

Children would re-visit their primary caregiver from time to time and were comfortable when their caregiver was close by. Children were also happy to wait for their turn when needed because teachers were able to communicate through the use of language and gesture that they were aware of them and that they would be next.

Through peaceful observation teachers were able to interpret infants' body language, cues and gestures. Caregivers used a sequential, predictable pattern of body language as invitation to engage. They used language as invitation and explanation with children and also to explain carefully what they were doing and why. Teachers responded to the child's pace and slowed their reactions and interactions accordingly. They also took breaks according to the individual needs and rhythms of the children as opposed to working by the clock. 


\subsection{Free movement}

Free movement principles were understood by both parents and teachers at the case study centre. Not all parents were following free-movement guidelines at home and some parents were propping their child to sit or restraining them in a high chair. Because of these differing practices between home and centre the teachers were flexible and would over-ride the guidelines set out by Pikler (1994) and make exceptions when children had become used to being sat up if they became frustrated lying down.

In this way, respect for the child was paramount. In other words, if a child was upset lying down and was not familiar with this practice at home then teachers would sit him up out of respect for parent and child's wishes. This finding highlighted the fundamental difference between the orphanage where the free movement philosophy originated and the case study centre. The children in the case study centre share their time between two different environments where the beliefs and practices might be quite different as opposed to the orphanage where children were in only one consistent environment. This finding is also in alignment with the two principles on which our curriculum Te Whäriki is based: relationships; and family and community.

This research has identified for me the difference between adoption and adaptation of a philosophy. Adopting the free movement philosophy would involve strictly practicing the principles of free movement. Whereas, adaptation, as happened in the case study centre, involves taking the ideas from a philosophy and weaving them into the cultural context and curriculum framework within which the centre operates. This results in a more flexible approach to practicing the principles of any given philosophy. 
Another finding regarding free movement was that teachers supported infants rather than intervening. They had a high level of trust in each infant's ability to solve his or her own problems and would allow them the privilege of space and time to do this without intervention. This high level of trust was enabled by the teachers' intimate knowledge of each child which was developed through peaceful observation. Teachers often engaged in something Gerber described as wants nothing time. This was when the caregiver was simply watching, listening, and deepening their understanding of the child they were observing.

\subsection{Respect for infants' confidence and competence}

My findings indicated that respect was at the heart of the philosophy and practices observed at the case study centre - with respect for children's confidence and competence evident throughout all aspects of the case study centre programme. Teachers invited children to engage with them and no action would be initiated for or with a child without his or her agreement. This agreement was demonstrated through cues and gestures, to which the teachers were all highly attuned.

Teachers were unhurried in their approach to time and slowed their pace to match the individual rhythms and competencies of each child. They offered children choices in their care and education and waited for the child's response each time. Break times were not observed by the clock but rather were taken at times which seemed convenient to the children and other teachers in the environment.

I have argued that in the use of these practices, teachers displayed an ethic of care and through peaceful observation were able to interpret the actual needs and wants of infants - as 
opposed to their own perceptions of infants needs and wants. Teachers would offer support to infants by being close by and observant rather than intervening unnecessarily.

Teachers demonstrated the idea that for infants care is education and education is care by maximising the time and attention they paid to routine care times. These were seen as times where a trusting and reciprocal relationship could be built with each child in the understanding that as children are cared for, they learn to care for others. Respect for children's confidence and competence in the case study centre meant inviting children to engage, slowing to the individual child's pace, offering choices, working as a team, paying close attention, and providing support rather than intervention.

\subsection{Limitations of this study}

I only studied one early childhood centre and completed observations over a limited period of two weeks. It is therefore not appropriate to draw generalisations based on two weeks of observations of one early childhood setting. The centre studied had ratios better than the minimum ratios required by early childhood regulations, which means that other early childhood settings may not be able to replicate the practices unless they also have a ratio of teachers to children greater than that required by law.

\subsection{Future research}

I found there was a distinct lack of local research investigating free movement; this is an area that could benefit from further enquiry. Future research could look into the efficacy and relevance of adopting free-movement practices, particularly the idea of unassisted motor development, into early childhood settings in New Zealand. Longitudinal research would be 
ideal to fully understand the benefits or otherwise of practicing free movement, particularly natural motor progression, with infants in early childhood settings.

\subsection{Implications and recommendations for policy makers}

The implications and recommendations for policy makers are as follows:

- During the time I was observing in the nursery the ratio of infants to teachers was never greater than 1:4. Most often it was 1:3 and often 1:2 or 1:1. It is possible that in order to create and maintain the conditions for this type of respectful practice the required ratio of teachers to children will need to be better than the minimum standard set out in the regulations which is currently 1:5.

- Practical recommendations for creating a peaceful environment and a curriculum based on respect for infants and toddlers would be useful to the sector. The following section presents some practitioner-oriented recommendations that draw both on the findings of this study as well as literature accessed in the course of this research.

\subsection{Practical recommendations for teachers}

\section{- Primary caregiving}

The primary caregiver /child relationship is not an exclusive relationship and nor is it a replacement for parents. On the contrary, primary caregiving involves a team approach and for a primary caregiving system to be effective it must be understood and supported by all members of the teaching team and families who attend the centre. What needs to be understood is that an infant needs to form a strong relationship with at least one other person in the environment and the formation of that relationship is reliant on continuity and trust. For infants, care and education are inseparable because valuable learning is taking place 
during routine care times and this learning is hindered if the child does not have a strong reciprocal and consistent relationship with the person who is caring for them (Kovach \& Da Ros-Vosales, 2008; Lally, 1995). In being cared for, the infant is learning to care for others. This is essentially the basis for a shared sense of humanity which will enable the infant to form and maintain relationships throughout his or her life (Greenspan \& Shanker, 2002).

\section{- Unhurried time}

Time is an essential issue for busy teachers in early childhood centres. In order to give infants unhurried time, teachers have to make a commitment to slow down and be emotionally present when they are interacting with infants. This valuable, uninterrupted, quality time and attention indicates to the child that he is valued which, in turn, enhances his developing self-esteem. This implies that as a team member, one needs to be considerate, thoughtful and aware of the interactions occurring and how one might enhance them by providing space, time, resources, and not interruptions.

\section{- Support not intervention}

Infants are capable of solving their own problems and having opinions. As the responsible adult we can be tempted to rush in and 'save' the child when he or she looks challenged. These are the moments we need to really challenge our own understanding of what it means to be a teacher in early childhood. Being close by and supportive but allowing an infant the space and time to learn for herself will prove more valuable to that child than 'helping' her by intervening in her learning. 


\section{- Peaceful observation}

Sitting quietly and observing the capabilities, development, understanding and characteristics of an infant will teach much of the knowledge required to be an effective teacher for him. Only when we observe peacefully can we truly know a child and begin to understand his body language, cues, gestures and uniqueness. Slow down and take time to simply observe peacefully as a child explores independently as opposed to trying to engage the infant in activity or always talking to the child. Peaceful observation will lead to a deep level of understanding and empathy.

\section{- Respect}

Respect is the key to relationships. When you show consideration for another person you communicate to them that they are valued. Feeling valued contributes to a sense of trust and self-esteem and is reflected in the individual's ability to form and maintain relationships with others. A culture of respect in your early childhood centre will mean that interactions between teachers and children are respectful and reciprocal. It will mean that teachers in the team show respect for one another and also that teachers and parents communicate and act respectfully.

We can show our respect for infants in early childhood centres in the following ways:

- Recognising that infants need to develop a strong and reciprocal relationship with at least one other person in the environment and implementing a primary caregiver system to cater for that need.

- Inviting infants' to engage and waiting for their approval prior to engaging in any interactions with them. 
- Interpret children's intentions by peacefully observing them and paying close attention to their body language, cues and gestures.

- Slow down and recognise that infants may prefer an unhurried approach to their individual care routines, learning and development. Be flexible about breaks and make them work according to the needs and rhythms of the infants as opposed to working by the clock.

- Offer infants choices about what is happening for them and wait for a response to the choice you have offered.

- Be available to the infant and support them in their learning but resist the urge to intervene unnecessarily in their problem solving efforts and mastery of their own physical development.

- Recognise the need for a strong philosophy and deep level of respect among team members. You can accomplish more and achieve greater quality for the benefit of the infants in your care when you share the same goals as a team, communicate effectively and demonstrate respect for one another.

\subsection{Chapter summary}

In this chapter I summarised my conclusions and recommendations in relation to the research questions. I considered the limitations of my study and made suggestions for further research into the natural motor progression of infants in early childhood settings. The implications for policy makers are around the ratio of teachers to infants required to achieve respectful practice. At the case study centre where my research was conducted there were more teachers to infants than is currently required by law. This more favourable ratio, I believe, enabled a deeper level of respect between teachers and infants in the environment and had a fundamental impact on the quality of provision at the case study centre. 
Practical recommendations were made for teachers which included: the use of a primary caregiving system; teachers slowing down and using unhurried time; providing support and not intervention for children; engaging in peaceful observation; and acknowledging that respect is the key to relationships. I also made practical recommendations for how teachers might show their respect for infants in early childhood centres. 


\section{REFERENCES}

Anderson, C. (2009). R-E-S-P-E-C-T - What it means to James L Hymes, Jr: The Educational Forum, 73, (4), 298 - 305.

Bary, R. (2009). Time. Yeah Baby! 2009. A collection of articles for teachers and parents of infants and toddlers (pp. 18-19). Wellington: Childspace Early childhood Institute.

Bary, R., Deans, C., Charlton, M., Hullett, H., Martin, F., Martin, L., Moana, P., Waugh, O., Jordan, B., \& Scrivens, C. (2009). Paying it forward: COI dissemination. Generating waves: innovation in early childhood education. (pp. $21-29$ ). Wellington: NZCER Press.

Bernhardt, J.L. (2000). A primary caregiving system for infants and toddlers: Best for everyone involved. Young Children, 55(2), $74-80$.

Brownlee, P. (2008). Dance with me in the heart: The adults guide to great infant-parent partnerships. Auckland: Playcentre Publications.

Brownlee, P. (2009). Ego and the baby, or why your colleagues huff and puff when you trust infants. Yeah Baby 2009! A collection of articles for teachers and parents of infants and toddlers. (pp. 4-5). Wellington: Childspace Early childhood Institute.

Brumbaugh, E. (2008). DAP in ECE: Respect. Kappa Delta Pi Record. 44 (4), 70 - 175.

Cairns-Cowan, N. \& McBride, B. (2010). In what ways does free movement impact on the social and emotional development of children. Wellington: Childspace Early Childhood Institute.

Cheshire, N. (2007). The 3 R's: Gateway to Infant and Toddler learning. Dimensions of Early Childhood. 35, (3), 36-38.

Creswell. J. W. (2003). Research design: Qualitative, quantitative, and mixed methods approaches $\left(2^{\text {nd }}\right.$ ed.). Thousand Oaks, CA: Sage.

Cullen, J., Hedges, H., \& Bone, J. (2008). Planning, undertaking and disseminating research in early childhood settings: An ethical framework. Retrieved October 30, 2008, from http://www.childforum.co.nz/rearticles_details.asp?REF_NO =5

Da Ros, D. \& Wong, A. (1996). The Art of being Fully in the Present with Young Children. Early Childhood Education Journal, 23(4) 215-216.

Dahlberg, G. \& Moss, P. (2005). What Ethics? In G. Dahlberg \& P. Moss (Eds.), Ethics and Politics in Early Childhood Education (pp. 64-85). London: Routledge.

Dalli, C., Kibble, N., Carins-Cowan, N., Corrigan, J. \& McBride, B. (2009). Reflecting on primary caregiving through action research: The centre of innovation experience at Childspace Ngaio Infants and Toddlers centre. The First Years: Nga Tau Tautahi. NZ Journal of Infant and Toddler Education. 11 (2), 38 - 45. 
Dalli, C. \& Kibble, N. (2010). Peaceful caregiving as curriculum: Insights on primary caregiving from action research. Dispersing Waves: Innovation in Early childhood Education. (pp. 27-34). Wellington: NZCER Press.

Dalli, C. (2000). Starting childcare: What young children learn about relating to adults in the first weeks of starting childcare. Early Childhood Research and Practice, 2 (2). Available at http://ecrp.uiuc.edu/v2n2/dalli.html.

David, M., \& Appell, G. (2001) Loczy: An unusual approach to mothering. Budapest: Association Pikler Loczy for Young Children.

Denscombe, M. (2007). The good research guide for small-scale social research projects. New York: Open University Press.

Denzin, N., \& Lincoln, Y. (2005). Introduction: The discipline and practice of qualitative research. In N. Denzin \& Y. Lincoln (Eds.), Handbook of qualitative research (pp. 132). Thousand Oaks, London, New Delhi: Sage.

Education Review Report: [Case study centre name $]^{1}$ (2008). Wellington: Education Review Office.

Elfer, P., Goldschmied, E., \& Selleck, D. (2003) Key persons in the nursery: Building relationships for quality provision. London: Fulton Publishers.

Falkner, A. (2009). You can't play peek-a-boo on your tummy. The First Years: Nga Tau Tautahi. NZ Journal of Infant and Toddler Education. 11 (2) 13-17.

Gerber, M. (1979). The RIE manual for parents and professionals. Los Angeles: Resources for Infant Educarers (RIE).

Gerber, M. (1984). Caring for infants with respect: The RIE approach. Zero to Three, 4(4), $1-3$.

Gerber, M. (1998, and reprinted 2002). Dear parent: Caring for infants with respect. $\left(2^{\text {nd }}\right.$ $E d$.). Edited by J. Weaver. Los Angeles: Resource for Infant Educarers.

Gerber, M., \& Johnson, A. (1998). Your self confident baby: How to encourage your child's natural abilities - from the very start. New York: Wiley.

Goffin, S. (1990). How well do we respect the children in our care? The Education Digest 55(8), 37-40.

Goldstein, L. (1998). More than gentle smiles and warm hugs: Applying the ethic of care to early childhood education. Journal of research in childhood education. 12, (2), $244-$ 256.

Gonzalez-Mena, J. (2007). What to do for a fussy baby: A problem solving approach. Young Children, 62 (5), $20-25$.

\footnotetext{
${ }^{1}$ In accordance with ethics approval the centre name cannot be identified.
} 
Gonzalez-Mena, J., \& Widmeyer Eyer, D. (2007). Infants, toddlers and caregivers: A curriculum of respectful, responsive care and education $\left(7^{\text {th }}\right.$ ed.). Boston: McGrawHill Higher Education.

Gonzalez-Mena, J. (2009). How to get infants and toddlers to co-operate: A simple but effective approach. Yeah Baby! 2009. A collection of articles for teachers and parents of infants and toddlers. Wellington: Childspace Early childhood Institute.

Greenman, J., \& Stonehouse, A. (1997). Prime times: A handbook for excellence in infant and toddler programs. Melbourne, Vic., Australia: Longman.

Greenspan, S., \& Shanker, S. (2002). Towards a psychology of global interdependency: A framework for international collaboration. Bethesda MD: Interdisciplinary Council on Developmental and Learning Disorders.

Hammond, R. (2009). Respecting babies: A new look at Magda Gerber's RIE approach. Zero to Three: Washington DC.

Hannaford, C. (2005). Smart moves: Why learning is not all in your head. $\left(2^{\text {nd }}\right.$ Ed). Salt Lake City, UT: Great River Books.

Hutchins, T., \& Sims, M. (1999). Program planning for infants and toddlers: An Ecological approach. Sydney, NSW, Australia: Prentice Hall.

Johnson, J. (2007). Journey through RIE: My experiences incorporating the RIE Philosophy into a traditional childcare setting. Fitchburg: Fitchburg State College.

Kibble, N. (2009). Re- thinking infant play spaces. Yeah Baby 2009! A collection of articles for teachers and parents of infants and toddlers (pp. 22-23). Wellington: Childspace Early Childhood Institute.

Kibble, N., Cairns-Cowan, N., McBride, B., Corrigan, J., Dalli, C. (2009). Primary caregiving: a way of being. Retrieved February 23, 2010, from http://www.educate.ece.govt.nz/EducateHome/Programmes/CentresOfInnovation/Rou $\underline{\text { ndFour/ /media/Educate/Files/Reference\%20Downloads/documents\%20for\%20uploa }}$ d/ChildspaceCOI.pdf.

Kibble, N., Cairns-Cowan, N., McBride, B., Corrigan, J., Dalli, C. (2010). Primary Caregiving: It's a team approach. Yeah Baby 2010! A collection of articles for teachers and parents of infants and toddlers (pp. 5-9). Wellington: Childspace Early childhood Institute.

Kovach, B., \& Da Ros, D. (1998). Respectful, individual, and responsive caring for infants: the key to successful care in group settings. Young Children 53(3), 61-74.

Kovach, B., \& Da Ros - Voseles, D. (2008) Being with babies: Understanding and responding to the infants in your care. Silver Spring, MD: Gryphon House. 
Lally, J.R. (1995). The impact of child care policies and practices on infant/toddler identity formation. Young children 51(1), 58-67.

Leon-Weil \& Hewitt (2008). Trust as a teaching skill. Young Children September 2008. (pp. $24-26)$.

Meade, A (Ed). (2010) Dispersing waves: Innovation in early childhood education. Wellington: NZCER Press.

Merriam, S. (1998). Qualitative research and case study applications in education. San Francisco: Jossey-Bass.

Merriam, S. (2003). Qualitative research in practice: examples for discussion and analysis. San Francisco: Jossey-Bass.

Miller, R. \& Pedro, J. (2006). Creating Respectful Classroom Environments. Early childhood education journal. 33 (5). 293 - 299.

Ministry of Education (1996). Te Whāriki: He whariki matauranga mo nga mokopuna o Aotearoa: Early childhood Curriculum. Wellington: Ministry of Education.

Ministry of Education. (2007). Education counts website. Retrieved June 5, 2008 from www.educationcounts.govt.nz.

Ministry of Education (2009). Annual ECE Summary Report 2009. Retrieved June 4, 2010, from http://www.educationcounts.govt.nz/statistics/ece/55413/licensed-services-andlicence-exempt-groups/65543.

Money, R. (Ed). (2006). Unfolding of infants' natural gross motor development. Los Angeles: Resources for Infant Educarers.

Mutch, C. (2005) Doing educational research. A practitioner's guide to getting started. Wellington: NZCER Press.

Noddings, N. (1984). Caring. Berkeley, CA: University of California Press.

Petrie, S., \& Owen, S. (2005). Authentic relationships in Group Care for Infants and Toddlers - Resources for Infant Educarers (RIE) Principles into practice. Philadelphia: Jessica Kingsley Publishers.

Pikler, E. (1971) Learning of motor skills on the basis of self-induced movements. In J. Hellmuth (ed) Exceptional Infant: Studies in Abnormalities Vol. 2. New York and London: Bruner / Mazel and Butterworth.

Pikler, E. (1994) Peaceful babies - contented mothers. In M.E. Roche (ed) Sensory Awareness Bulletin 14, Muir Beach, CA: Sensory Awareness foundation.

Porter, P (2003). Social relationships of infants in daycare. http://www.educarer.com/current-article-relationships.htm Accessed 19 February 2008. 
Rockel, J. (2002). Teachers and parents understandings of primary care for infants in early childhood centres within a New Zealand context. : Unpublished master's thesis, Massey University, Palmerston North, New Zealand.

Rogoff, B. (2003). The cultural nature of human development. New York: Oxford University Press.

Saracho, O. \& Spodek, B. (2003). Recent Trends and Innovations in the Early Childhood Education Curriculum. Early Child Development and Care, 173(2-3), 175-183.

Sensory Awareness Foundation (1994). Emmi Pikler 1902 - 1984. Sensory Awareness Bulletin, 14, 1-48.

Shonkhoff, J., \& Phillips, D. (Eds.). (2000). From neurons to neighborhoods. Washington, DC: National Academy Press.

Silverman, D. (1997). Qualitative research: Theory, method and practice. London: Sage.

Slaveron, M., Arney, F., \& Scott, D. (2006). Sowing the seeds of innovation: Ideas for child and family services. Family Matters, 73, 38-45.

Smith, A. (2007). Children's rights and early childhood education: Links to theory and advocacy. Australian Journal of Early Childhood, 32(3), 1-8.

Stake, R. (1995). The art of case study research. Thousand oaks, London, New Delhi: Sage.

Terreni, L. (2009). A case study: How young children and teachers use an interactive whiteboard in a New Zealand Kindergarten setting for visual art learning experiences. Unpublished master's thesis, Victoria University of Wellington College of Education, Wellington, New Zealand.

Te One, S. (2010). Supporting Children's rights. The Space, 19, 8.

Te One. S. (2008). Children's perceptions of their rights in a New Zealand Kindergarten. Paper presented at the NZARE Annual Conference, Palmerston North, New Zealand.

Tharp, R.G., \& Gallimore, R. (1988). Rousing minds to life: Teaching, learning, and schooling in social context. New York: Cambridge University Press.

Theilheimer, R. (2006). Molding to the children: Primary caregiving and continuity of care. Zero to Three, 26 (3), 50-54.

Toma, J. (2006). Approaching rigor in applied qualitative research. In Clifton, F. Conrad \& Ronald, C. Serlin (Eds). (2006). The Sage handbook for research in education. Thousand Oaks, London: Sage.

Triulzi, M. (2008). Do the Pikler and RIE methods promote infant-parent attachment? Unpublished master's thesis, Smith College School for Social Work, Northampton, Massachusetts. 
Tronto, J. (1993). Moral boundaries: A political argument for an ethic of care. New York: Routledge.

United Nations Committee on the Rights of the Child. (2003). Concluding observations of the Committee on the Rights of the Child: New Zealand, $34^{\text {th }}$ session. UN Doc CRC/C/15/Add.216, 3 October, Geneva

Wilkinson, S. (2004). Focus group research. In D. Silverman (Ed.), Qualitative research: Theory, methods and practice. London: Sage.

Yin, R. (2003) Case study research: design and methods $\left(3^{\text {rd }}\right.$ Ed). Thousand Oaks, London, New Delhi: Sage. 


\section{APPENDIX A}

\section{INFORMATION FOR PARENTS}

\section{Research project title: A case study of primary caregiving, freedom of movement and respect for infants' confidence and competence.}

Kia ora,

My name is Toni Christie and I am the principal of [case study centre name]. I am also an M.Ed student at Victoria University of Wellington conducting research on infants in group care. For my Master's thesis I am interested in exploring the practices teachers use at [case study centre name] with regard to primary caregiving, freedom of movement and respect for infants competence and confidence.

In order to research this subject I will need to make detailed observations of teachers and children here at [case study centre name]over a two week period next February. These observations will be gathered by pen and paper as well as using digital images and video recording. I will also be conducting interviews with each of the infant teachers and would like to interview a focus group of parents. A focus group is a relaxed, non-threatening discussion with a number of people. The focus group will enable me to more fully understand how parents perceive primary caregiving, freedom of movement and respect for infants' confidence and competence.

Any data recorded in the research (through photos, videos or interviews) will be stored securely for five years without identifying details.

I would like to invite you to participate in this research and am approaching you because your child is currently attending or will be attending [case study centre name] in the infant room during the time I will be collecting the data for my research. As such I require consent from you for your child to be observed and to be involved in this research.

If you consent to your child's involvement in this research you are consenting to my observing and recording your child through video and digital still images as well as pen and paper observations. If you consent to being involved in this research this will involve your participation in a focus group interview one evening. Please read, complete and return the attached consent form either to [manager and assistant manager names at case study centre] or to Dr. Anne Meade. Anne will distribute consent forms, answer participant questions to do with consent (and withdrawal), and gather the completed consent forms. Should you have any concerns regarding this process, please feel free to contact Dr Anne Meade on 566-1526 orannemeade@xtra.co.nz.

There will be an information evening for everyone who will be involved in this research early next year. The purpose of this evening meeting will be to explain further the purpose of my research and what it will entail as well as clarify any queries participants may have.

My thesis supervisors are Associate Professor Carmen Dalli (Phone 463-5404 or email Carmen.dalli@vuw.ac.nz) and Dr. Mary Jane Shuker (phone 463-9659 or email 
mary-jane.shuker@vuw.ac.nz). If at any time you have questions regarding this research feel free to contact either Carmen or Mary Jane or myself at our home office on 478-5220 or childspace@xtra.co.nz

It is likely that the findings of this research will be published. These findings may be of interest to you as a parent and as a participant in the study. At the completion of this research if you would like to receive a summary of the findings they will be available at the centre. Thank you for your consideration. I look forward to your prompt response.

Toni Christie 


\section{APPENDIX B}

\section{INFORMATION FOR TEACHERS}

\section{Research project title: A case study of primary caregiving, freedom of movement and respect for infants' confidence and competence.}

Kia ora,

My name is Toni Christie and I am an M.Ed student at Victoria University of Wellington conducting research on infants in group care. For my Master's thesis I am interested in exploring the practices teachers use at [case study centre name] with regard to primary caregiving, freedom of movement and respect for infants' competence and confidence.

In order to research this subject I will need to make detailed observations of teachers and children here at [case study centre name]over a two week period next February. These observations will be gathered by pen and paper as well as using digital images and video recording. I will also be conducting interviews with each of the infant teachers and would like to interview a focus group of parents. These interviews and focus group will enable me to more fully understand how parents and teachers perceive primary caregiving, freedom of movement and respect for infants' confidence and competence.

Any data recorded in the research (through photos, videos or interviews) will be stored securely for five years without identifying details. Individual teachers will not be identified anywhere in the final report.

I would like to invite you to participate in this research and am approaching you because you are currently teaching or will be teaching in the infant room during the time I will be collecting the data for my research. As such I require your consent to be observed and to be involved in a semi-structured interview.

If you consent to being involved in this research my expectation is that you will continue working as you normally would while I am observing your practices and the children in the infant room. I also would require your honest answers to a brief (approx one hour) semistructured interview. Please read, complete and return the attached consent form either to [manager and assistant manager names at case study centre] or to Dr. Anne Meade. Anne will distribute consent forms, answer participant questions to do with consent (and withdrawal), and gather the completed consent forms. Should you have any concerns regarding this process, please feel free to contact Dr Anne Meade on 566-1526 or annemeade@xtra.co.nz.

There will be an information evening for everyone who will be involved in this research early next year. The purpose of this evening meeting will be to explain further the purpose of my research and what it will entail as well as clarify any queries participants may have.

My thesis supervisors are Associate Professor Carmen Dalli (Phone 463-5404 or email Carmen.dalli@vuw.ac.nz) and Dr. Mary Jane Shuker (phone 463-9659 or email maryjane.shuker@vuw.ac.nz).If at any time you have questions regarding this research feel free 
to contact either Carmen or Mary Jane or myself at our home office on 478-5220 or childspace@xtra.co.nz

It is likely that the findings of this research will be published. At the completion of this study if you would like to receive a summary of the research findings they will be available at the centre. Thank you for your consideration. I look forward to your prompt response.

Toni Christie 


\section{APPENDIX C}

\section{CONSENT FORM FOR PARENTS}

Research project title: A case study of primary caregiving, freedom of movement and respect for infants' confidence and competence.

As parent or legal guardian, I have read the information letter regarding this research and understand what it is about. All my questions have been answered to my satisfaction. I understand that I can ask for more information at any time.

I / We know that: -

I/We agree / do not agree to our child's participation in this study.

I/We agree / do not agree to participate in a focus group (relaxed discussion group) one evening after the data collection part of this study has been completed. One or more parents of each child are welcome to attend and contribute to the focus group evening.

$\square \quad \mathrm{I} /$ We can withdraw from the study or withdraw my child from the study at any time prior to the data analysis stage of the research, or ask that recording and observation of my child be stopped temporarily or permanently.

$\square$ The findings of the study will be published with identifying information removed and pseudonyms used as appropriate.

This research involves direct observations of teachers and your child over a two week period.

$\square$ I/We give / do not give consent for our child to participate in this research under the conditions stated on the information sheet.

I/We give / do not give consent for our child's image to be used in the final documentation for this study and any subsequent publications (without identifying information).

I/We consent / do not consent to participate in this research under the conditions stated on the information sheet.

Name of child:

Name of Parent(s):

Signature(s):

Date: 


\section{APPENDIX D}

\section{CONSENT FORM FOR TEACHERS}

Research project title: A case study of primary caregiving, freedom of movement and respect for infants' confidence and competence.

I have read the information letter regarding this research and understand what it is about. All my questions have been answered to my satisfaction. I understand that I can ask for more information at any time.

I know that: -

It is voluntary for me to participate in this study.

I can withdraw from the study or ask that recording and observation is stopped at any time up until the point of data analysis.

The findings of the study will be published with no names provided and pseudonyms used as appropriate.

$\square$ This research involves direct observations of you and the other teachers and children over a two week period as well as an individual interview with you.

I understand that my involvement or non-involvement in this research will not impact on my employment.

I give / do not give my consent to participate in this research under the conditions stated on the information sheet.

$\square$ I give / do not give my consent for digital images of my interactions with children to be used for publication and presentation purposes.

I agree to take part in this research:

Yes No

Name of teacher:

Signature:

Date: 


\section{APPENDIX E}

\section{TEACHER INTERVIEW FORMAT (For both teachers and centre manager)}

The purpose of this interview is to gain information about what you understand about the philosophy and practices at [case study centre name] and how you consider them to be impacting on the children you are teaching.

Name:

Position:

Qualification:

Length of service:

1. Tell me about your understanding of the term 'primary caregiving'?

2. Could you comment on your understanding of the term 'freedom of movement'?

3. Tell me about your understanding of the term 'respect for children's confidence and competence'?

4. Do you consider these aspects of your programme to be enhancing infants' development and learning? How?

5. What, in your opinion, are the benefits of primary caregiving? For infants and toddlers? For families? For teachers?

6. Could you comment on the challenges / limitations / difficulties of primary caregiving?

7. How does this differ to your prior teaching experiences?

8. Are there specific environmental factors which promote freedom of movement?

9. Anything else you would like to mention about freedom of movement or independent exploration?

\section{NOTES TO INTERVIEWER}

- Ask if they have any questions about the research.

- Thank them for their time. 


\section{APPENDIX F}

\section{PARENT FOCUS GROUP FORMAT}

The purpose of this FOCUS GROUP is to gain information about what you understand about the philosophy and practices at [case study centre name] and how you consider them to be impacting on your child and family.

Your answers to the following questions will be treated with absolute confidentiality. Neither you nor your child will be identified specifically in the research.

Researcher will gather the following information from everyone present at the focus group meeting

Name:

Child's name:

Child's place in family:

Length of time enrolled:

Other siblings attended:

Draft questions for group:

1. Tell me about your understanding of the term 'primary caregiving'?

2. Could you comment on your understanding of the term 'freedom of movement'?

3. What is your understanding of the term 'respect for children's confidence and competence'?

4. How do you think primary caregiving is affecting your child's development and learning? 
5. How do you think freedom of movement is affecting your child's development and learning?

6. How do you think respect for infant's confidence and competence is affecting your child's development and learning?

7. (Brief explanation of primary caregiving) What, in your opinion, are the benefits to your child and family of having a primary caregiver?

8. Do you think the environment here promotes freedom of movement and independent exploration? If so, how?

9. Any other comments that anyone would like to make? (Challenges/limitations/difficulties of primary caregiving?)

\section{NOTES TO INTERVIEWER/FOCUS GROUP FACILITATOR}

- Ensure everyone is contributing to the discussion.

- Keep focused on the questions and keep the meeting moving by being succinct and try to obtain closure on each answer - no one should feel they have important ideas that are not discussed.

- Chatham house rules (confidentiality) no one will be identified.

- Thank them for their time. 